\title{
Recent advances on the synthesis of azoles, azines and azepines fused to benzimidazole
}

\author{
Kamal M. Dawood, ${ }^{\mathrm{a}, *}$ Nehal M. Elwan, ${ }^{\mathrm{a}}$ and Bakr F. Abdel-Wahab ${ }^{\mathrm{b}}$ \\ ${ }^{a}$ Department of Chemistry, Faculty of Science, University of Cairo, Giza, Egypt \\ ${ }^{b}$ Department of Chemistry, Faculty of Science and Arts, King Abdulaziz University, Khulais \\ Branch, Saudi Arabia \\ E-mail: dr_dawood@yahoo.com
}

\begin{abstract}
The current review article represents a survey covering the literatures on azoles, azines and azepines fused to the $a$ face of a benzimidazole moiety since 1980. Synthetic routes leading to benzimidazole fused with different ring systems; five-, six-, and seven-membered heterocyclic rings, containing one-, two- and three-heteroatoms were reported utilizing simple reactive benzimidazole synthons
\end{abstract}

Keywords: Benzimidazoles, triheterocycles, synthesis, azoles, azines, azepines

\section{Contents}

1. Introduction

2. Synthesis of Azolo-fused-benzimidazoles

2.1. Pyrrolobenzimidazoles

2.2. Pyrazolobenzimidazoles

2.3. Imidazobenzimidazoles

2.4. Oxazolobenzimidazoles

2.5. Thiazolobenzimidazoles

2.6. Triazolobenzimidazoles

2.7. Thiadiazolobenzimidazoles

2.8. Oxadiazolobenzimidazoles

3. Synthesis of Azino-fused-benzimidazoles

3.1. Pyridobenzimidazoles

3.2. Pyrimidobenzimidazoles

3.3. Pyrazinobenzimidazoles

3.4. Triazinobenzimidazoles

3.5. Thiazinobenzimidazoles 
4. Synthesis of Azepino-fused-benzimidazoles

4.1. Azepinobenzimidazoles

4.2. Diazepinobenzimidazoles

4.3. Triazepinobenzimidazoles

4.4. Thiazepinobenzimidazoles

5. References

\section{Introduction}

In the recent years, many biologically active fused benzimidazoles exhibiting interesting medicinal properties for the potential treatment of human diseases have been disclosed. For example, pyrrolobenzimidazoles, ${ }^{1-5}$ thiazolobenzimidazoles, ${ }^{6}$ pyrimidobenzimidazoles, ${ }^{7}$ and pyridobenzimidazoles $^{8}$ were reported as potent antitumor agents. Furthermore, pyrrolobenzimidazoles, ${ }^{9}$ pyridobenzimidazoles, ${ }^{10}$ were found to be useful in treating central nervous system disorder. Pyridobenzimidazoles have also anxiolytic activity in humans, ${ }^{11-13}$ and pyrimidobenzimidazoles were anti-rheumatic agents. ${ }^{14}$ Also, 1,2,4-triazinobenzimidazoles were found to be aldose reductase inhibitors ${ }^{15}$ and to possess antimicrobial activity. ${ }^{16}$

There are a large number of pharmacologically interesting benzimidazole molecules fused to a five membered rings containing one heteroatom (pyrrolobenzimidazoles), two heteroatoms (pyrazolo-, imidazo-, oxazolo-, and thiazolo-benzimidazoles) and three heteroatoms (triazolo-, thiadiazolo- and oxadiazolo-benzimidazoles). Also, several benzimidazole moieties are fused to a six membered ring containing one heteroatom (pyridobenzimidazoles), two heteroatoms (pyrimido-, pyrazino-, thiazino-benzimidazoles) and three heteroatoms (triazinobenzimidazoles). Seven membered rings fused to benzimidazole (azepino-, diazepino-, triazepino- and thiazepinobenzimidazoles) are also well known.

As a continuation of our very recently published review article concerning the synthesis of benzimidazole-based polyheterocycles, ${ }^{17}$ herein we wish to publish our current review reporting the numerous publications declaring various synthetic routes to the benzimidazole-based triheterocycles that are mentioned above, since 1980, utilizing simple reactive benzimidazole synthons.

\section{Synthesis of Azolo-fused-benzimidazoles}

\subsection{Pyrrolobenzimidazoles}

3-Hydroxypyrrolo[1,2-a]benzimidazoles 3 were prepared by Michael-type addition of benzimidazole 1 to $\alpha, \beta$-unsaturated carbonyl compounds 2 in refluxing dioxane in the presence of $\mathrm{Et}_{3} \mathrm{~N}$ (Scheme 1). ${ }^{18}$ 


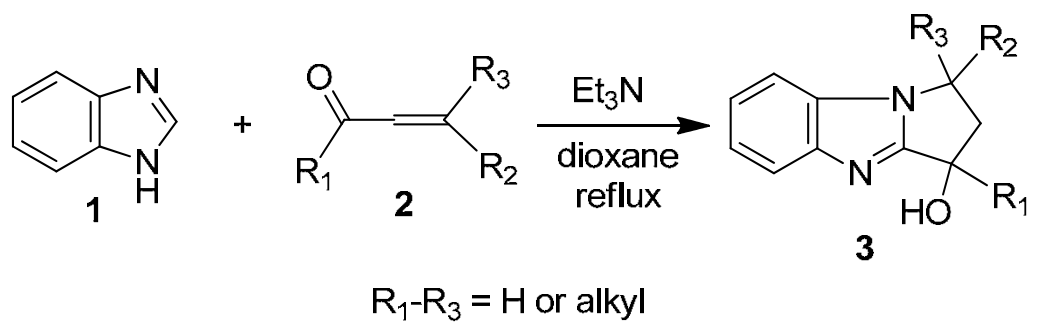

\section{Scheme 1}

Treatment of 1-benzyl-1H-benzimidazole $\mathbf{4}$ with phenacyl bromide $\mathbf{5}$ gave the benzimidazolium salt 6. An oxidant promoted 1,3-dipolar cycloaddition of 6 to activated alkenes was developed for the preparation of $4 H$-pyrrolo[1,2-a] benzimidazole derivatives 7 in moderate yields under mild conditions. In the presence of a suitable oxidant, alkenes could be used as dipolarophiles successfully. Moreover, $\mathrm{CrO}_{3} / \mathrm{Et}_{3} \mathrm{~N}$ has been proved to be a more effective dehydrogenating reagent than $\mathrm{MnO}_{2}$ (Scheme 2). ${ }^{19}$

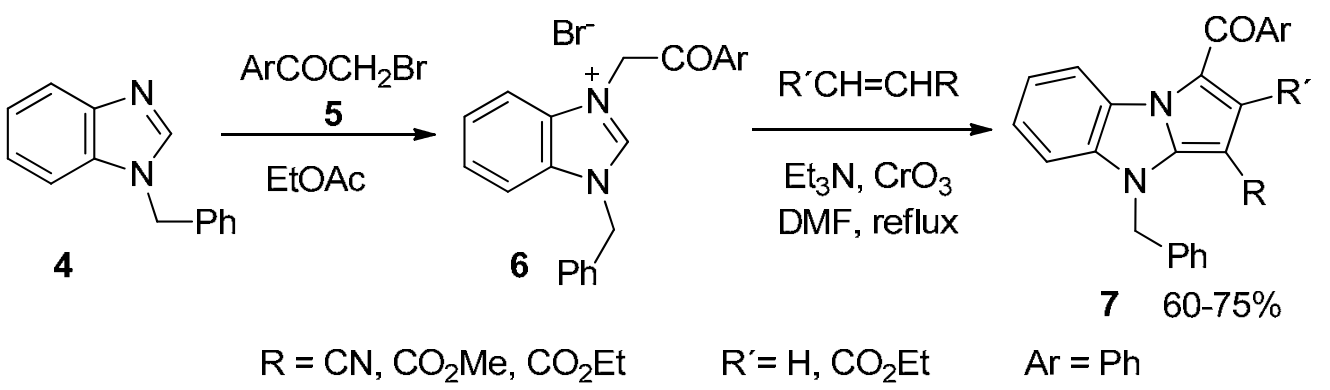

\section{Sceme 2}

Reaction of 1-benzyl-1H-benzimidazole 4 with 2-(bromoacetyl)thiophene 8 gave the benzimidazolium salt $\mathbf{9}$ which on treatment with activated acetylenes $\mathbf{1 0}$ resulted in the formation of thenoylpyrrolo[1,2-a]benzimidazole derivatives 11 (Scheme 3). ${ }^{20}$

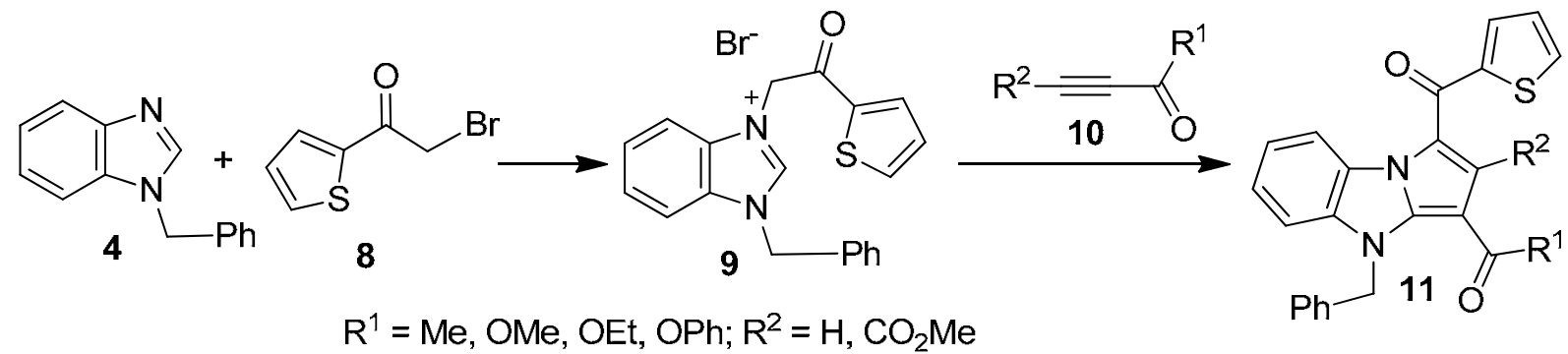

\section{Scheme 3}

Alkylation of 2-benzylbenzimidazole 12 with propargyl bromide 13 in refluxing ethanol gave 
1-(2-propynyl)-2-benzylbenzimidazole 14 which upon treatment with $\mathrm{KOH}$ in $\mathrm{THF}$ at $20{ }^{\circ} \mathrm{C}$ gave pyrrolo[1,2-a]benzimidazole derivative $\mathbf{1 5}$ in $81 \%$ yield. Treatment of $\mathbf{1 4}$ with MeI in ethanolic $\mathrm{KOH}$ gave 2-methylpyrrolo[1,2-a]benzimidazole 16 (Scheme 4). ${ }^{21}$

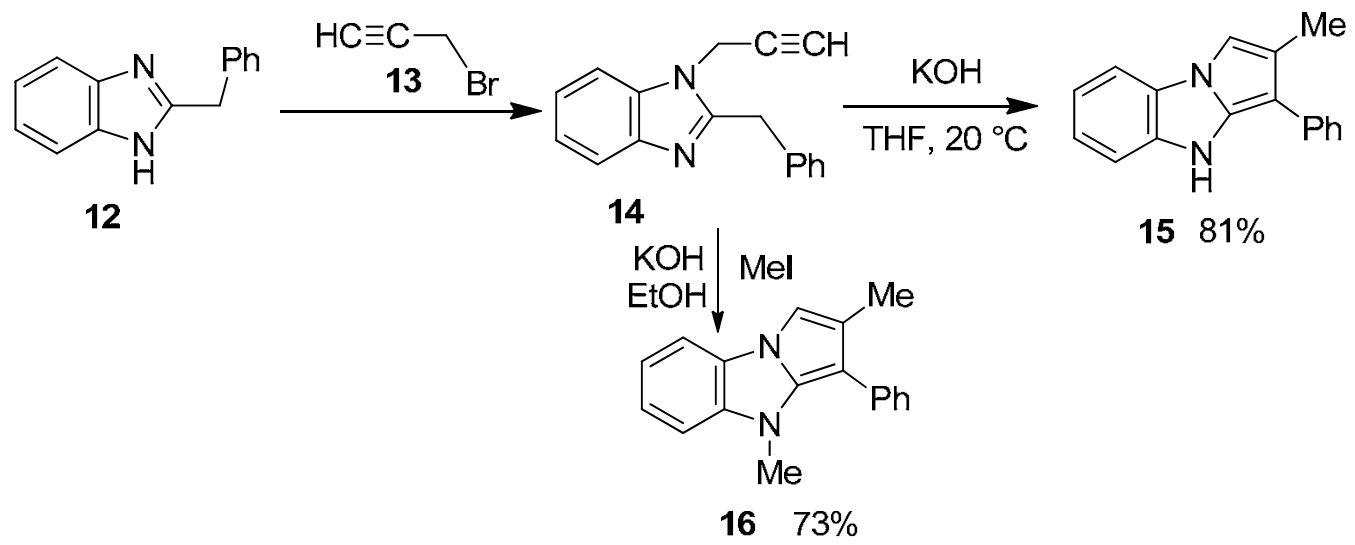

\section{Scheme 4}

Fusion of 2-cyclopropylbenzimidazoles 17 with ammonium iodide at $150{ }^{\circ} \mathrm{C}$ with no solvent resulted in the formation of a mixture of the 2,3-dihydro- $1 H$-pyrrolo[1,2-a]benzimidazoles 18 and 19. Yield and reaction time was greatly affected by the type of electron withdrawing and electron donating groups $\mathrm{R}^{1}$ and $\mathrm{R}^{2}$ (Scheme 5). ${ }^{22}$

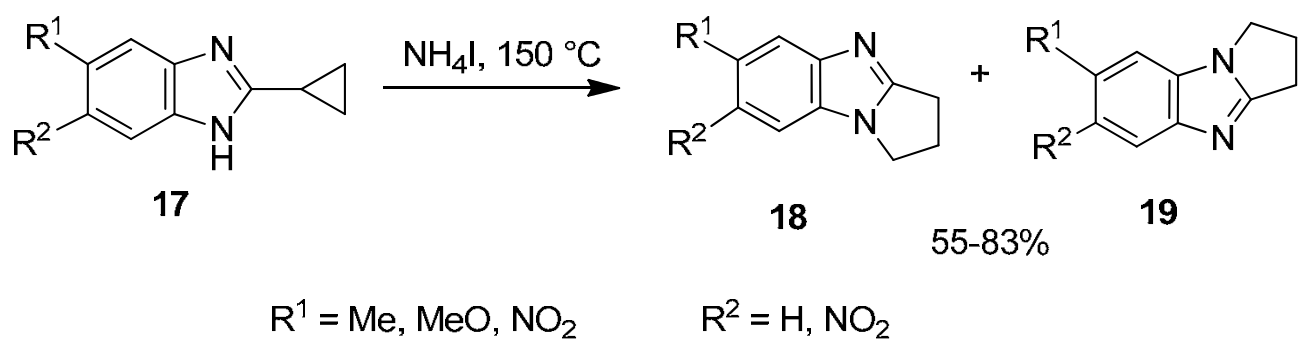

\section{Scheme 5}

The reaction of 2-benzyl-1-dialkylaminoethylbenzimidazoles $\mathbf{2 0}$ with phenacyl bromides $\mathbf{5}$ in refluxing acetone gave the quaternary salts 21 in high yields. Cyclization of the salts 21 proceeded smoothly upon boiling in water in the presence of sodium carbonate to give the pyrrolo[1,2-a] benzimidazoles 22 (Scheme 6). ${ }^{23}$ 


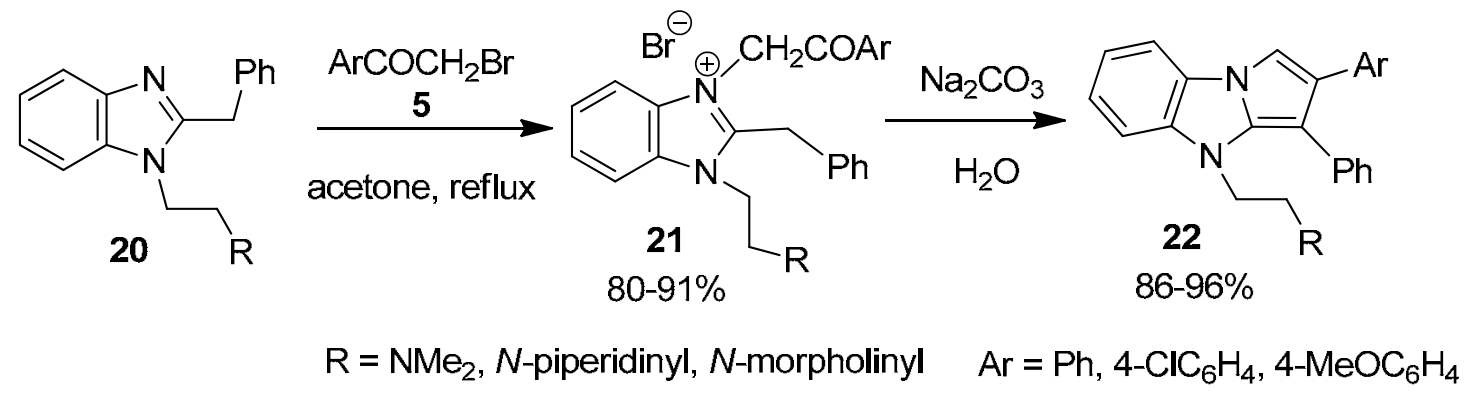

\section{Scheme 6}

Rhodium-catalyzed microwave irradiation of $N$-allyl benzimidazoles 23 using $5 \mathrm{~mol} \%$ of $\left[\mathrm{RhCl}(\mathrm{coe})_{2}\right]_{2}(\mathrm{coe}=$ cis-cyclooctene $)$ in the presence of tricyclohexylphosphine hydrochloride $\left(\mathrm{HClPCy}_{3}\right)$ gave the corresponding dihydropyrrolobenzimidazoles $\mathbf{2 4}$ in moderate to excellent yields after $20 \mathrm{~min}$ (Scheme 7). ${ }^{24}$

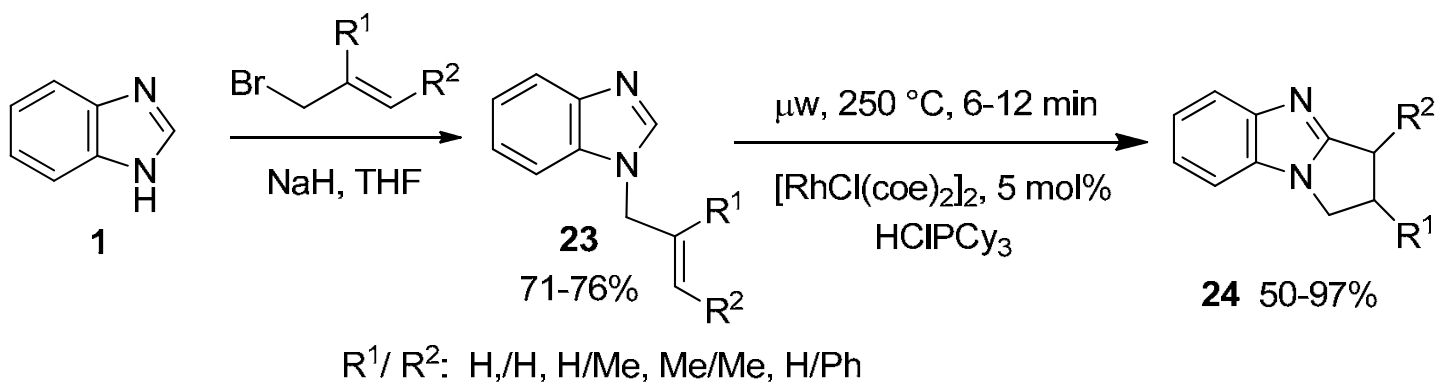

\section{Scheme 7}

Cyclization of the amidine 25 with strong base such as sodium methoxide in DMF at $150{ }^{\circ} \mathrm{C}$ was reported to give the pyrrolo[1,2-a]benzimidazole 26 in 75\% yield via loss of HF (Scheme $8)^{25}$

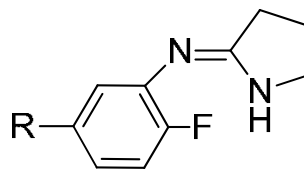

25

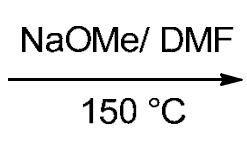

$\mathrm{R}=\mathrm{NO}_{2}$<smiles>[R]c1ccc2c(c1)nc1n2CCC1</smiles>

$2675 \%$

\section{Scheme 8}

Pyrrolo[1,2-a]benzimidazolium salt 28 was prepared in high yield and selectivity from the catalytic ring closing of 1-(3-butenyl)-3-methylbenzimidazolium bromide 27 using nickel dicyclooctadiene, $\mathrm{Ni}(\mathrm{COD})_{2}$, as catalyst in DMF at $70{ }^{\circ} \mathrm{C}$ (Scheme 9$) .{ }^{26}$ The reaction proceeded 
through azolium, $\mathrm{C} 2-\mathrm{H}$, oxidative addition to $\mathrm{Ni}(0)$ followed by intramolecular insertion of the $\mathrm{N}$-alkenyl double bond into the $\mathrm{Ni}$ hydride to give an intramolecularly bound carbene-Ni-alkyl intermediate A. Reductive elimination of the linked carbene and alkyl groups $\mathbf{B}$ gave the fusedring azolium product $\mathbf{2 8}$ and regenerated the $\mathrm{Ni}(0)$ catalyst. The catalyst was formed in situ from $\mathrm{Ni}(\mathrm{COD})_{2}$ and ligand $\mathrm{L}$ (where $\mathrm{L}=\mathrm{IMes}, \mathrm{SMes}, \mathrm{PPh}_{3}, \mathrm{PCy}_{3}, \mathrm{PCy}_{2}\left(\right.$ biphenyl), $\mathrm{P}(\mathrm{t}-\mathrm{Bu})_{3}$ in $\mathrm{DMF}^{26}$<smiles>C=CCCn1c[n+](C)c2ccccc21</smiles>

\section{Scheme 9}

The $N$-arylpyrrolidine derivative $\mathbf{2 9}$ was cyclized to pyrrolo[1,2- $a$ ] benzimidazole 26 in low yield by heating in formic acid in the presence of hydrogen peroxide at $70{ }^{\circ} \mathrm{C}$ (Scheme 10$) .{ }^{27}$

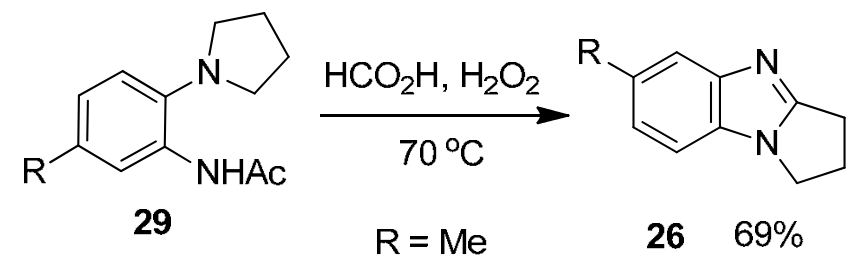

\section{Scheme 10}

Treatment of 3-(N-pyrrolidinyl)-4-nitrotoluene 30 with $\mathrm{ZnCl}_{2} / \mathrm{Ac}_{2} \mathrm{O}$ followed by treatment with a mixture of $\mathrm{Ac}_{2} \mathrm{O}$, dimethylaminopyridine (DMAP) and $\mathrm{Et}_{3} \mathrm{~N}$ gave pyrrolo[1,2a]benzimidazole 31 in $53 \%$ yield (Scheme 11). ${ }^{28,29}$
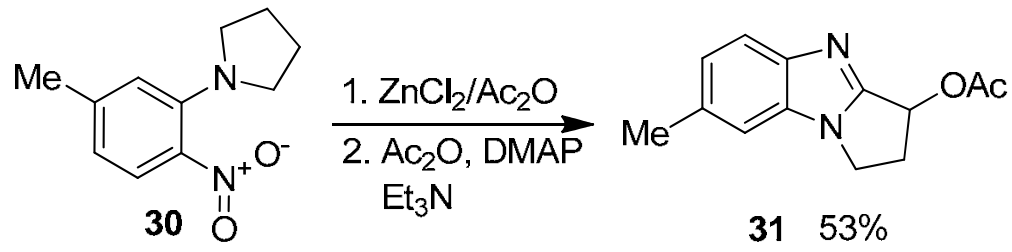

\section{Scheme 11}

Cyclocondensation of 2-(1H-benzimidazol-2-yl)-4-chloro-3-oxobutanenitrile 32 in refluxing dioxane in the presence of triethylamine gave the pyrrolo[1,2-a]benzimidazol-2-one derivative 33 (Scheme 12). ${ }^{30}$ 


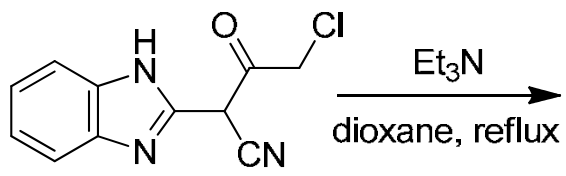

32<smiles>N#CC1=C2Nc3ccccc3N2CC1=O</smiles>

33

\section{Scheme 12}

1-Carboxymethylbenzimidazolium chlorides 34 were converted into 4-methyl-4Hpyrrolo[1,2-a] benzimidazol-2(1H)-one derivatives 35 in fair yields by treating 34 with $N, N^{\prime}-$ carbonyldiimidazole (CDI) in DMF at room temperature followed by addition of $\mathrm{Et}_{3} \mathrm{~N}$ and heating the mixture at $70{ }^{\circ} \mathrm{C}$ for $5 \mathrm{~h}$ (Scheme 13). ${ }^{31}$

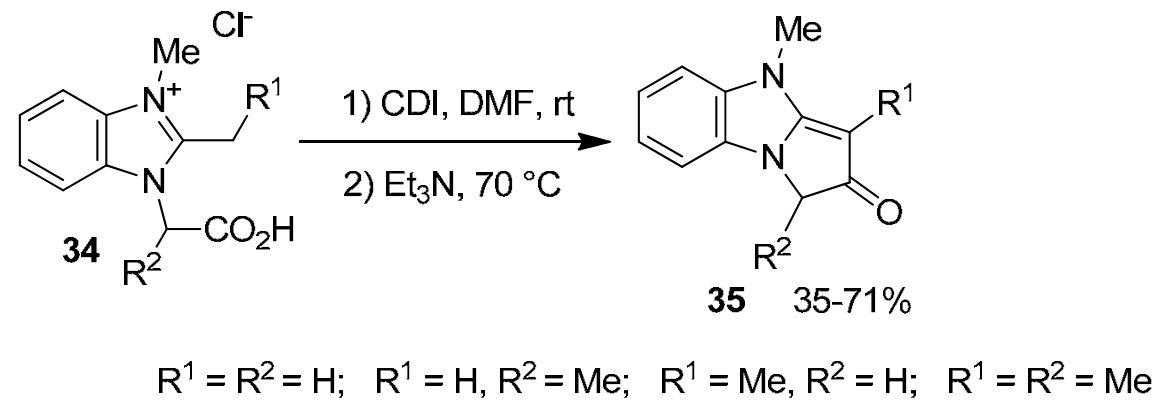

\section{Scheme 13}

Reaction of $o$-phenylenediamines 36 with maleic anhydrides 37 gave $\mathrm{N}$-(o-aminophenyl)maleimides 38 which were cyclized to give pyrrolobenzimidazoles 39 (Scheme 14). ${ }^{32}$

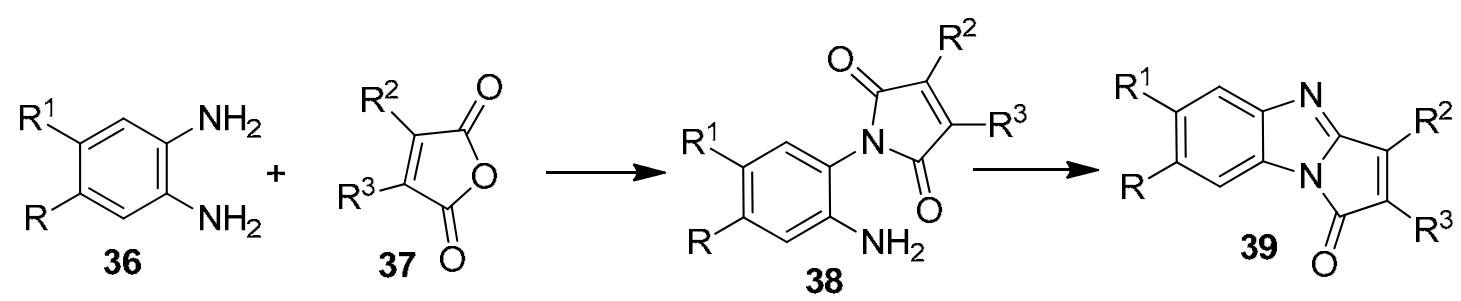

$$
\mathrm{R}=\mathrm{H}, \mathrm{NO}_{2} ; \mathrm{R}^{1}=\mathrm{H}, \mathrm{Cl}, \mathrm{Me} \quad \mathrm{R}^{2}=\mathrm{R}^{3}=\mathrm{Me} ; \mathrm{R}_{2}=\mathrm{OMe}, \mathrm{R}_{3}=\mathrm{Ph}
$$

\section{Scheme 14}

Cyclocondensation of $\gamma$-lactones $\mathbf{4 0}$ with $o$-phenylenediamine $\mathbf{3 6}$ in refluxing aq. $\mathrm{HCl}$ gave the benzimidazoles $\mathbf{4 1}$ which were cyclized by thionyl chloride in DMF to give pyrrolobenzimidazoles 42. Pyrrolobenzimidazoles 44 were prepared by condensing $o$ phenylenediamine with 2-alkyl-4-oxopentanoic acid 43 at $180-200^{\circ} \mathrm{C}$ (Scheme 15). ${ }^{33}$ 


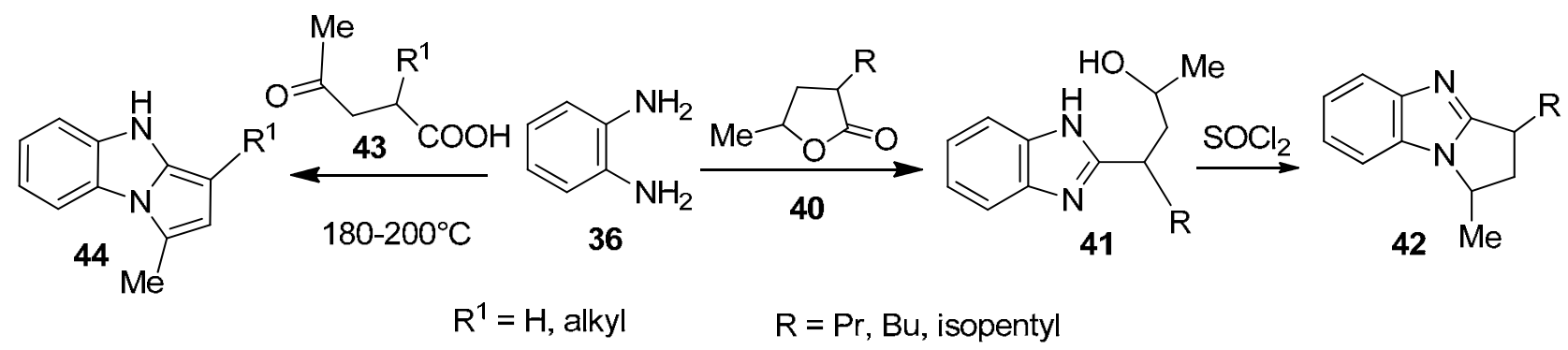

\section{Scheme 15}

Reaction of benzimidazolium salts 45 with aq. $\mathrm{NaHCO}_{3}$ afforded the pyrrolobenzimidazole derivatives 46 (Scheme 16). ${ }^{34}$

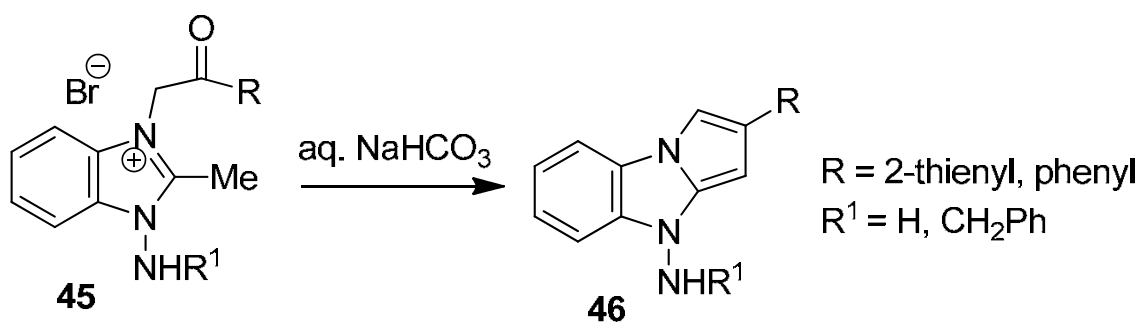

\section{Scheme 16}

Inaba et al. reported the ring-opening reaction of cyclopropane dicarboxylate $\mathbf{4 8}$ on heating with 2-chlorobenzimidazole 47 in $N$-methylpyrrolidine (NMP) at $120{ }^{\circ} \mathrm{C}$ using sodium hydride to provide the pyrrolo[1,2-a]benzimidazole derivative 49 in 56\% yield (Scheme 17). ${ }^{35}$

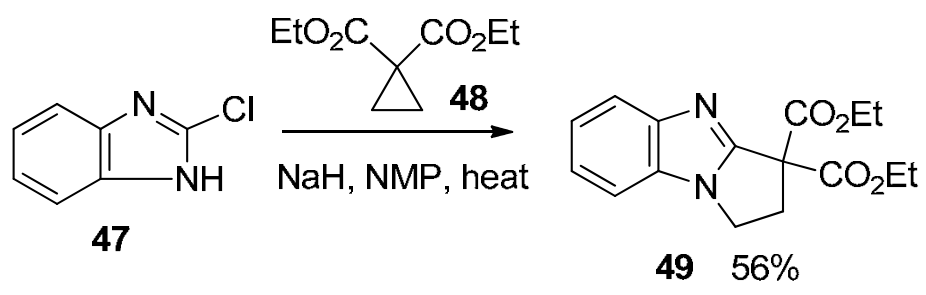

\section{Scheme 17}

Reaction of 1-but-3-enylbenzimidazole 50 with xanthates 51 using 10-camphorsulfonic acid (CSA) in dichloromethane (DCM) under reflux condition gave the pyrrolo[1,2-a]benzimidazole derivatives 52 in $37-57 \%$ yields. The reaction procceded via radical chain mechanism initiated by a small amount of lauroyl peroxide to give 52 (Scheme 18). ${ }^{36}$ 


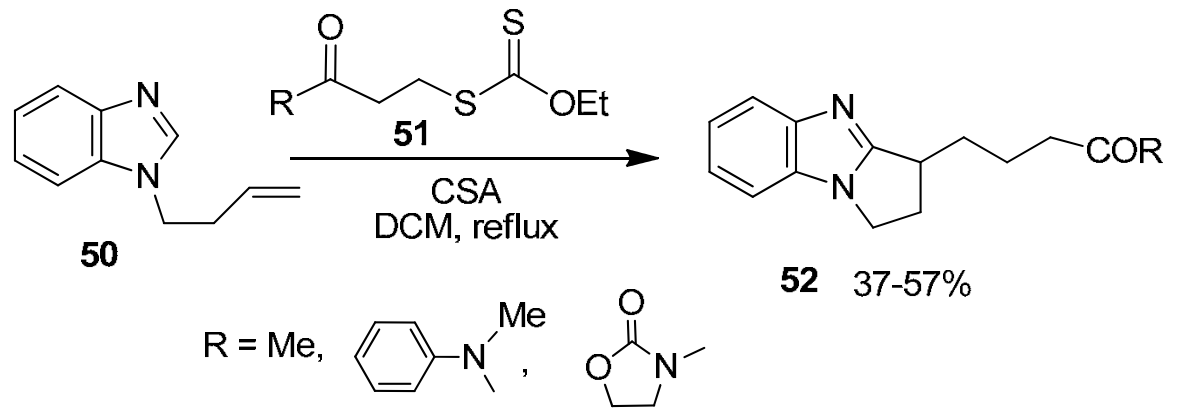

\section{Scheme 18}

1,3-Dipolar cycloaddition reaction between fluorinated vinyl tosylate and the benzimidazolium salts 53 afforded $4 H$-pyrrolo[1,2-a]benzimidazoles $55(\mathrm{Y}=\mathrm{H})$ in 10-68\% yields via elimination of $\mathrm{TsOH}$ and $\mathrm{HF}$ molecules from the $3+2$ cycloadduct intermediates $\mathbf{5 4}$ (Scheme 19). ${ }^{37}$ Benzimidazolium bromide 53 reacted also with 1-chloro-1,2,2-trifluoroethene to produce $55(\mathrm{Y}=\mathrm{F})$ in $45-80 \%$ yields via elimination of $\mathrm{HCl}$ and $\mathrm{HF}$ molecules from the intermediate 54 (Scheme 19). ${ }^{38}$

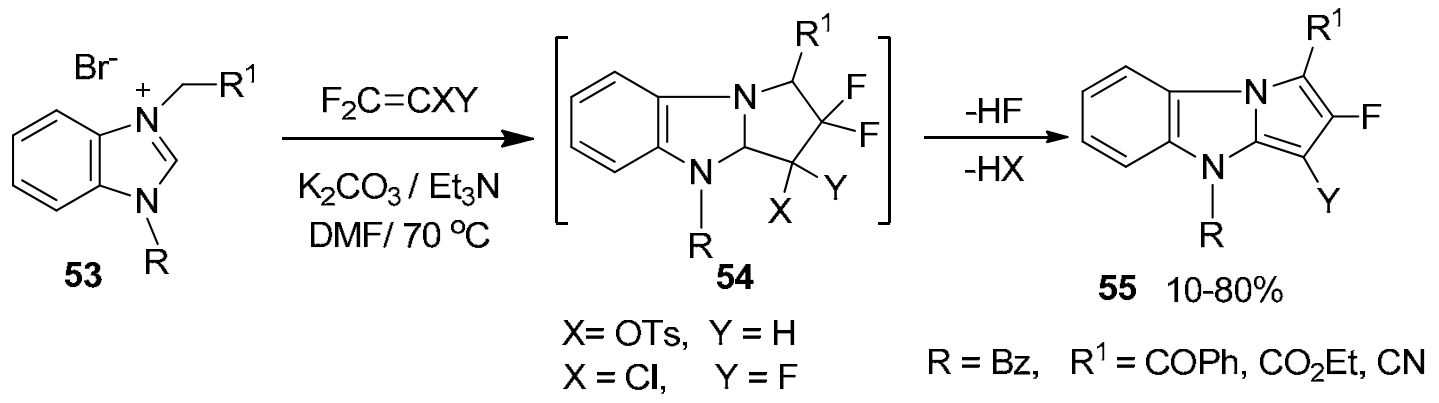

\section{Scheme 19}

Condensation of ethyl 2-thenoylpyruvate 56 with $o$-phenylenediamine 36 in glacial acetic acid under reflux gave the corresponding 2-[(2-thienoyl)acetyl]benzimidazole 57. Pyrrolo[1,2a]benzimidazole derivative $\mathbf{5 8}$ was prepared in $58 \%$ via heating of compound $\mathbf{5 7}$ with phosphorus oxychloride on a water bath (Scheme 20). ${ }^{39}$

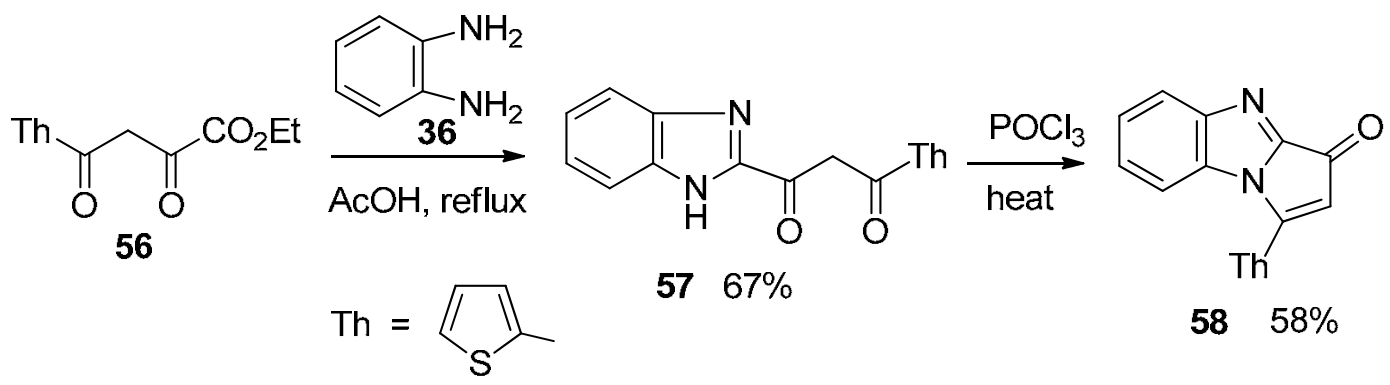

Scheme 20 
Reaction of 2-cyanomethylbenzimidazole 59 with hydrazonoyl halides $\mathbf{6 0}$ in the presence of triethylamine apparently led to the formation of pyrrolo[1,2-a]benzimidazoles $\mathbf{6 1}$ via the initial exocyclic $C$-attack (Scheme 21). ${ }^{40}$ However, later Awadallah et al. repeated the above reaction and they found that the product was 3-arylazo-2-methylpyrrolo[1,2-a]benzimidazoles 62 rather than 2-arylazo-3-methylpyrrolo[1,2-a]benzimidazoles $\mathbf{6 1}$ based on X-ray crystallography via the initial endocyclic $N$-attack (Scheme 21). ${ }^{41}$

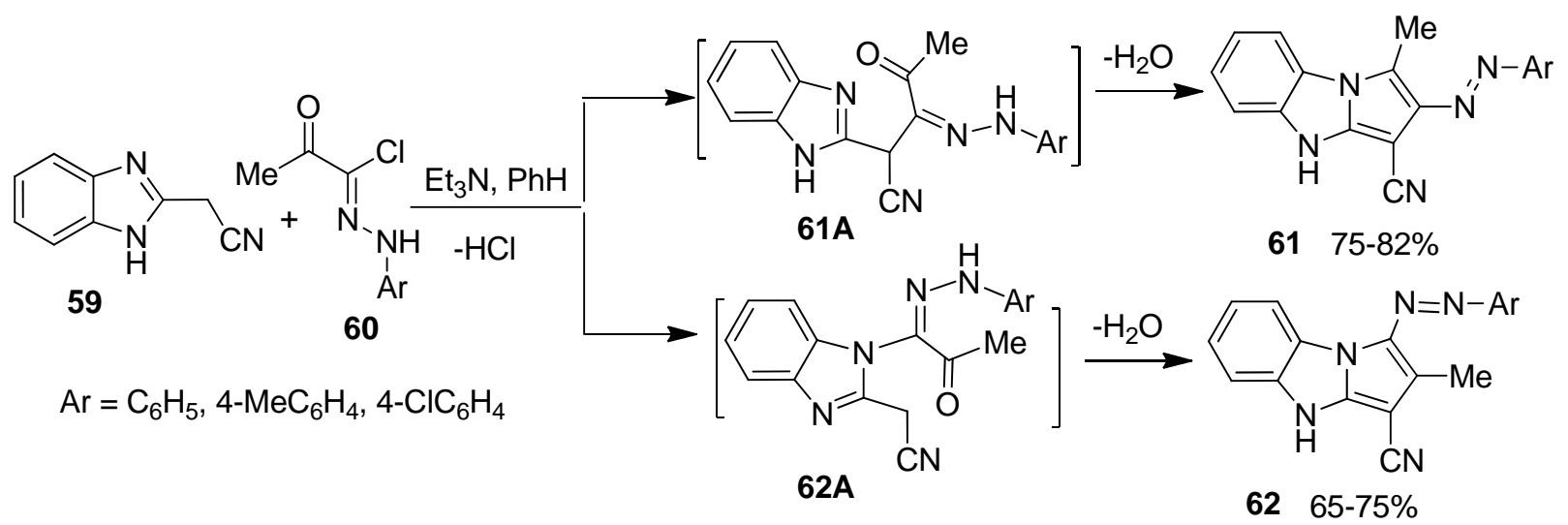

Scheme 21

Pyrrolo[1,2-a]benzimidazol-2-amine derivative 64 was prepared in a moderate yield by reaction of 2-cyanomethylbenzimidazole 59 with oxalbis (p-tolylimidoyl) dichloride 63 in toluene in the presence of triethylamine at room temperature (Scheme 22). ${ }^{42}$ Furthermore, treatment of 2-methylbenzimidazole 65 with $n$-butyl lithium in THF at $0{ }^{\circ} \mathrm{C}$ followed by addition of 63 resulted in the formation of 1-arylimino- $1 H$-pyrrolo[1,2- $a$ ] benzimidazole-2-amines 66 in moderate yields (Scheme 22). ${ }^{43}$

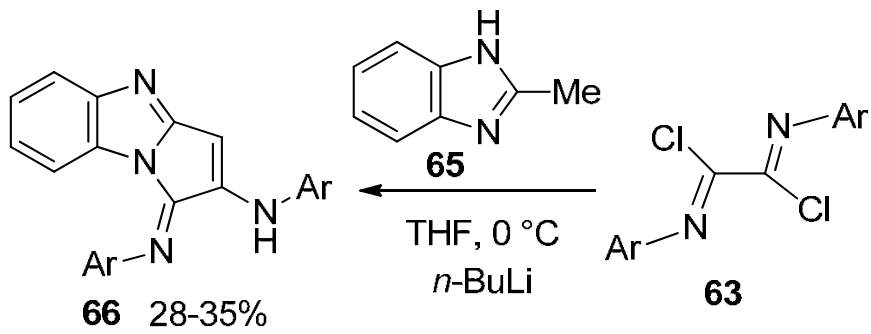

$\mathrm{Ar}=\mathrm{Ph}, 4-\mathrm{MeC}_{6} \mathrm{H}_{4}$

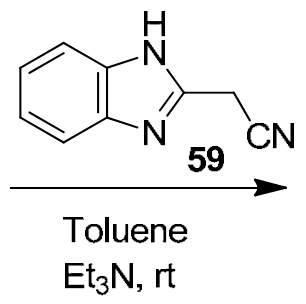

$\mathrm{Et}_{3} \mathrm{~N}, \mathrm{rt}$<smiles>N#CC1=C(N[Al])/C(=N/[Al])n2c1nc1ccccc12</smiles>

$6425 \%$

$\mathrm{Ar}=4-\mathrm{MeC}_{6} \mathrm{H}_{4}$

\section{Scheme 22}

When a mixture of the benzimidazolium bromide 53 and methyl acrylate in DMF in the presence of triethylamine was treated with chromium trioxide, the 4-methylpyrrolo[1,2a] benzimidazole-1,3-dicarboxylate 67 was isolated in a good yield (Scheme 23). ${ }^{44}$ 


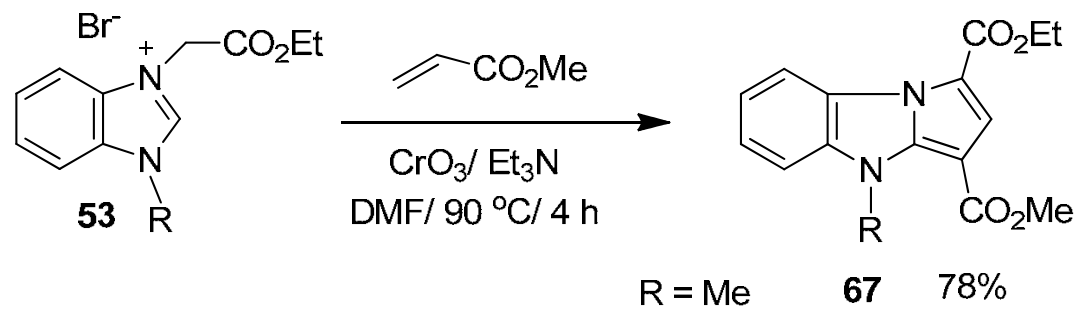

\section{Scheme 23}

Heating the benzimidazolium salts 68 with aqueous sodium carbonate in the presence of sodium bisulfite gave 2-phenylpyrrolo[1,2-a]benzimidazoles 69 in low yields (Scheme 24). ${ }^{45}$

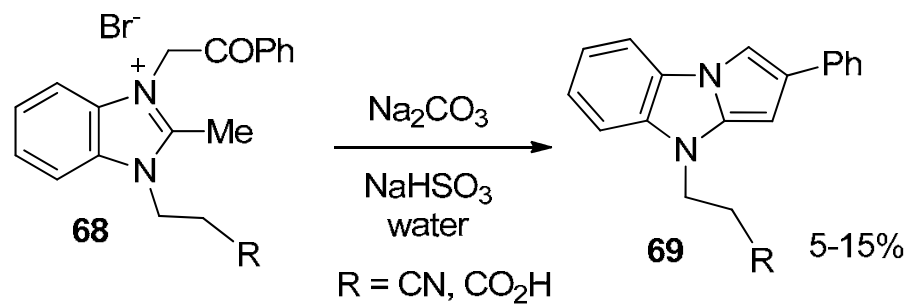

\section{Scheme 24}

Reaction of benzimidazole-2-carboxaldehyde 70 with trans-1-amino-2,3-diphenylaziridine 71 gave 1-[1-allyl-1 $H$-benzimidazol-2-yl-methylidene]-2,3-diphenyl-1-aziridinamine 72 which underwent thermolysis facilitated intramolecular 1,3-dipolar cycloaddition followed by loss of $\mathrm{N}_{2}$ to give the cyclopropapyrrolo[1,2-a] benzimidazole 73 (Scheme 25) in excellent yield. ${ }^{46}$

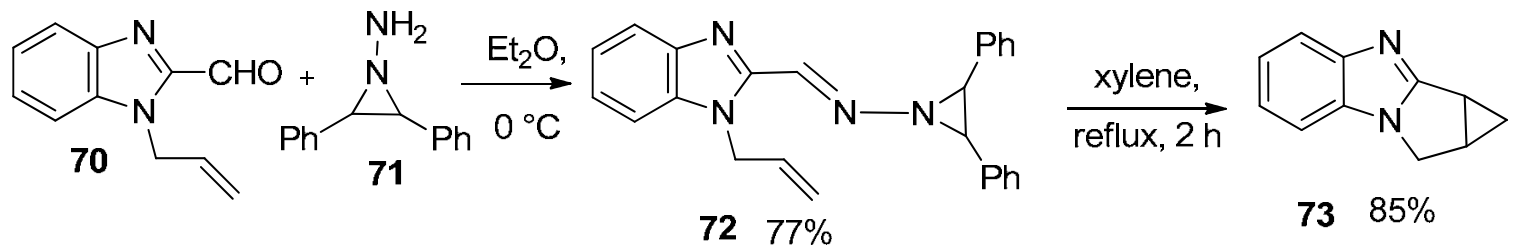

\section{Scheme 25}

\subsection{Pyrazolobenzimidazoles}

1-Amino-3-alkylbenzimidazolethione $\mathbf{7 4}$ was transformed to 1-amino-3-alkyl-2(methylthio)benzimidazolium salt 75 upon treatment with methyl iodide. The latter salt reacted with different active methylenes to give the corresponding 2-substituted methylenebenzimidazoline derivatives $\mathbf{7 6}$ which underwent base or acid catalyzed cyclization to give 2aminopyrazolo[1,5- $a$ ]benzimidazoles 77 and pyrazolo[1,5- $a$ ] benzimidazol-2-ones 78, respectively. Compounds 78 underwent $N$ - and $O$-methylation when treated with methyl iodide under basic condition to give the corresponding pyrazolo[1,5-a]benzimidazoles 79 and 80 (Scheme 26). ${ }^{47}$ 


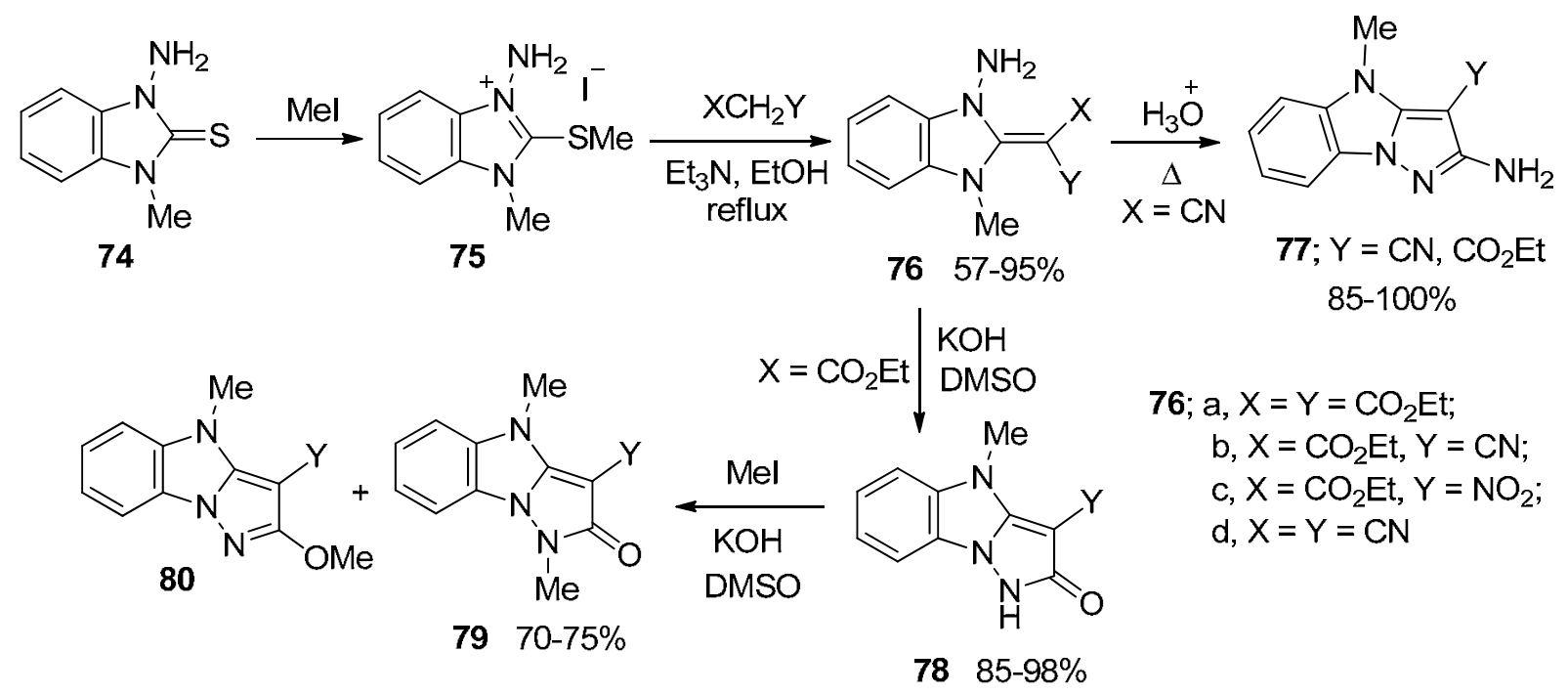

78-80; $\mathrm{Y}=\mathrm{CN}, \mathrm{CO}_{2} \mathrm{Et}, \mathrm{NO}_{2}$

\section{Scheme 26}

Acylation of 1-amino-2-methylbenzimidazole 81 with acetic anhydride gave the $N, N$ diacylated derivative 82. The latter was alkylated with alkyl iodide to give benzimidazolium salts $\mathbf{8 3}$ which were cyclized with acetic anhydride to give pyrazolobenzimidazoles $\mathbf{8 5}$ in good yields. Pyrazolobenzimidazoles 85 were alternatively obtained via alkylation of 1-amino-2methylbenzimidazole $\mathbf{8 1}$ with alkyl iodide to give benzimidazolium salts $\mathbf{8 4}$ followed by reflux in acetic anhydride (Scheme 27). ${ }^{48} 3$-( $\alpha$-Bromoacetyl)pyrazolo[1,5-a]benzimidazole 86 was obtained by brominating 3-acetylpyrazolo[1,5-a]benzimidazoles 85 with bromine in $\mathrm{AcOH}$ (Scheme 27). ${ }^{49}$

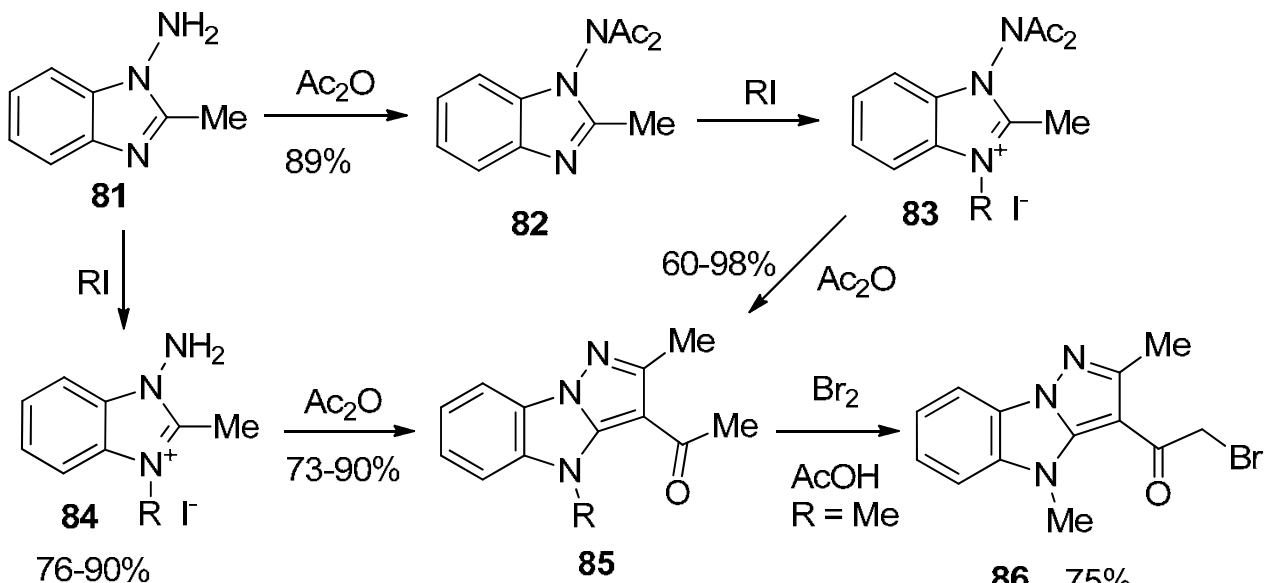

83-85: $R=M e$, Et, $\operatorname{Pr}$

\section{Scheme 27}


Treatment of 1-amino-2-methylbenzimidazolium chlorides 87 with acetic anhydride in the presence of potassium carbonate under reflux afforded a mixture of pyrazolo[1,5a] benzimidazoles 88 and pyrrolo[1,2-a] benzimidazoles 89 (Scheme 28). ${ }^{50}$

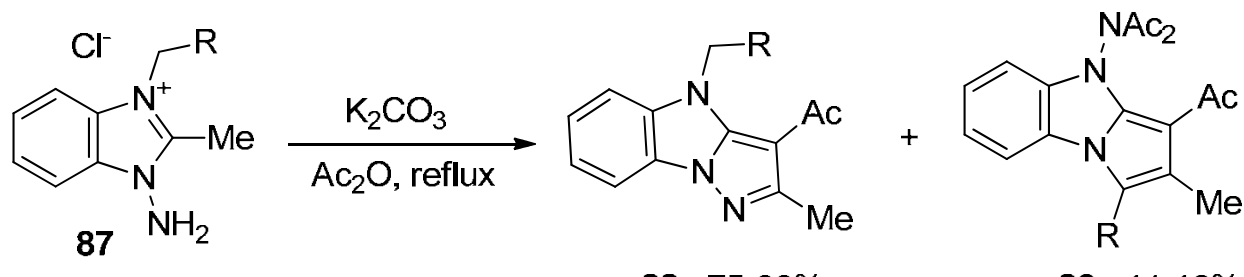

$\mathrm{R}=\mathrm{CN}, \mathrm{CO}_{2} \mathrm{Et}$

$88 \quad 75-80 \%$

$89 \quad 14-18 \%$

\section{Scheme 28}

Pyrazolo[1,5- $a$ ] benzimidazoles 92 were prepared in moderate yields by reacting 1aminobenzimidazole derivative 90 with phenacyl bromides 5 to form the thiadiazino-, and selenadiazino-benzimidazoles $\mathbf{9 1}$, which underwent ring contraction to give $\mathbf{9 2}$ (Scheme 29). ${ }^{51,52}$<smiles>[R]c1cc2c(cc1[R])N(N)C([X])N2C</smiles>

$$
\mathrm{R}^{1}, \mathrm{R}^{2}=\mathrm{H}, \mathrm{Me} \quad \mathrm{Ar}=\mathrm{Ph}, 4-\mathrm{MeOC}_{6} \mathrm{H}_{4}, \text { 2-naphthyl } \quad \mathrm{X}=\mathrm{S} \text {, Se }
$$

Scheme 29

Ring contraction of 1,2,4-triazepino[2,3-a]benzimidazol-4-ones 93 in acetic anhydride afforded pyrazolo[1,5-a]benzimidazole derivatives $\mathbf{9 6}$ in low to high yields probably according to the mechanism depicted in Scheme $30 . .^{53}$

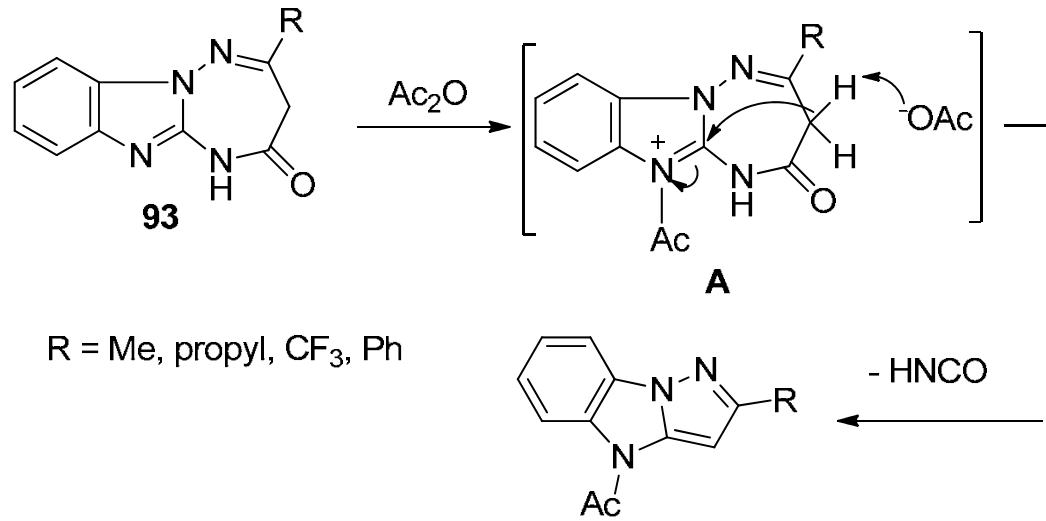

$9612-98 \%$<smiles>[R]c1[nH]n2c1C(=O)NC21C2Nc3cc(C)ccc3N21</smiles>

94<smiles></smiles>

95

Scheme 30 
Free radical oxidation of anilinopyrazoles 97 by dibenzoyl peroxide or lead(IV) oxide resulted in the formation of the pyrazolo[1,5-a]benzimidazoles 98 in moderate yields (Scheme $31) .^{54}$

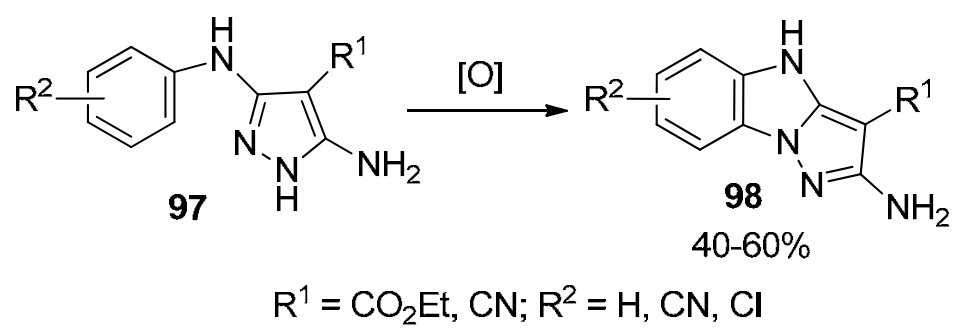

\section{Scheme 31}

4H-Pyrazolo[1,5-a]benzimidazoles $\mathbf{1 0 0}$ were prepared in moderate to good yields by hydrogenation of the hydrazones 99 in acetic acid containing Pt-metal (Scheme 32). ${ }^{55}$<smiles>[R]C(CC(=O)OCC)=NNc1cc([R])c([R])cc1[N+](=O)[O-]</smiles>

99<smiles>[R]c1cc2[nH]c3cc([R])c([R])cc3n2n1</smiles>

$100 \quad 45-87 \%$

$\mathrm{R}=\mathrm{Me}, \mathrm{Ph}, 4-\mathrm{MeOC}_{6} \mathrm{H}_{4}, 4-\mathrm{NO}_{2} \mathrm{C}_{6} \mathrm{H}_{4} ; \mathrm{R}^{1}=\mathrm{H}, \mathrm{Me}, \mathrm{Br}, \mathrm{Cl}, \mathrm{NHAc} ; \mathrm{R}^{2}=\mathrm{H}, \mathrm{Cl}$

\section{Scheme 32}

When 5-amino-1-(o-chlorophenyl)pyrazoles 101 were heated with copper(II) oxide in DMF and anhydrous $\mathrm{K}_{2} \mathrm{CO}_{3}$, the $4 \mathrm{H}$-pyrazolo[1,5-a]benzimidazoles 102 were formed. Treatment of 102 (R $=\mathrm{CN}$ ) with sodium azide gave 3-(tetrazol-5'-yl)-4H-pyrazolo[1,5-a]benzimidazole 103. Basic hydrolysis of $102\left(\mathrm{R}=\mathrm{CO}_{2} \mathrm{Et}\right)$ led to 4H-pyrazolo[1,5-a]benzimidazole-3-carboxylic acid 104. When 104 was heated above its melting point in vacuo, it smoothly decarboxylated to give the parent 4H-pyrazolo[1,5-a] benzimidazole 105 (Scheme 33). ${ }^{56}$

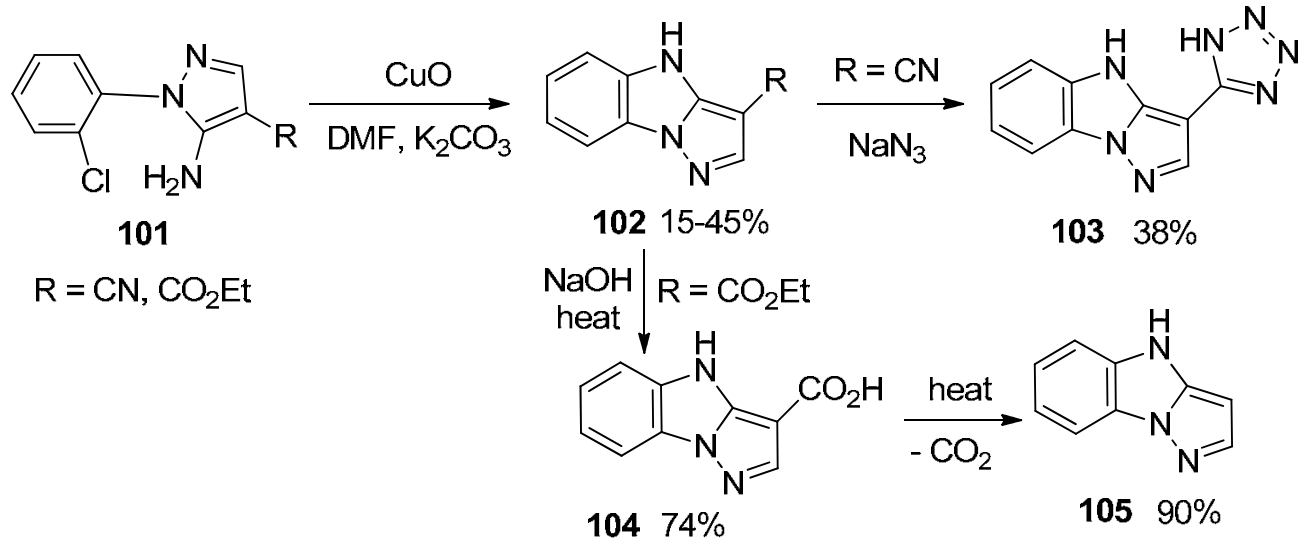

Scheme 33 
Flash vacuum pyrolysis (FVP) of 1-(2-azidophenyl)pyrazoles 106 or photolysis at $254 \mathrm{~nm}$ in ethanol and diethylamine gave the pyrazolo[ 1,5-a]benzimidazoles 105 in reasonable yields via the intermediate 2-(1-pyrazolyl)phenylnitrene 107 (Scheme 34). ${ }^{57,58}$<smiles>[X]c1ccc(N)c(-n2cccn2)c1</smiles>

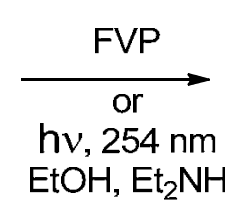<smiles></smiles><smiles>[X]c1ccc2[nH]c3ccnn3c2c1</smiles>

$105 \quad 15-55 \%$

\section{Scheme 34}

The hydrazine derivative 108 was cyclocondensed with ethyl 3-ethoxy-3-iminopropanoate hydrochloride 109 to give the ethoxypyrazolinone derivative 110 which was hydrogenated in acetic acid in the presence of $\mathrm{Pd} / \mathrm{C}$ and then cyclized by refluxing in HOAc after removal of $\mathrm{Pd} / \mathrm{C}$ to give the pyrazolobenzimidazole derivative 111 (Scheme 35$){ }^{59}$

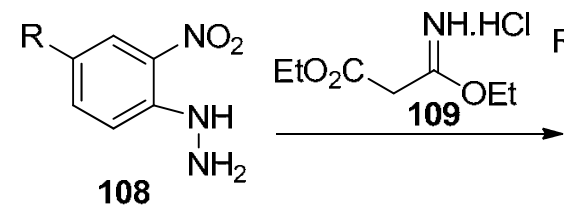<smiles>[R]c1ccc(N2N=C(OCC)CC2=O)c([N+](=O)[O-])c1</smiles><smiles>[R]c1ccc2c(c1)[nH]c1cc(OCC)nn12</smiles><smiles>[R]=NCC(C)(C)C(=O)NCC(C)C</smiles>

\section{Scheme 35}

\subsection{Imidazobenzimidazoles}

Imidazo[1,5-a]benzimidazole derivative $\mathbf{1 1 3}$ was prepared by reaction of 2aminomethylbenzimidazole 112 with acetic anhydride (Scheme 36). ${ }^{60}$<smiles></smiles>

\section{Scheme 36}


Reaction of 1,2-diaminobenzimidazole 114 with one equivalent of 1-phenyl-2-bromo-3phenylpropanone $\mathbf{1 1 5}$ in methanol led to the formation of 2-phenyl-3-benzyl-9aminoimidazo[1,2-a]benzimidazole 116 (Scheme 37). ${ }^{61}$<smiles>NN1c2ccccc2N(N)C1CC(=O)Oc1ccccc1</smiles>

\section{Scheme 37}

Treatment of 2-aminobenzimidazole 117 with ethyl bromopyruvate 118 in THF at room temperature followed by reflux in ethanol gave the imidazo[1,2-a]benzimidazole 119 in low yield (Scheme 38). ${ }^{62}$

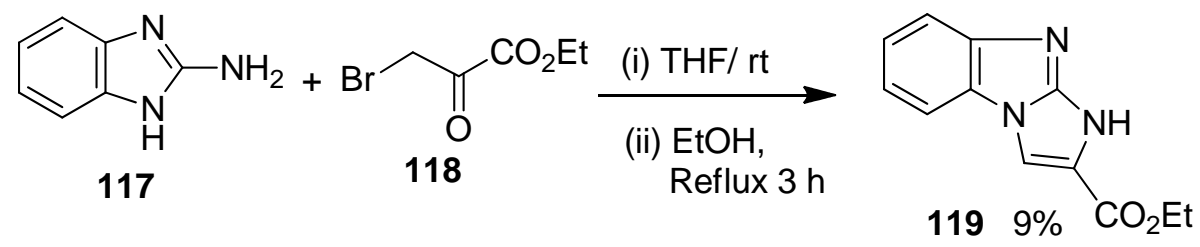

\section{Scheme 38}

2-(Chloromethyl)imidazo[1,2-a]benzimidazole 122 was prepared by condensation of 1methyl-2-aminobenzimidazole 120 with 1,3-dichloroacetone 121 (Scheme 39). ${ }^{63}$

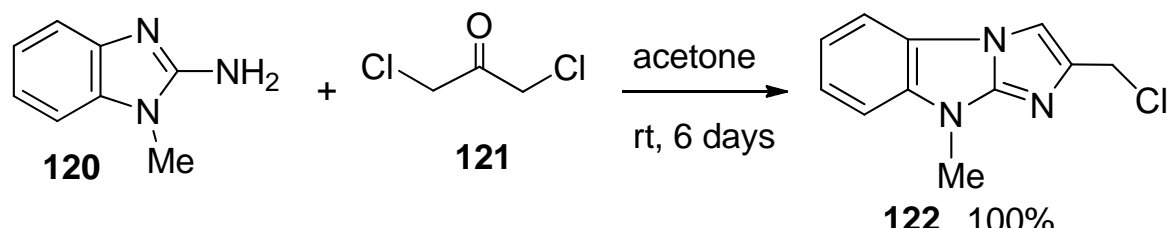

\section{Scheme 39}

Treatment of 2-aminobenzimidazole 117 with 2-bromoacetaldehyde diethylacetal in a solution of $\mathrm{NaOMe}$ in $\mathrm{MeOH}$ under reflux gave 2-amino-1-(2,2-diethoxyethyl)benzimidazole 123. Refluxing the latter compound $\mathbf{1 2 3}$ in $\mathrm{HCl}$ afforded imidazo[1,2-a]benzimidazole 124 which on treatment with dimethyl sulfate in aq. $\mathrm{NaOH}$ gave a mixture of 1-methylimidazo[1,2a]benzimidazole 125 and 9-methylimidazo[1,2-a] benzimidazole 126 (Scheme 40). ${ }^{64}$ 


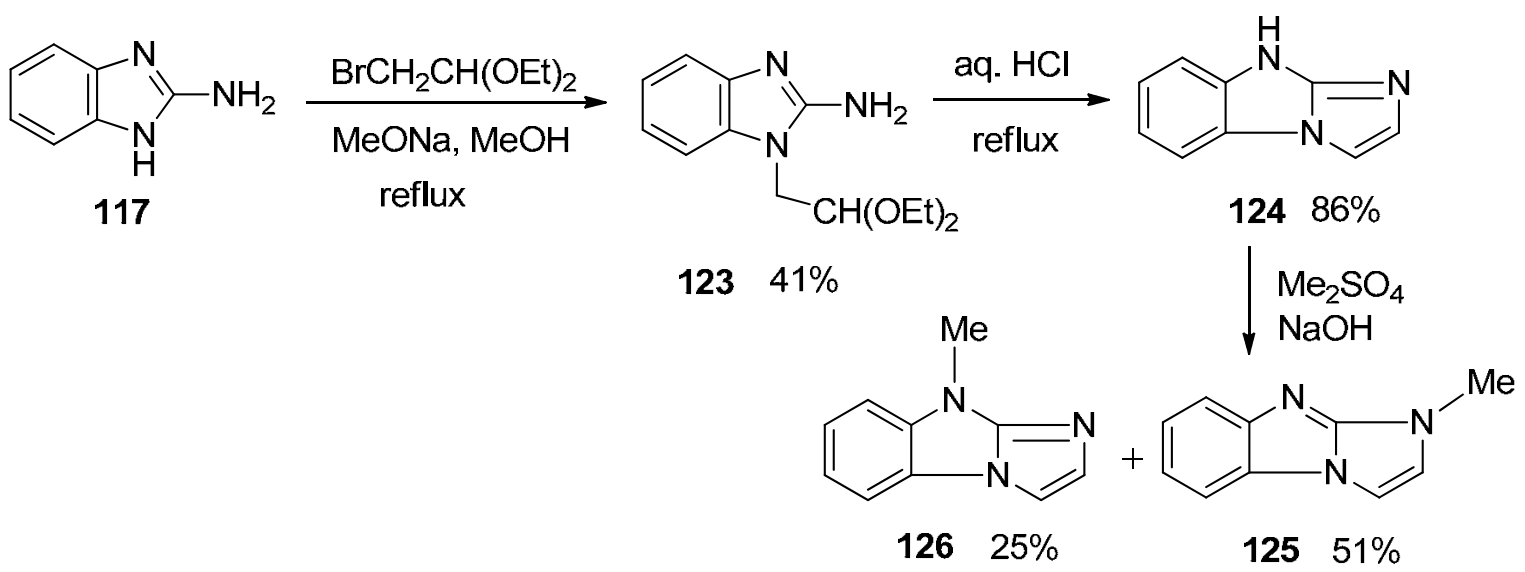

\section{Scheme 40}

When 2-aminobenzimidazole 117 was refluxed with 2-bromoacetylnaphthalene or 3bromoacetylpyrazole derivatives $\mathbf{1 2 7}$ or $\mathbf{1 2 8}$ in ethanol, it afforded the $1 H$-imidazo[1,2a]benzimidazole derivatives $\mathbf{1 2 9}$ and 130, respectively, in good yields (Scheme 41). ${ }^{65,66}$

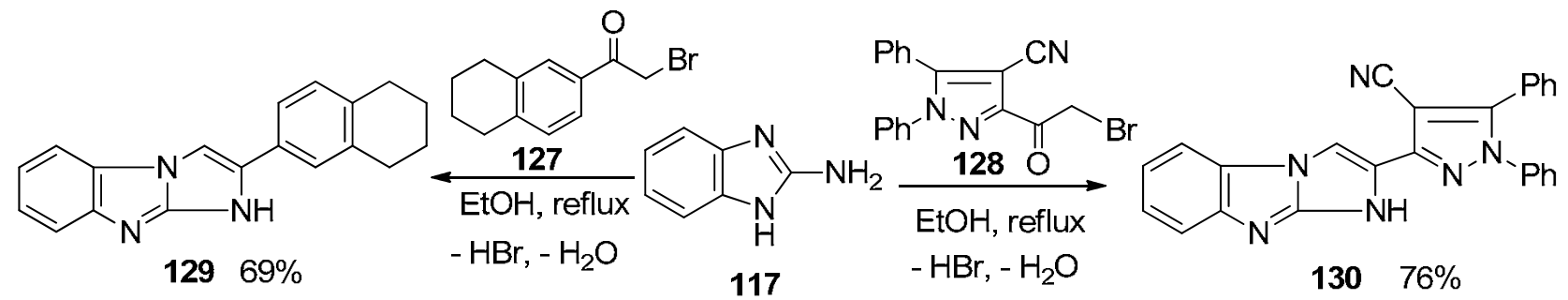

\section{Scheme 41}

Photolysis of 1-(4,5-dihydro- $1 H$-imidazol-2-yl)benzotriazole 131 in acetonitrile at $254 \mathrm{~nm}$ for $18 \mathrm{~h}$ gave dihydroimidazo[1,2-a]benzimidazole 133 in good yield. The reaction took place via the diradical intermediate 132 (Scheme 42). ${ }^{67}$



\section{Scheme 42}

Treatment of the diimidoyl dichlorides 63 with 2-aminobenzimidazole 117 in refluxing THF in the presence of $\mathrm{Et}_{3} \mathrm{~N}$ resulted in the formation of the $3 \mathrm{H}$-imidazo[1,2-a]benzimidazol-2- 
amines 134 in good yield. Acylation of the latter 134 ( $\mathrm{Ar}=4$-tolyl) with acetyl chloride in the presence $\mathrm{NaN}\left(\mathrm{SiMe}_{3}\right)_{2}$ at low temperature gave 9-acetyl-3H-imidazo[1,2-a]benzimidazole 135 in $53 \%$ yield (Scheme 43$){ }^{68}$

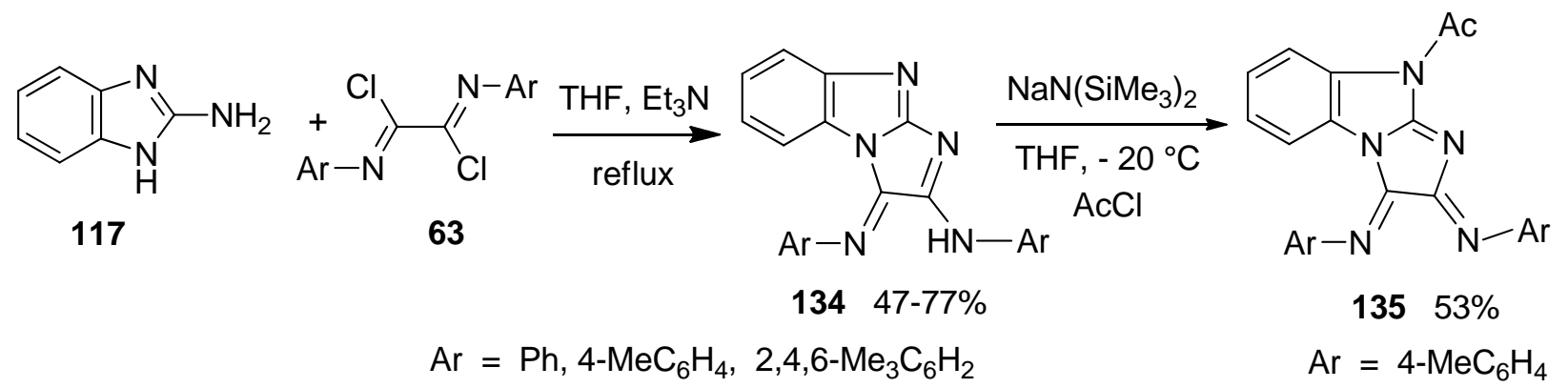

\section{Scheme 43}

2-Aminobenzimidazolium bromides 137 were formed by reaction of o- $(N-$ aryl)phenylenediamines 136 with cyanogen bromide in ethanol at $150^{\circ} \mathrm{C}$, followed by alkylation with ethyl bromoacetate in acetone at reflux. Condensation with acid anhydrides along with their respective sodium salts afforded the imidazo[1,2-a] benzimidazole esters 138 (Scheme 44). ${ }^{69}$<smiles></smiles>

\section{Scheme 44}

Treatment of hydrazonoyl bromides 139 with 2-aminobenzimidazole 117 in refluxing ethanol furnished 3-arylazo-1H-imidazo[1,2-a]benzimidazoles 140 (Scheme 45). ${ }^{70}$

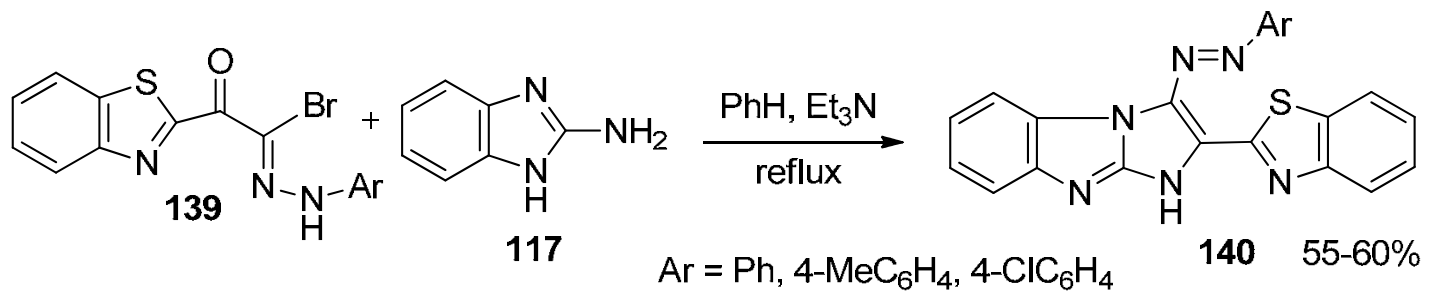

\section{Scheme 45}


2-Azidomethylbenzimidazole 141 reacted with benzoyl chlorides and gave the benzoyl(azidomethyl)benzimidazoles 142 which reacted with tributylphosphine to give the corresponding 3-aryl-9H-imidazo[1,2-a] benzimidazoles 143 (Scheme 46). ${ }^{71}$

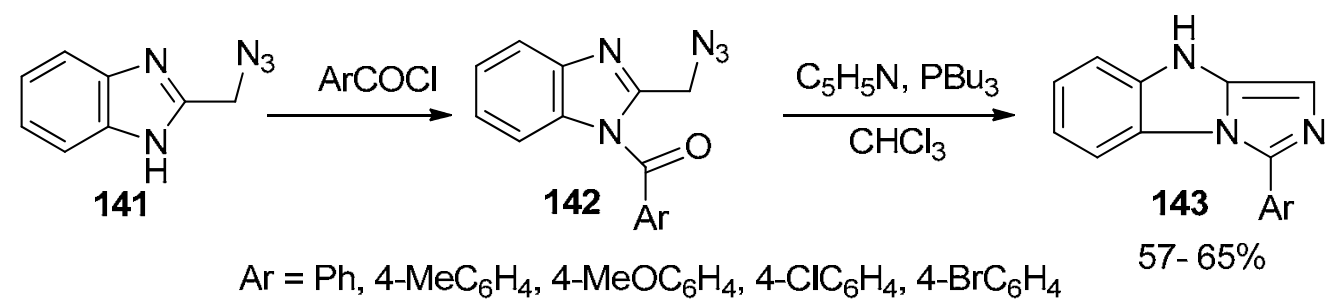

\section{Scheme 46}

2,9-Disubstituted imidazo[1,2-a] benzimidazoles 145 were obtained regioselectively in good yields by heating a mixture of 2-aminobenzimidazole 117 and $\alpha$-tosyloxy ketones 144 in acetic acid (Scheme 47). ${ }^{72}$

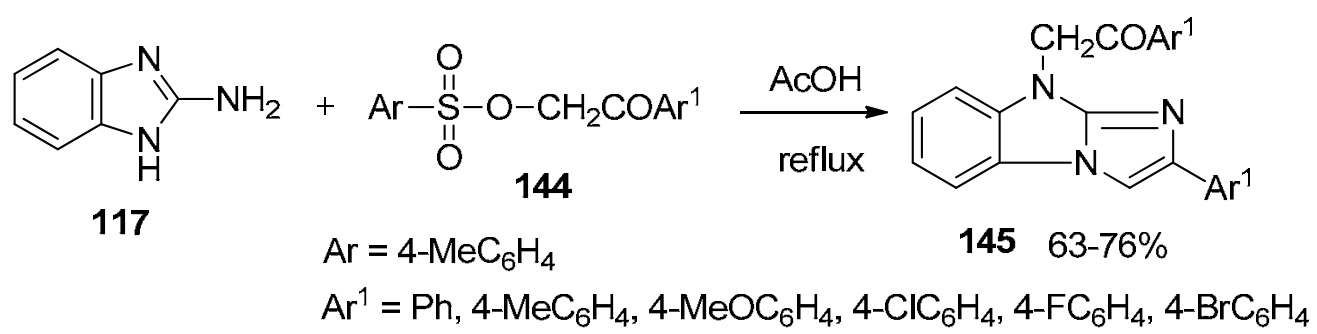

\section{Scheme 47}

\subsection{Oxazolobenzimidazoles}

Reaction of 2-aminoxazoles 146 with $p$-benzoquinone 147 in acetic acid at $40-50^{\circ} \mathrm{C}$ for one hour gave the corresponding 6-hydroxyoxazolo[3,2-a]benzimidazoles $\mathbf{1 4 8}$ in moderate yields according to the mechansim shown in Scheme $48 .^{73}$

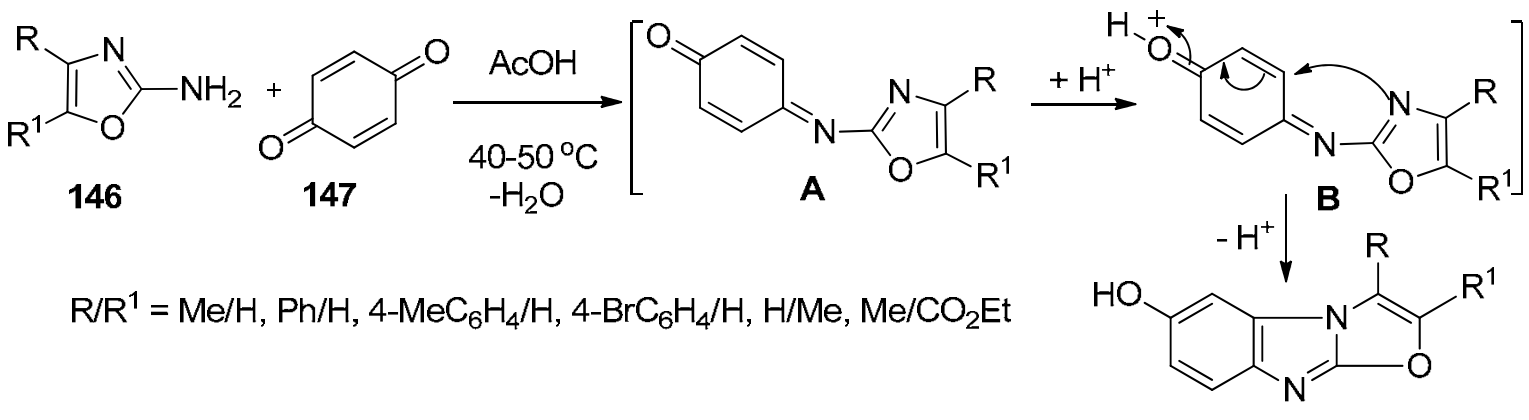

$14815-41 \%$

\section{Scheme 48}


Benzimidazo[2,1-b]benzoxazole 150 was prepared photolytically at $360 \mathrm{~nm}$ from 1-(2benzoxazolyl)benzotriazole 149 (Scheme 49$){ }^{74}$<smiles>c1ccc2oc(-n3nnc4ccccc43)nc2c1</smiles>

149

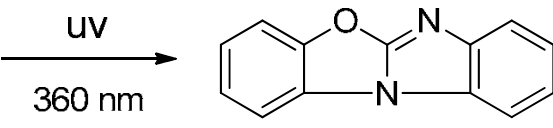

150

\section{Scheme 49}

3-Cyanomethylene-1,3-oxazolo[3,2-a]benzimidazole 153 was obtained by condensation of 2alkylthiobenzimidazoles 151 with 4-hydroxy-4-methylpent-2-ynenitrile 152 in acetonitrile containing $\mathrm{LiOH}$ (Scheme 50). ${ }^{75}$

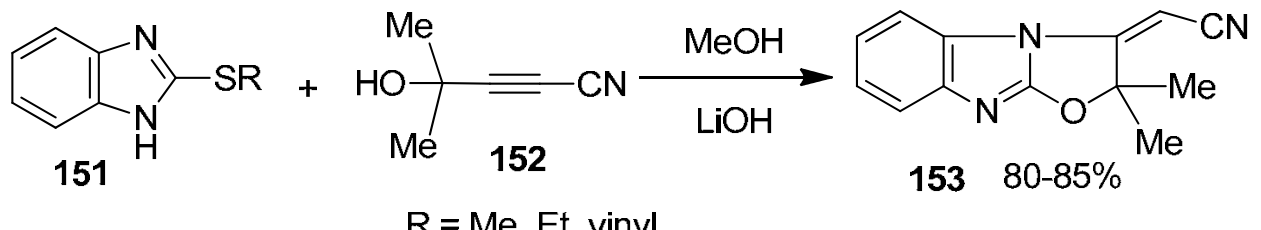

\section{Scheme 50}

2,3-Dihydrooxazolo[3,2-a]benzimidazole derivatives 153 were also obtained by heating 2aminobenzimidazoles 117 with 4-hydroxy-2-alkyenenitrile derivatives 152 in DMF probably according to the mechanism illustrated in Scheme $51 .^{76}$

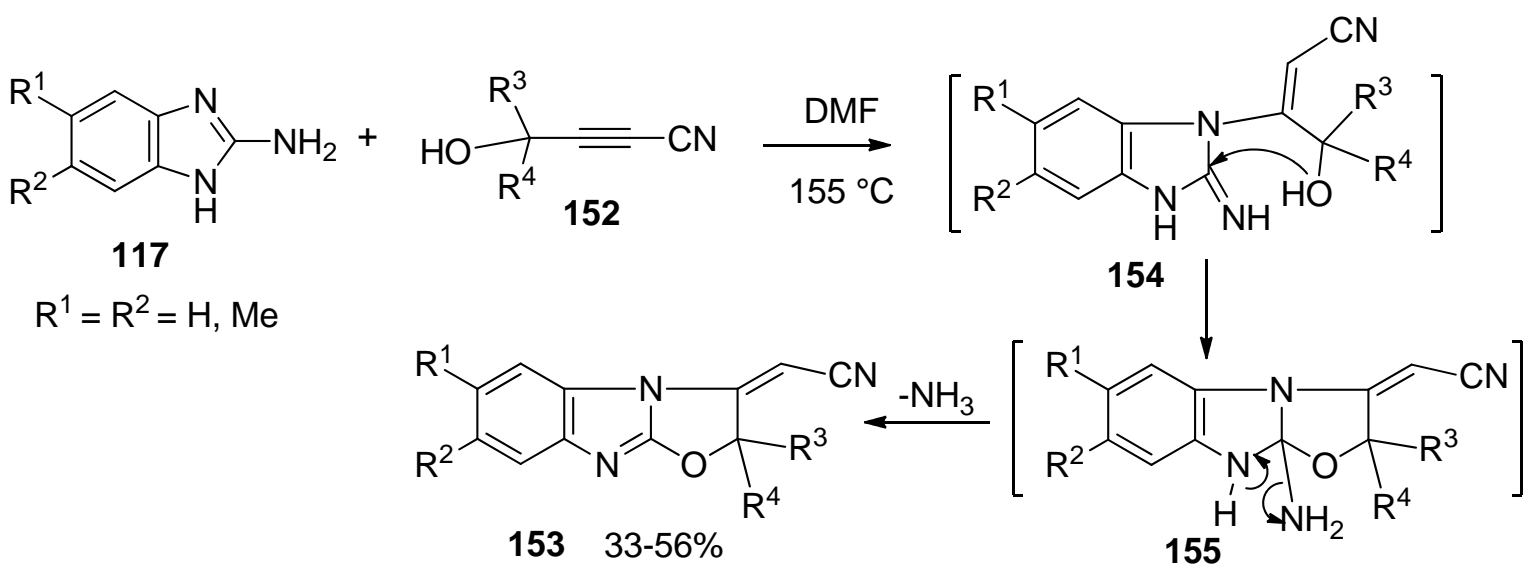

$\mathrm{R}^{1} / \mathrm{R}^{2} / \mathrm{R}^{3} / \mathrm{R}^{4}=\mathrm{H} / \mathrm{H} / \mathrm{Et} / \mathrm{Et}, \mathrm{Me} / \mathrm{Me} / \mathrm{Et} / \mathrm{Et}, \mathrm{Me} / \mathrm{Me} / \mathrm{Me} / \mathrm{Me}, \mathrm{Me} / \mathrm{Me} / \mathrm{Bu}^{i} / \mathrm{Et}$

\section{Scheme 51}


1-Substituted benzimidazoles 156 were readily annulated regio- and stereoselectively when treated with $\alpha, \beta$-acetylenic- $\gamma$-hydroxy nitrile 152 under mild conditions, at $20-25^{\circ} \mathrm{C}$ without catalyst and without solvent, to form 3-cyanomethylene-2,2-dimethyl-1,3-oxazolo[3,2a] benzimidazoles 157 in excellent yields (Scheme 52). ${ }^{77}$

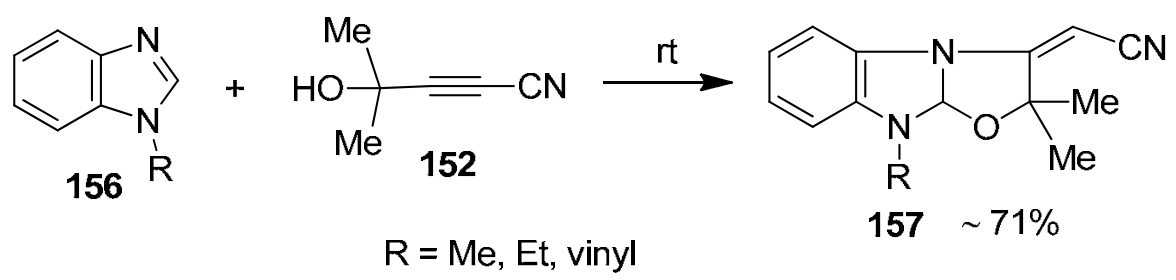

\section{Scheme 52}

The reaction of 2-chloro-1-phenacylbenzimidazole 158 with sodium benzoate, as a base, in DMF gave 2-phenyloxazolo[3,2-a]benzimidazole 159 in $76 \%$ yield (Scheme 53 ). ${ }^{78}$

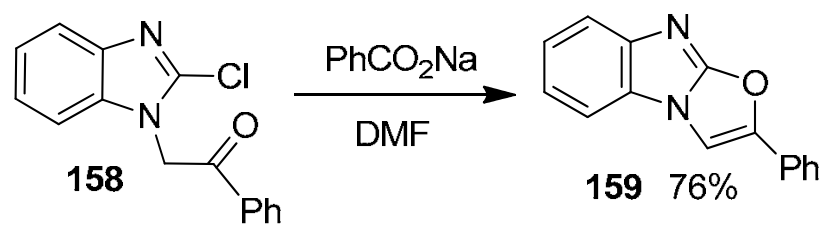

\section{Scheme 53}

Condensation of $o$-phenylenediamine 36 with $(S)$-lactic acid in $4 N \mathrm{HCl}$ at reflux gave 2(hydroxyethyl)benzimidazole $\mathbf{1 6 0}$ in $85 \%$ yield. Heating the latter compound $\mathbf{1 6 0}$ with benzaldehyde dimethyl acetal using a catalytic amount of $p$-toluenesulfonic acid gave the oxazolo[3,4-a] benzimidazole derivative 161 (Scheme 54). ${ }^{79,80}$

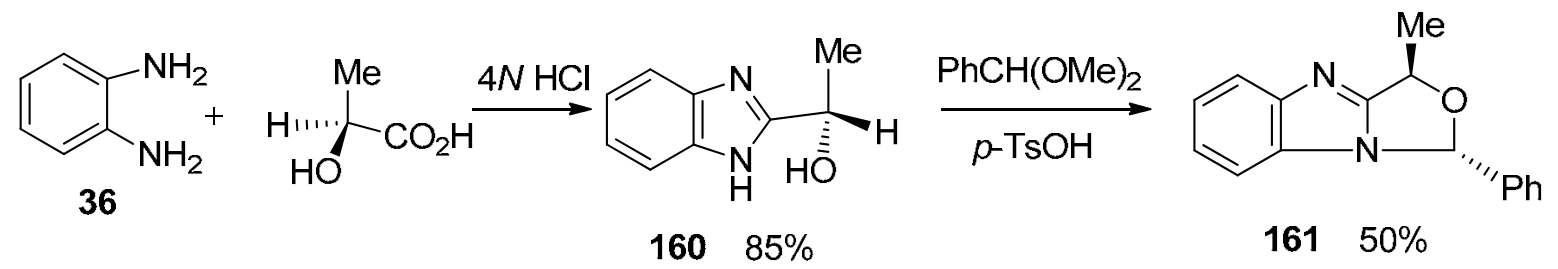

\section{Scheme 54}

Heating a mixture of 2-(hydroxymethyl)benzimidazole 162 and benzaldehyde dimethyl acetals 163 in dry toluene and a catalytic amount of $p$-toluenesulfonic acid for $48 \mathrm{~h}$ gave the oxazolo[3,4-a] benzimidazole derivatives 164 (Scheme 57). ${ }^{81}$ 


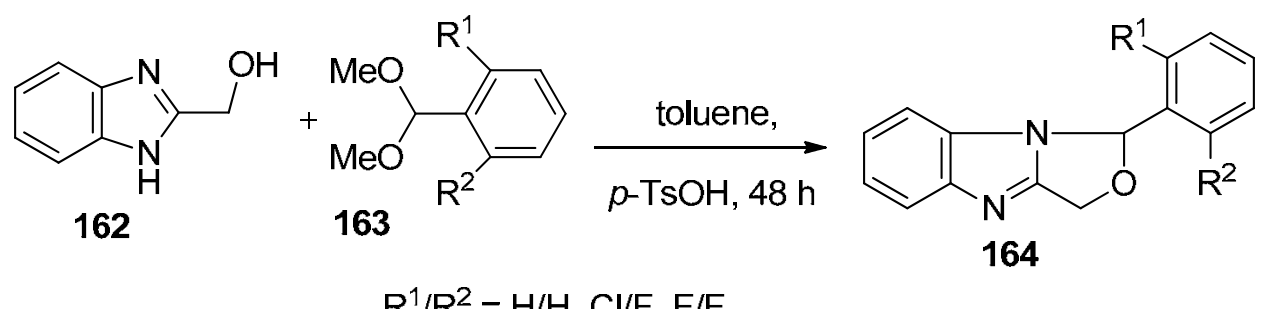

$\mathrm{R}^{1} / \mathrm{R}^{2}=\mathrm{H} / \mathrm{H}, \mathrm{Cl} / \mathrm{F}, \mathrm{F} / \mathrm{F}$

\section{Scheme 55}

\subsection{Thiazolobenzimidazoles}

Reaction of hydrazonoyl bromides 139 with benzimidazole-2-thiol $\mathbf{1 6 5}$ in ethanolic triethylamine solution at reflux gave the thiazolo[3,2-a]benzimidazoles 166 in good yields (Scheme 56). ${ }^{82-84}$

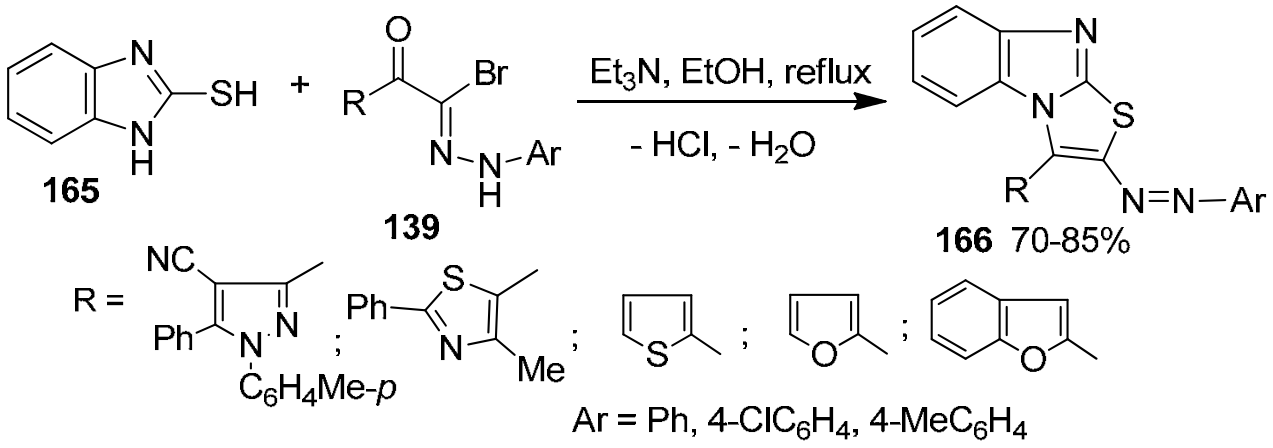

\section{Scheme 56}

Benzimidazole-2-thiol 165 reacted similarly with bis-hydrazonoyl chlorides 167 in refluxing ethanol in the presence of triethylamine to give 2,3-bis(arylhydrazono)-2,3-dihydrothiazolo[3,2a]benzimidazoles $\mathbf{1 6 8}$ in high yields (Scheme 57). ${ }^{85,86}$

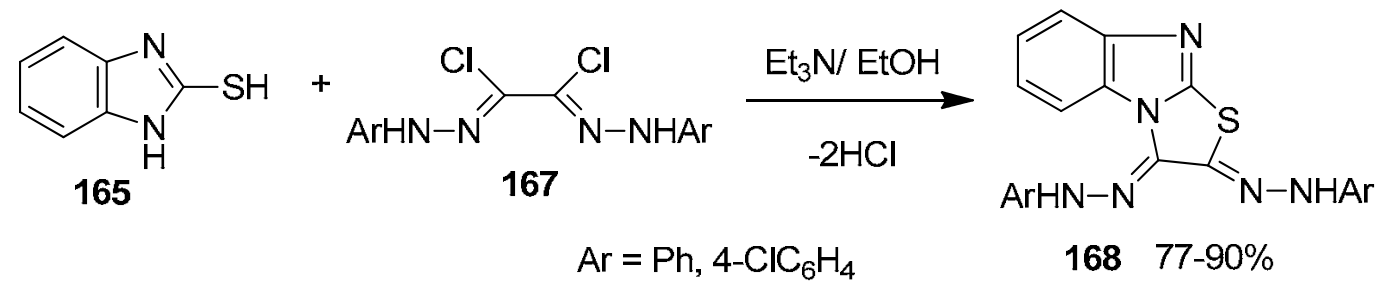

\section{Scheme 57}

Refluxing of oxal-bis(arylimidoyl) dichlorides 63 in THF with benzimidazole-2-thiol 165 in the presence of $\mathrm{Et}_{3} \mathrm{~N}$ afforded the thiazolo[3,2-a]benzimidazole derivatives 170 (Scheme 58). ${ }^{68}$ 


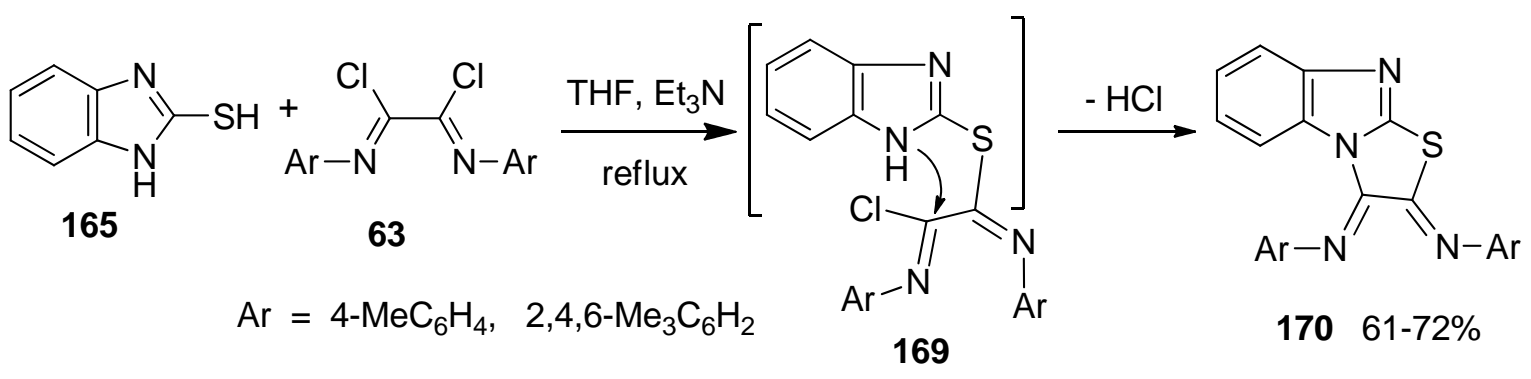

\section{Scheme 58}

When a mixture of benzimidazole-2-thiol 165 and the maleimide derivatives 171 was heated in acetic acid in the presence of sulfuric acid, it furnished the thiazolo[3,2-a]benzimidazole derivatives $\mathbf{1 7 3}$ in moderate yields via Michael-type addition followed by ring opening of the intermediate 172 (Scheme 59). ${ }^{87}$

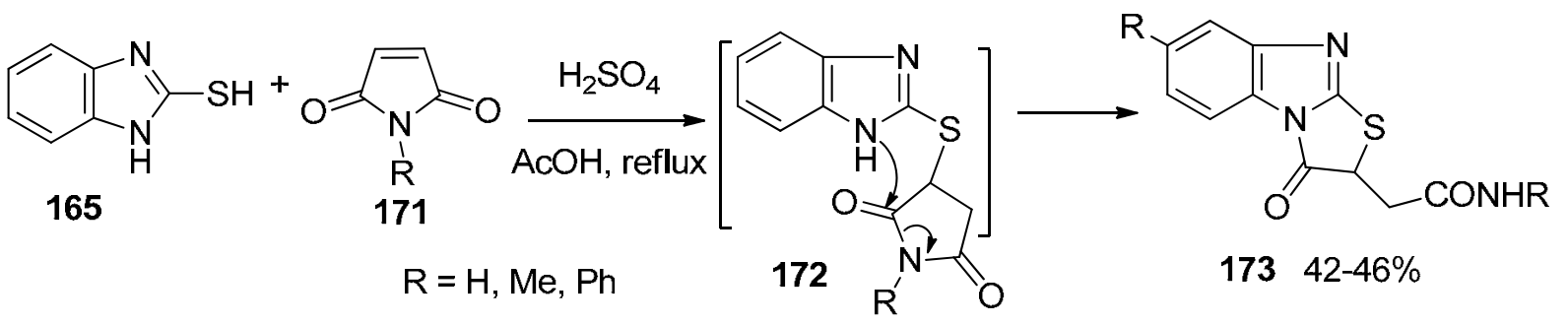

\section{Scheme 59}

Thiazolo[3,4- $a$ ] benzimidazoles 175 were prepared by heating a mixture of $o$ phenylenediamine, 2-mercaptoacetic acid and the appropriate carbonyl compounds $\mathbf{1 7 4}$ in benzene under conventional reflux or microwave irradiation (Scheme 60). ${ }^{88-92}$

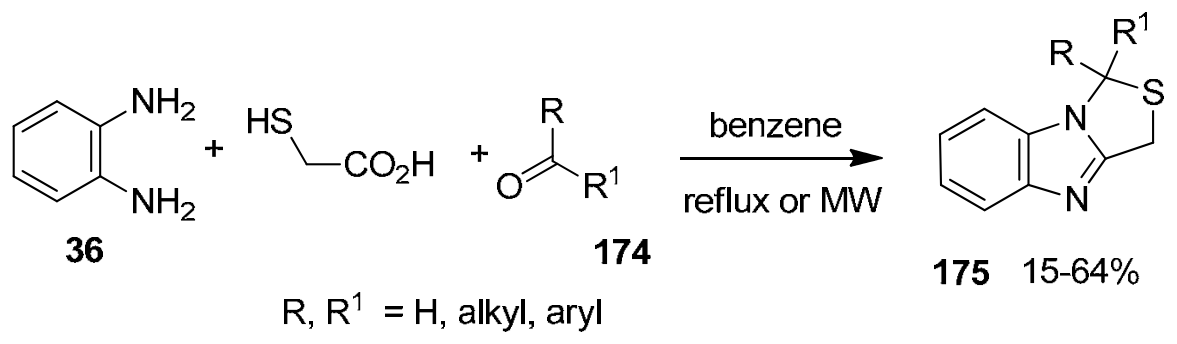

\section{Scheme 60}

Condensation of 2-mercaptobenzimidazoles 165 with chloroacetic acid and acetic anhydride gave the thiazolo[3,2-a] benzimidazol-3(2H)-ones 177 in good yields. ${ }^{93-96}$ Reaction of 165 with $\alpha$-bromoketones 5 followed by polyphosphoric acid (PPA) yielded the thiazolo[3,2- 
a]benzimidazoles 179. ${ }^{97-102}$ Condensation of 165 with 1,2-dibromoethane in ethanol yielded the thiazolo[3,2-a] benzimidazole derivatives 180 (Scheme 61). ${ }^{103}$

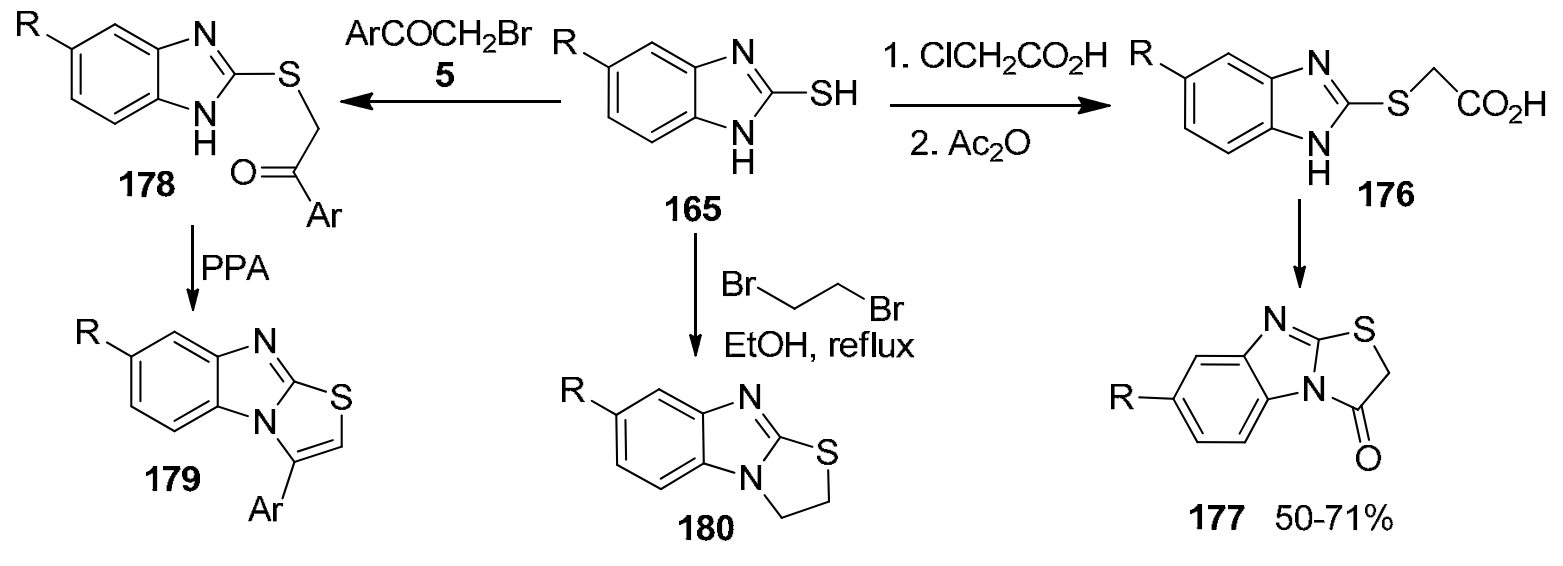

$\mathrm{R}=\mathrm{H}, \mathrm{Me}, \mathrm{Br}, \mathrm{Cl}, \mathrm{F}, \mathrm{NO}_{2} ; \quad \mathrm{Ar}=\mathrm{Ph}, 4-\mathrm{ClC}_{6} \mathrm{H}_{4}, 4-\mathrm{BrC}_{6} \mathrm{H}_{4}, 4-\mathrm{MeC}_{6} \mathrm{H}_{4}$

\section{Scheme 61}

2,3-Dihydrothiazolo[3,2-a]benzimidazole 182 was prepared by condensation of 2-(1,2dibromoethyl)pyridine 181 in DMF with 2-mercaptobenzimidazole 165 (Scheme 62). ${ }^{104-106}$<smiles>CC(C)(C)c1ccc2c(c1)nc1n2CC(c2ccccn2)S1</smiles>

\section{Scheme 62}

Treatment of benzimidazole-2-thiol 165 with 1,3-dichloroacetone 121 gave 1-(2benzimidazolylthio)-3-chloro-2-propanone hydrochloride 183. Cyclization of $\mathbf{1 8 3}$ in sulfuric acid followed by basic work up provided 3-chloromethylthiazolo[3,2- $a$ ] benzimidazole $184 .^{107-}$ ${ }^{109}$ An efficient regioselective synthesis of 2-methoxycarbonylthiazolo[3,2- $a$ ]benzimidazoles 186 from benzimidazole-2-thiols 165 and $\alpha$-chloroaldehyde ester 185 was reported (Scheme 63). ${ }^{110}$ 


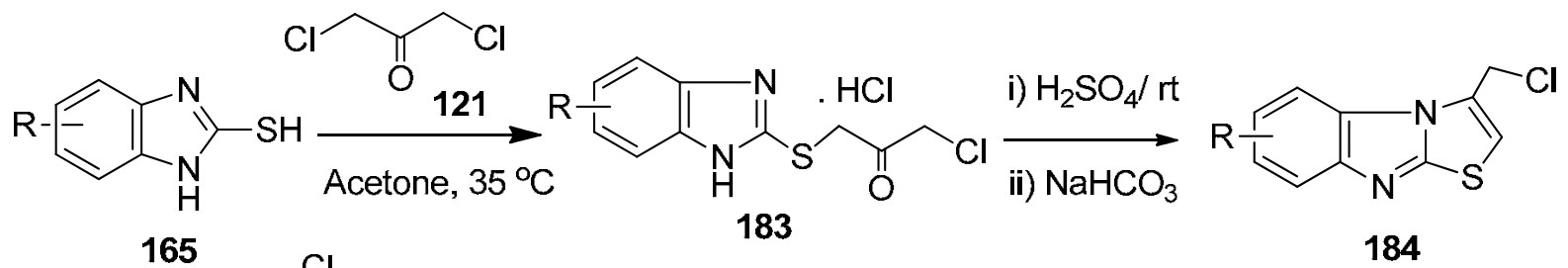

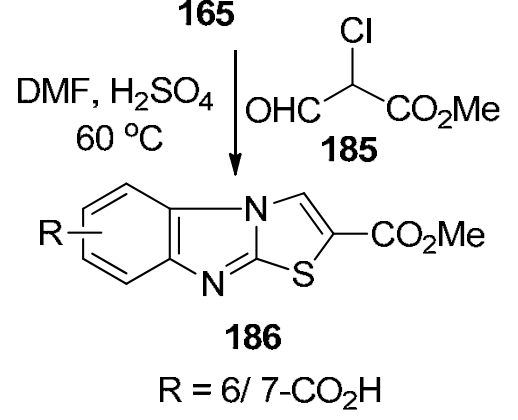

\section{Scheme 63}

Treatment of 2-(allylthio)benzimidazole 187 with iodine in $\mathrm{CHCl}_{3}$ and then with aqueous potassium hydroxide gave the thiazolo[3,2-a]benzimidazole 188 (Scheme 64). ${ }^{11}$

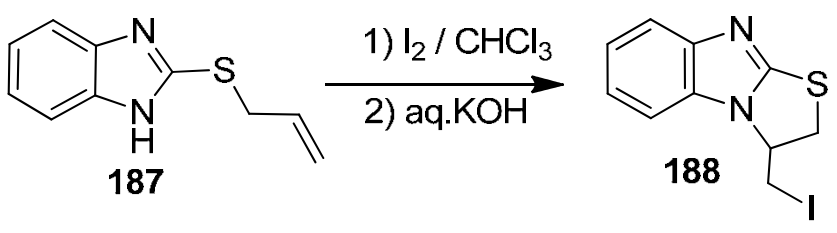

\section{Scheme 64}

2-Methoxy-7-trifluoromethyl-2,3-dihydrothiazolo[3,2-a]benzimidazole 190 was prepared in $78 \%$ yield by the interamolecular cyclization of 1-(2,2-dimethoxyethyl)-2mercaptobenzimidazole 189 using diethyl ether-boron trifluoride in dry dichloromethane (DCM) (Scheme 65). ${ }^{112}$<smiles>COCC(Cn1c(S)nc2cc(C(F)(F)F)ccc21)OC</smiles>

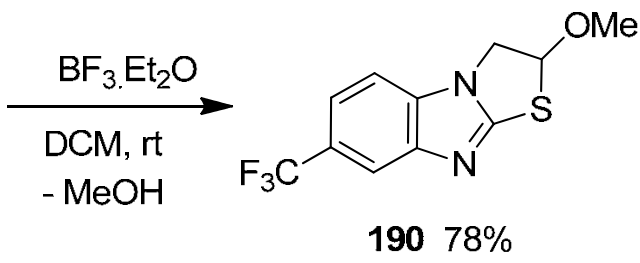

\section{Scheme 65}

The reaction between 2,3-dihydro-2,2,4-trimethyl-1H-1,5-benzodiazepine 191 and mercaptoacetic acid under reflux gave the thiazolobenzimidazole derivative 193 (Scheme 66). ${ }^{113}$ 
<smiles>CC1=Nc2ccccc2NC(C)(C)C1</smiles>

\section{Scheme 66}

The reaction of benzimidazole-2-thiol 165 with bromomalononitrile 194 in cold ethanolic potassium hydroxide solution afforded 2-dicyanomethylthiobenzimidazole 195 which underwent cyclization when treated with ethanolic sodium acetate at reflux to give 3-aminothiazolo[3,2a]benzimidazole-2-carbonitrile 196 (Scheme 67). ${ }^{114}$ Heating benzimidazole-2-thiol 165 with acetophenones in acetic acid afforded 2-benzimidazolylthioacetophenone derivatives 197 in very good yield. Reaction of 197 in acetic anhydride afforded 2-benzoyl-3-methylthiazolo[3,2a]benzimidazoles 198 in high yield (Scheme 67). ${ }^{115}$

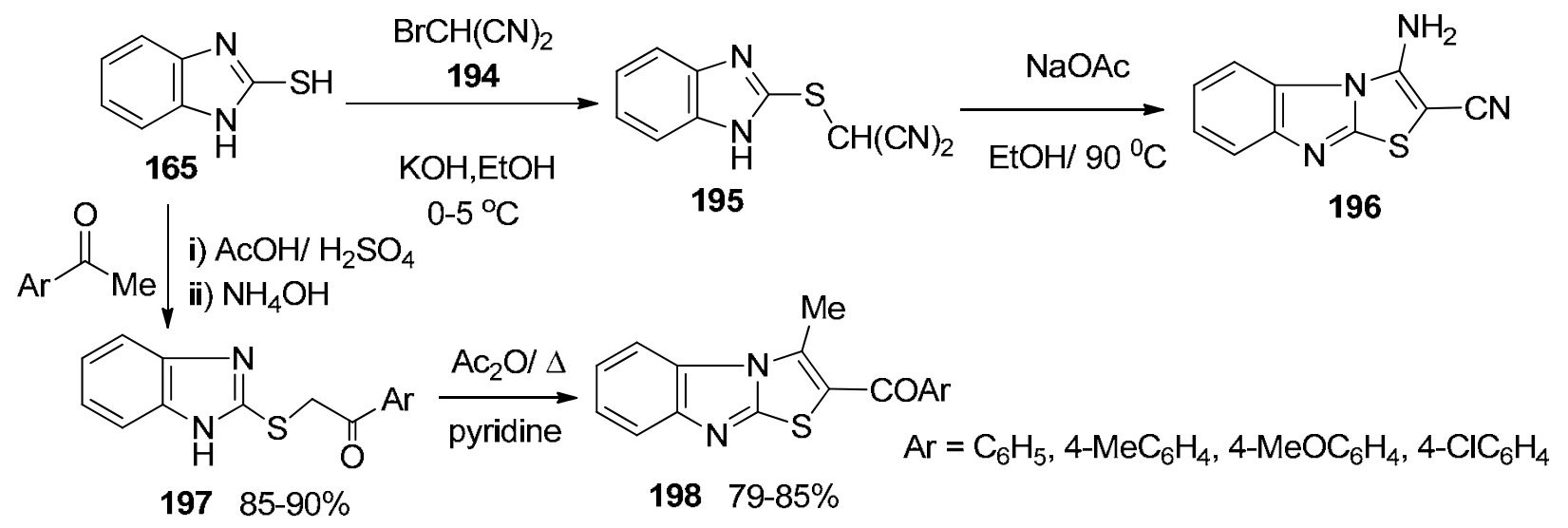

\section{Scheme 67}

Treatment of thiazolinethione derivative 199 with iodomethane in anhydrous acetone at room temperature afforded quantitatively the thiazolium iodide 200. Heating 200 in methanol then treatment of the cold product with aqueous sodium bicarbonate gave 3-methylthiazolo[3,2a]benzimidazole 201 in 100\% yield. ${ }^{116-118}$ Alternatively, 3-methylthiazolo[3,2-a]benzimidazole 201 was obtained in $95 \%$ by refluxing 202 in ethanolic $\mathrm{KOH}$ solution (Scheme 68). ${ }^{119}$ 

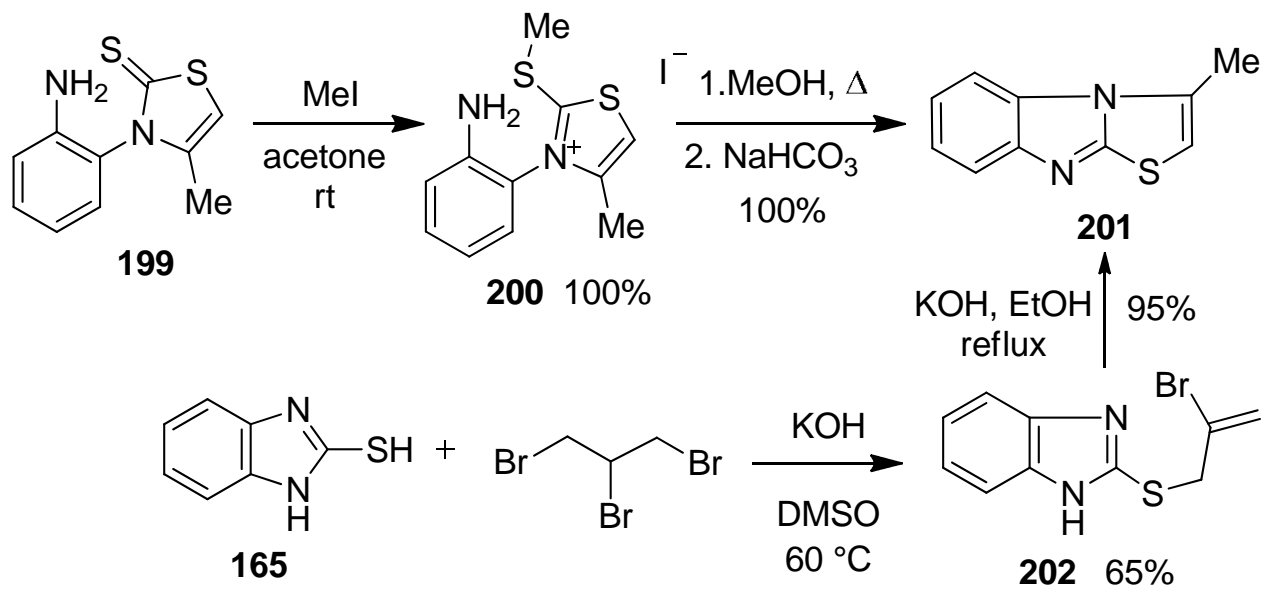

\section{Scheme 68}

Exposure of 1-alkynyl[4-(trifluoromethyl)phenyl](tetrafluoroborato)- $\lambda^{3}$-bromanes 203 to benzimidazole-2-thiol 165 in dichloromethane (DCM) at $0{ }^{\circ} \mathrm{C}$ under argon resulted in a domino Michael addition-carbene rearrangement-cyclization reaction to produce directly 3-substituted thiazolo[3,2-a]benzimidazoles 204 in high yields (Scheme 69). ${ }^{120}$ The epoxyphosphonate 205 reacted with 165 in refluxing toluene in the presence of tosyl alcohol to give the thiazolo[3,2a]benzimidazole 206 in good yield (Scheme 69). ${ }^{121}$

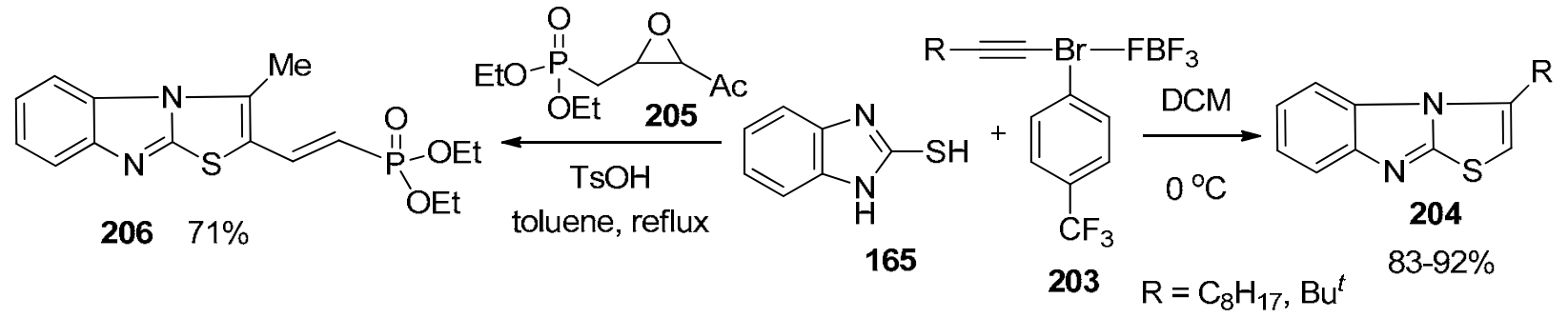

\section{Scheme 69}

\subsection{Triazolobenzimidazoles}

Heating benzimidazole-2-thiol 165 with hydrazonoyl halides 207 in chloroform in the presence of $\mathrm{Et}_{3} \mathrm{~N}$ gave the 1,2,4-triazolo[4,3-a]benzimidazoles 210 through the spiro intermediate 208 which underwent ring opening to yield the thiohydrazide 209 (Scheme 70). ${ }^{122}$

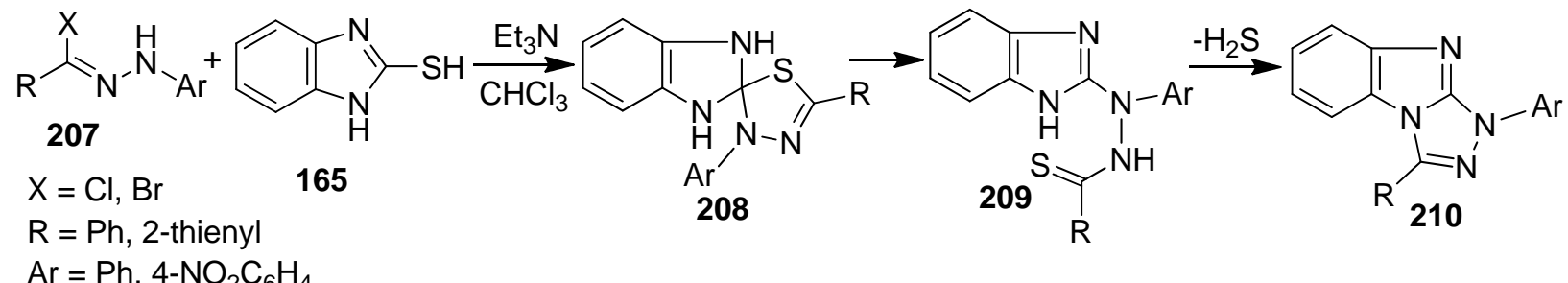

\section{Scheme 70}


Similarly, the hydrazonoyl bromides 211 reacted with 2-methylthiobenzimidazole 212 in refluxing ethanol in the presence of triethylamine to give 1,2,4-triazolo[4,3-a]benzimidazole derivatives 213 (Scheme 71). ${ }^{70,84,123,124}$

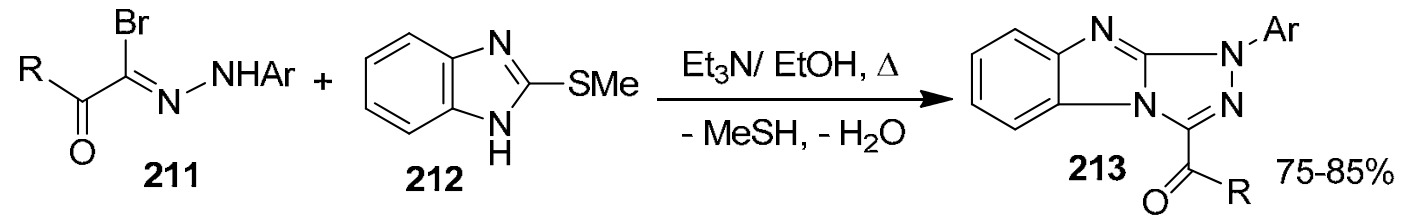

$$
\mathrm{Ar}=\mathrm{Ph}, 4-\mathrm{MeC}_{6} \mathrm{H}_{4}, 4-\mathrm{ClC}_{6} \mathrm{H}_{4}, \quad \mathrm{R}={\underset{\mathrm{Me}}{\mathrm{C}_{\text {tolyl-p }}}}_{\mathrm{EtO}_{2} \mathrm{C}}^{\mathrm{N}}
$$

\section{Scheme 71}

3-Arylazo[1,2,4]triazolo[4,3-a]benzimidazoles 215 were prepared from the reaction of 3chloro-1,5-diarylformazans 214 with 2-methylthiobenzimidazole 212 in refluxing chloroform and triethylamine (Scheme 72). ${ }^{125}$

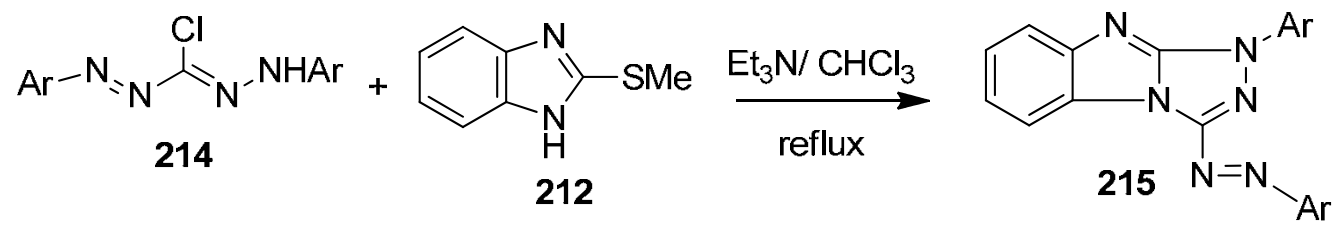

$\mathrm{Ar}=\mathrm{C}_{6} \mathrm{H}_{5}, 4-\mathrm{CH}_{3} \mathrm{C}_{6} \mathrm{H}_{4}, 4-\mathrm{NO}_{2} \mathrm{C}_{6} \mathrm{H}_{4}, 3-\mathrm{NO}_{2} \mathrm{C}_{6} \mathrm{H}_{4}, 4-\mathrm{ClC}_{6} \mathrm{H}_{4}, 3-\mathrm{ClC}_{6} \mathrm{H}_{4}$

\section{Scheme 72}

Bis-hydrazonoyl chlorides 168 reacted with 2-methylthiobenzimidazole 212 in 1:2 molar ratio in refluxing ethanol in the presence of triethylamine to give 1,1'-diaryl-3,3'-bi-1,2,4triazolo[4,5-a]benzimidazoles 216 (Scheme 73). ${ }^{85}$

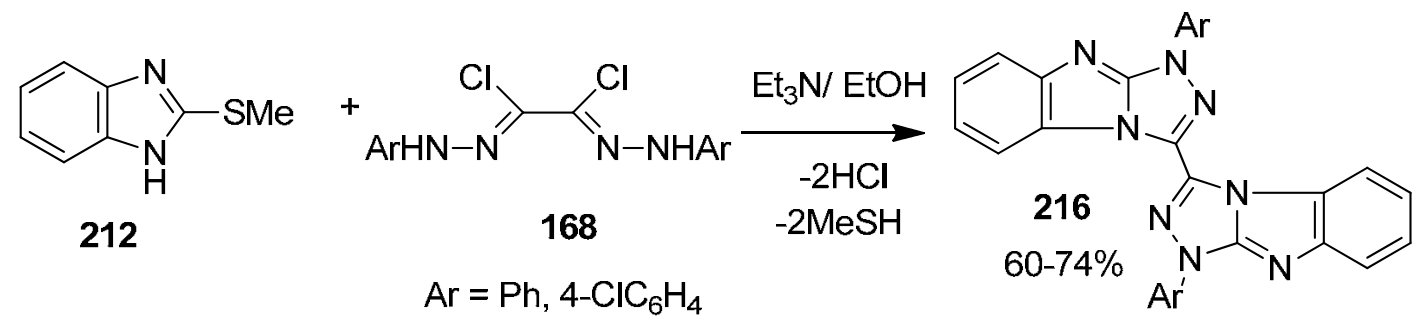

\section{Scheme 73}


Reaction of 2-aminobenzimidazole 117 with the hydrazonoyl chloride 139 gave 1-phenyl-3acetyl-1,2,4-triazolo[4,3-a]benzimidazole 217 (Scheme 74). ${ }^{126}$<smiles>CCOC(=O)c1nn(-c2ccccc2)c2nc3ccccc3n12</smiles>

\section{Scheme 74}

1,3-Dipolar cycloaddition reaction of 1-acylbenzimidazoles 218 with two equivalents of hydrazonoyl chloride 207 in refluxing benzene and $\mathrm{Et}_{3} \mathrm{~N}$ gave the triazolobenzimidazole derivatives 219 (Scheme 75). ${ }^{127}$

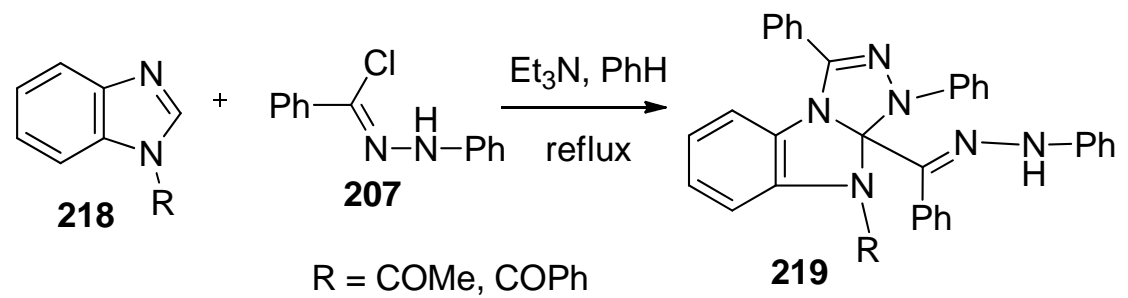

\section{Scheme 75}

Reaction of 2-hydrazinobenzimidazole 220 with aromatic aldehydes 221 in refluxing ethanol afforded the corresponding arylhydrazones 222 which, in turn, were cyclized upon heating in acetic acid to afford 3-aryl-9H-1,2,4-triazolo[4,3-a]benzimidazoles 223 (Scheme 76). ${ }^{128}$

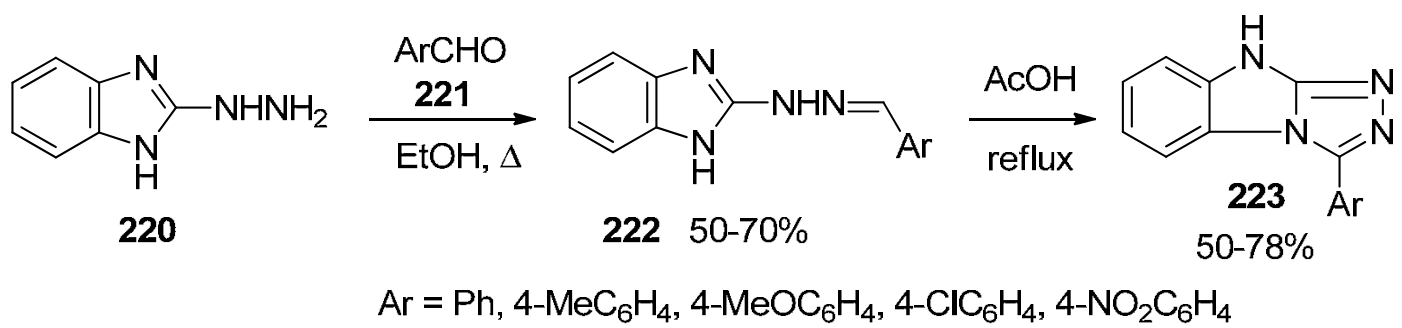

\section{Scheme 76}

Heating 4-methyl-1,5-benzodiazepin-2-one 224 in xylene induced rearrangement into the 1( $\alpha$-methylvinyl)benzimidazole 225. Treatment of 225 with $\mathrm{POCl}_{3}$ gave the 2-clorobenzimidazole derivative 226 which on reaction with sodium methoxide followed by hydrazine then triethyl ortho-acetate afforded the 9-( $\alpha$-methylvinyl)triazolobenzimidazole 228 (Scheme 77$).{ }^{129}$ 


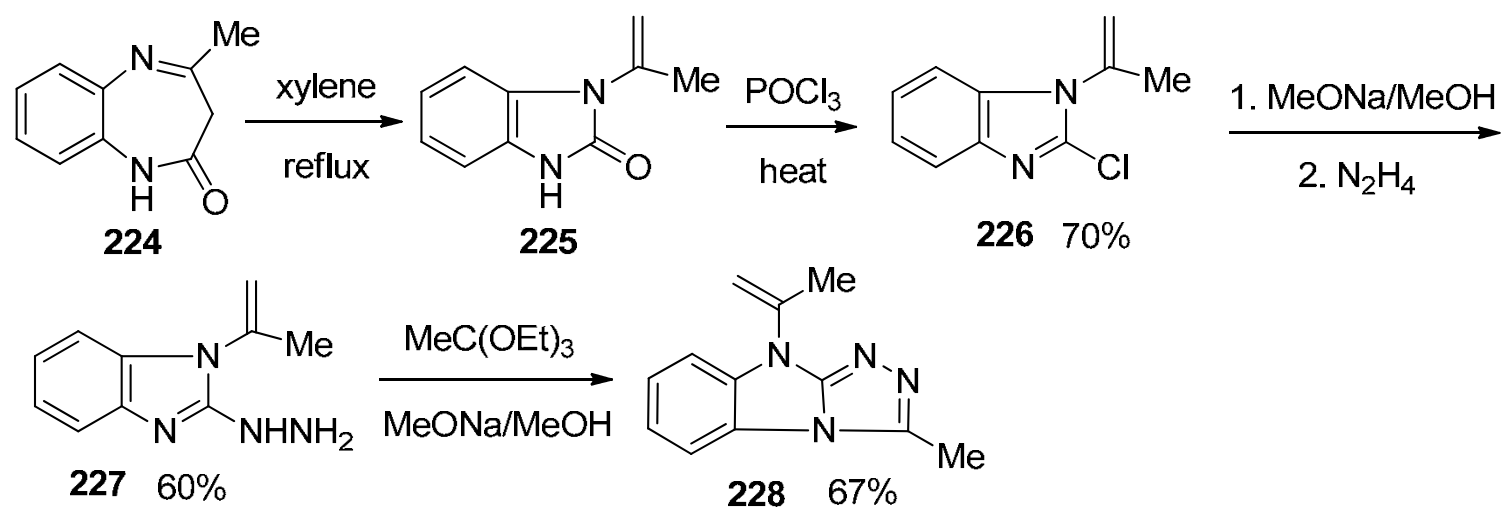

\section{Scheme 77}

Cyclisation of 2-hydrazinobenzimidazoles 220 with $\mathrm{CS}_{2}$ and with triethyl orthoacetate gave the corresponding triazolobenzimidazoles 229 and 230, respectively (Scheme 78). ${ }^{130,131}$<smiles>[R]c1cc2[nH]c3nnc(S)n3c2cc1[R]</smiles>

\section{Scheme 78}

Cyclization of 1,2-diaminobenzimidazolium salt 231, by boiling it in acetic anhydride in the presence of $\mathrm{K}_{2} \mathrm{CO}_{3}$ gave the triazolobenzimidazole derivative 232 (Scheme 79). ${ }^{132}$

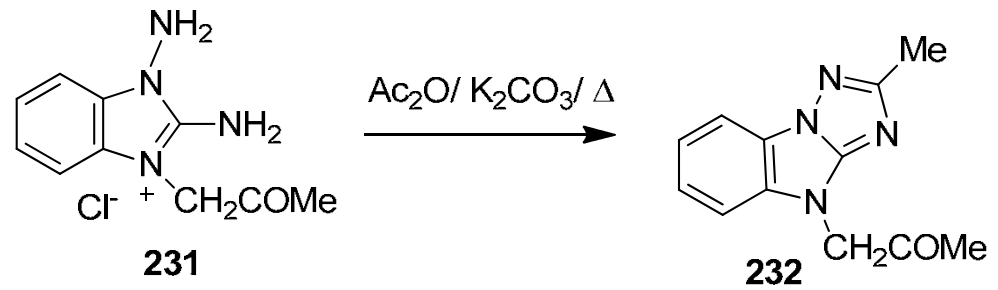

\section{Scheme 79}

\subsection{Thiadiazolobenzimidazoles}

Reaction of (1-amino-1H-benzimidazol-2-yl)methanol 233 with thionyl chloride at reflux afforded 3-chlorobenzimidazo[1,2-c]-1,2,3-thiadiazoliuum chloride 234. Treatment of the salt 234 with sodium bicarbonate gave 3-chlorobenzimidazo[1,2-c]-1,2,3-thiadiazole 235 (Scheme 80). ${ }^{133-135}$ 


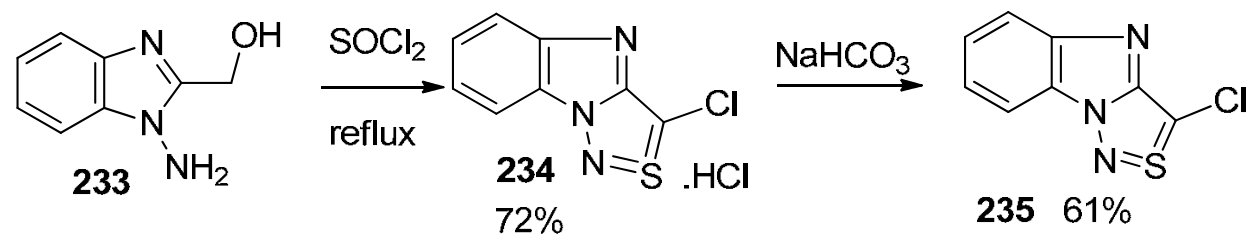

\section{Scheme 80}

Condensation of 2-amino-1,3,4-thiadiazoles 236 with $p$-benzoquinone 147 in acetic acid gave 6-hydroxy[1,3,4] thiadiazolo[3,2-a] benzimidazoles 238 (Scheme 81). ${ }^{136}$

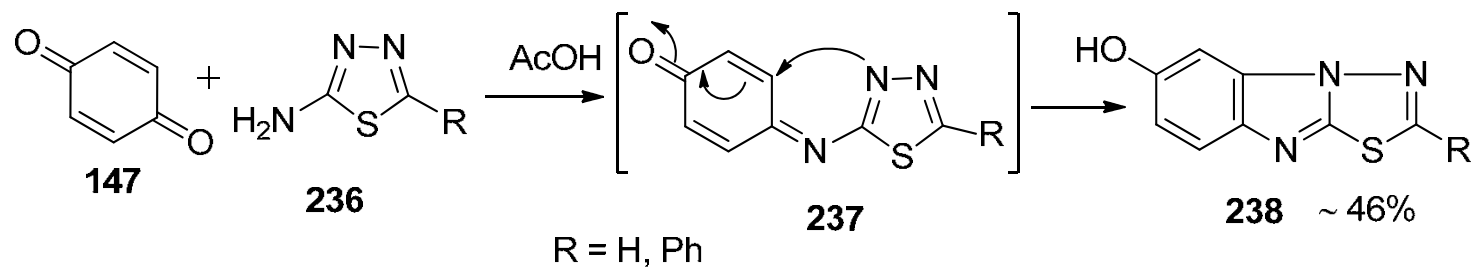

\section{Scheme 81}

The reaction of 1,3,4-oxadiazolinones 239 with phosphorus pentasulfide $\left(\mathrm{P}_{4} \mathrm{~S}_{10}\right)$ in refluxing xylene gave 1,3,4-thiadiazolo[3,2-a] benzimidazoles 240 probably according to the mechanism shown in Scheme 82. ${ }^{137}$ After an induction period of approximately $10 \mathrm{hrs}$, the system, $\mathrm{P}_{4} \mathrm{~S}_{10^{-}}$ refluxing xylene, generated $\mathrm{H}_{2} \mathrm{~S}$ which, in turn, was capable of reducing the nitro group.

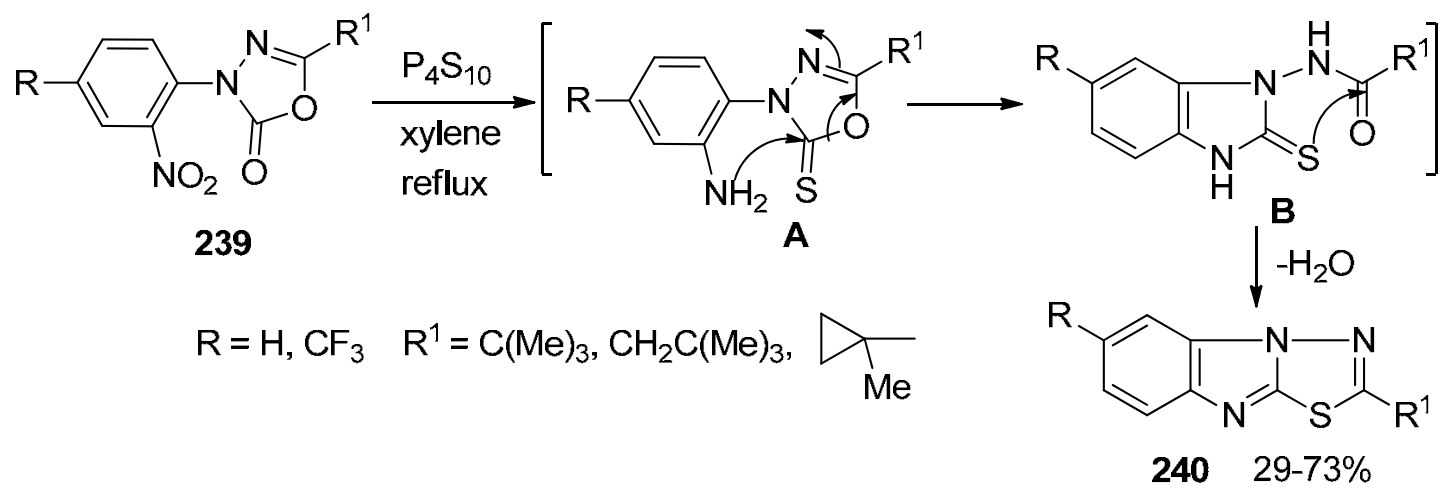

\section{Scheme 82}

Amidation of 2-mercaptobenzimidazole 165 by tert-butyl isocyanate followed by cyclization gave 2-tert-butyl-1,2,4-thiadiazolo[4,5-a]benzimidazole 241 which on treatment with nitriles afforded the 1,2,4-thiadiazolo[4,5-a]benzimidazoles 242 (Scheme 83). ${ }^{138-140}$ 


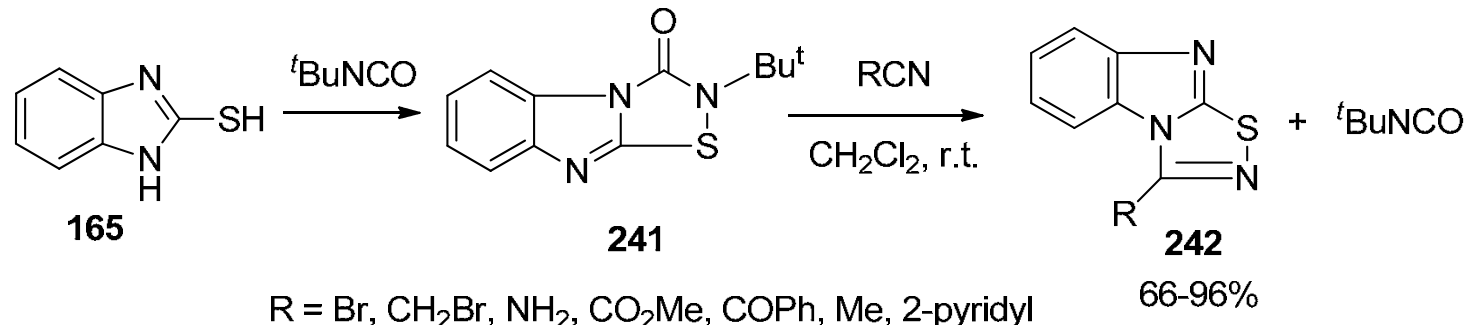

\section{Scheme 83}

Thermal rearrangement of 1-(1,2,3-thiadiazol-5-yl)-1,2,3-benzotriazoles 243 afforded zwitterionic $[1,2,3]$ thiadiazolo[3,4-a] benzimidazol-8b-ium-4-ides 244 (Scheme 84). ${ }^{141}$

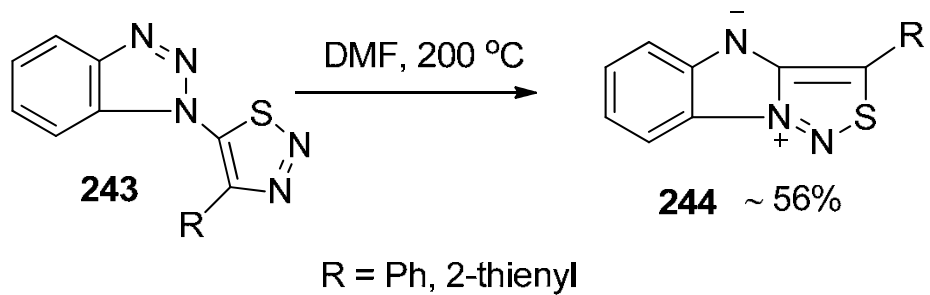

\section{Scheme 84}

1,2,4-Thiadiazolo[2,3-a] benzimidazole derivative 246 was prepared in high yield from the reaction of 1,2,4-thiadiazol-3-(2H)-one 245 with 2-aminobenzimidazole 117 via rearrangement of the adduct $\mathbf{A}$ through hypervalent sulfur intermediates $\mathbf{B}$ (Scheme 85$){ }^{142}$

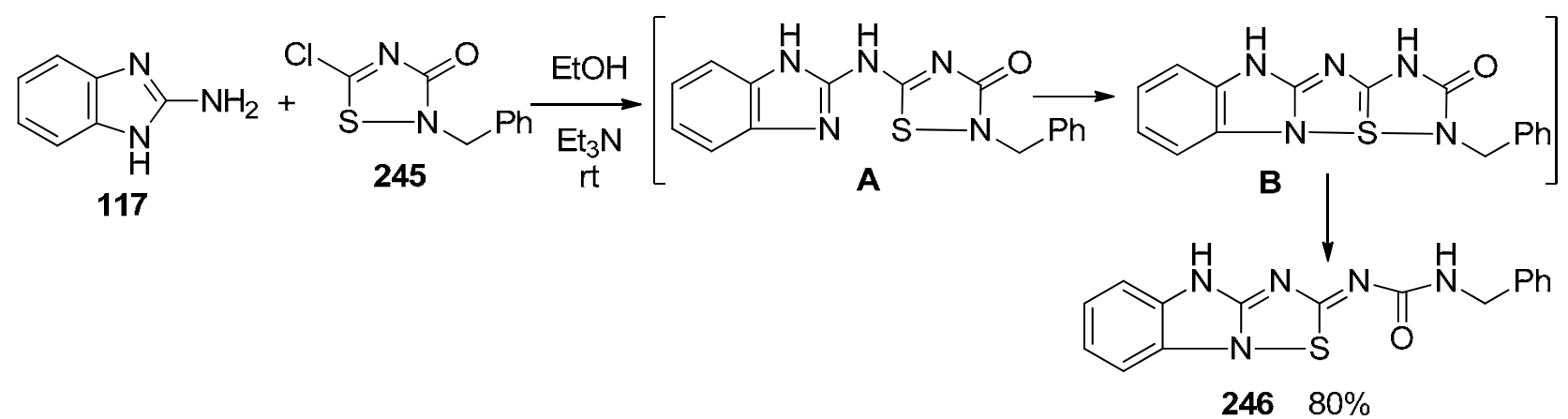

\section{Scheme 85}

\subsection{Oxadiazolobenzimidazoles}

Refluxing 2-(1-methylbenzimidazolyl)carbonylhydroximoyl chloride 247 with 2-methylthiobenzimidazole 212 in ethanol and triethylamine gave the benzimidazo[1,2- $d]-1,2,4$-oxadiazole 248 (Scheme 86). ${ }^{143}$ 


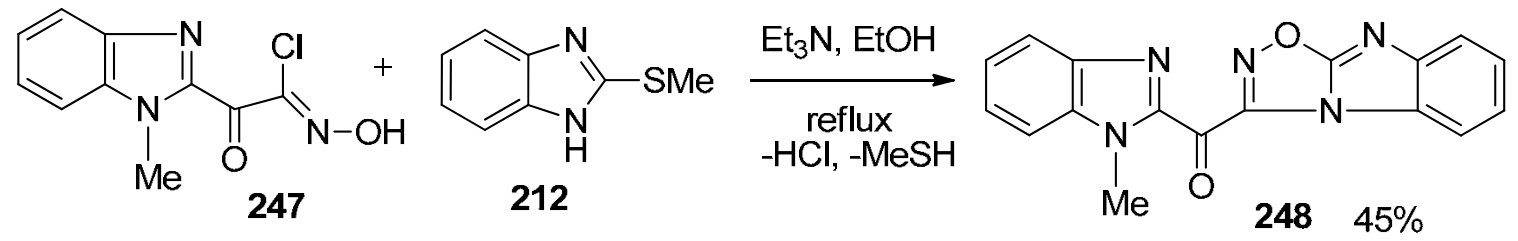

Scheme 86

\section{Synthesis of Azino-fused-benzimidazoles}

\subsection{Pyridobenzimidazoles}

Treatment of $N$-(2-azidophenyl)imines 249 with trimethylphosphine in toluene gave the phosphazenes 250. Reaction of $\mathbf{2 5 0}$ with ketenes led to the formation of the nonisolable ketenimines A which underwent [4+2] intramolecular cycloaddition to give the corresponding 3aryl-3,4-dihydropyrido[1,2-a] benzimidazoles 251 (Scheme 87). ${ }^{144}$

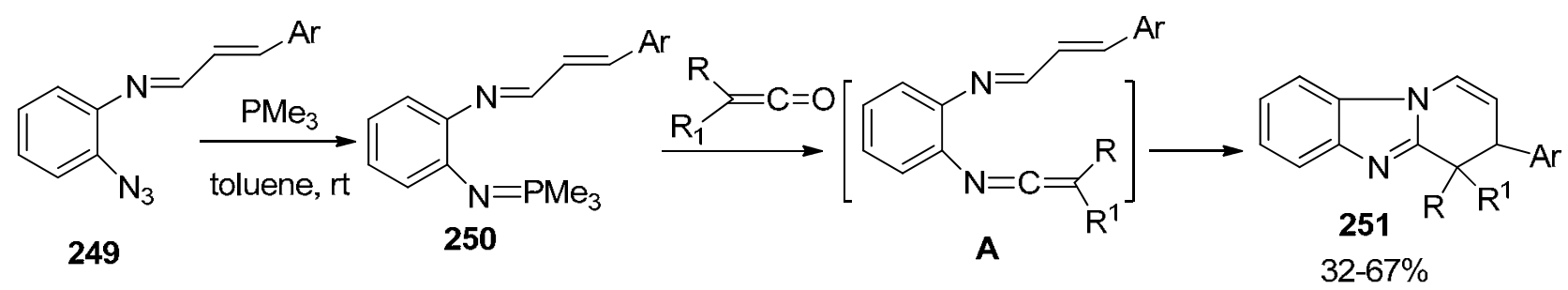

\section{Scheme 87}

$$
\mathrm{R}=\mathrm{H}, \mathrm{Me}, \mathrm{Ph} \quad \mathrm{R}^{1}=\mathrm{H}, \mathrm{Ph} \quad \mathrm{Ar}=\mathrm{Ph}, 4-\mathrm{ClPh}, 4-\mathrm{NO}_{2} \mathrm{Ph}, 4-\mathrm{MeOPh}
$$

Cyclocondensation and ring opening of triarylpyrylium salts 252 with 2benzimidazoleacetonitrile 59 gave pyrido[1,2-a]benzimidazole-4-carbonitriles 253 via loss of acetophenones probably according to the mechanism depicted in Scheme $88 .{ }^{145}$

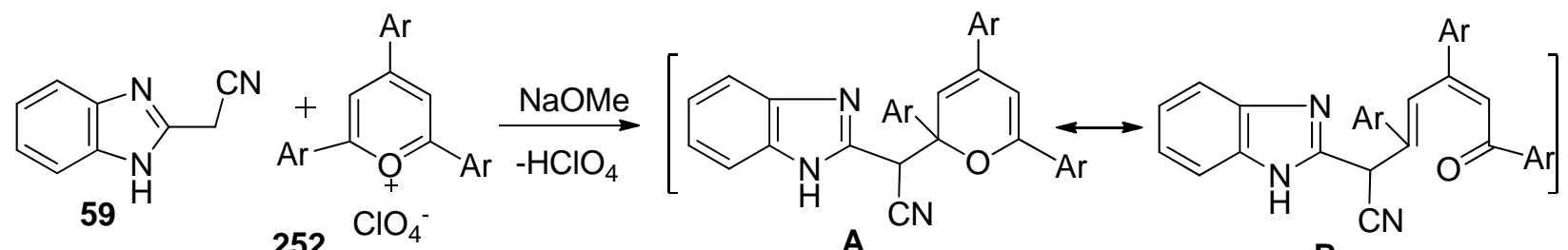

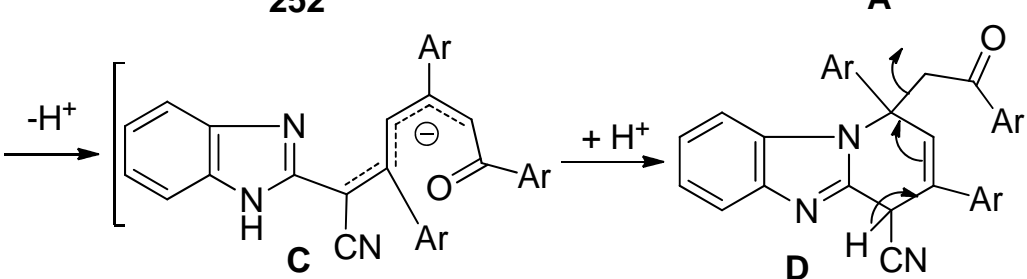

$\mathrm{Ar}=\mathrm{Ph}, 4-\mathrm{ClC}_{6} \mathrm{H}_{4}, 4-\mathrm{BrC}_{6} \mathrm{H}_{4}, 4-\mathrm{MeC}_{6} \mathrm{H}_{4}$

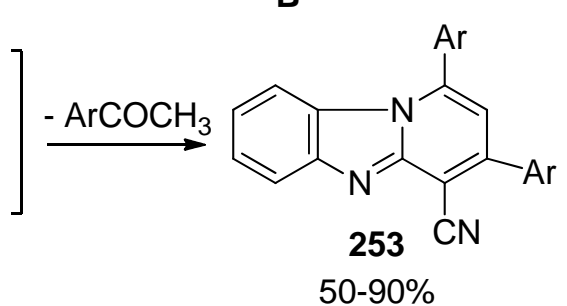

$50-90 \%$

Scheme 88 
Acylation of arylhydroxylamines 254 gave the $N$-acetyl derivatives 255, which on reaction with pyridine afforded the pyrido[1,2-a]benzimidazoles 256 (Scheme 89). ${ }^{146}$

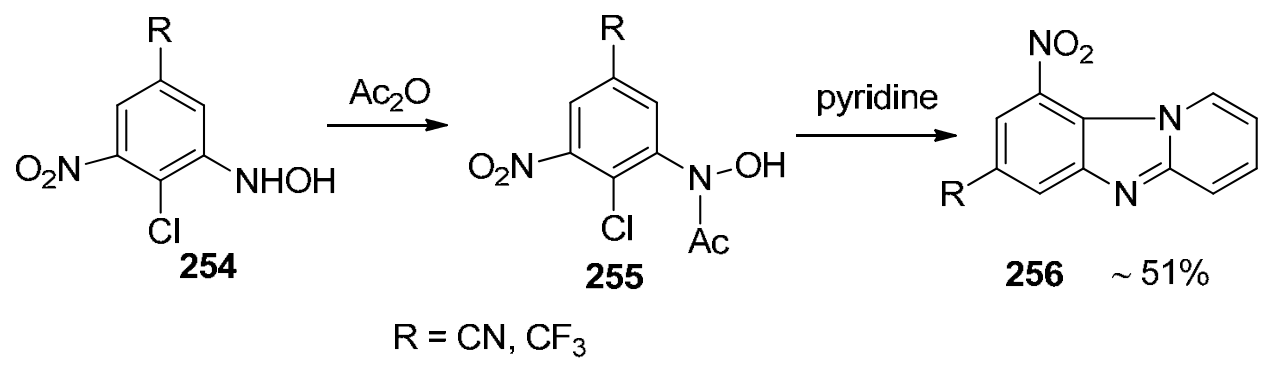

\section{Scheme 89}

Diels-Alder cycloaddition of 3-methylthiazolo[3,2-a]benzimidazole 201 with dimethyl acetylenedicarboxylate (DMAD) 257 in acetonitrile gave the pyrido[1,2-a]benzimidazole derivative 258 in $24 \%$ yield probably according to the mechanism outlined in Scheme $90 .{ }^{147}$

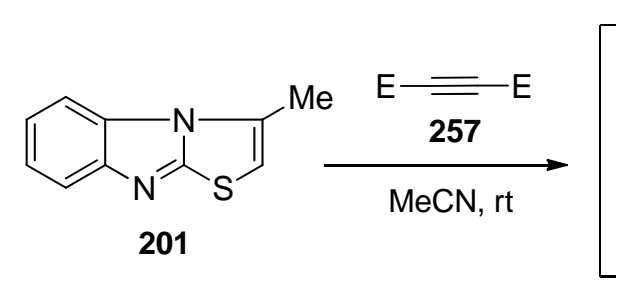

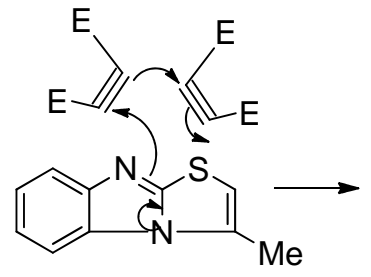

A

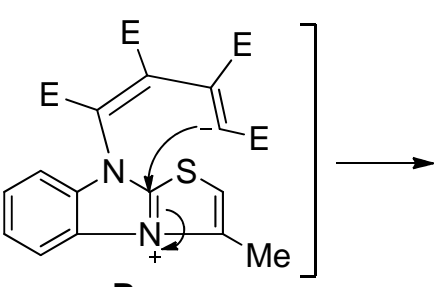

B<smiles>CC1=C(F)C(F)=C(F)N2c3ccccc3-c3cccc(C)c3N12</smiles>

C

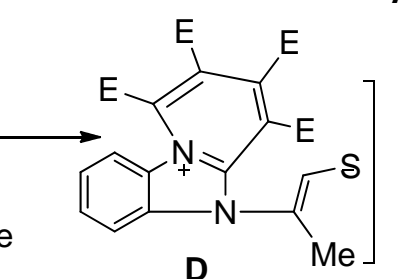

D<smiles>Cc1csc(F)c1F</smiles>

$25824 \%$

$$
\mathrm{E}=\mathrm{CO}_{2} \mathrm{Et}
$$

\section{Scheme 90}

Cyclization of benzylidene-1H-benzimidazol-2-ylacetonitriles 259 with activated acetonitriles in ethanol in the presence of piperidine gave pyridobenzimidazoles 260. Compound 259 reacted also with ethyl acetoacetate and with cyanoacetohydrazide to give the pyridobenzimidazole derivatives 261 and 262, respectively (Scheme 91). ${ }^{148-150}$ 


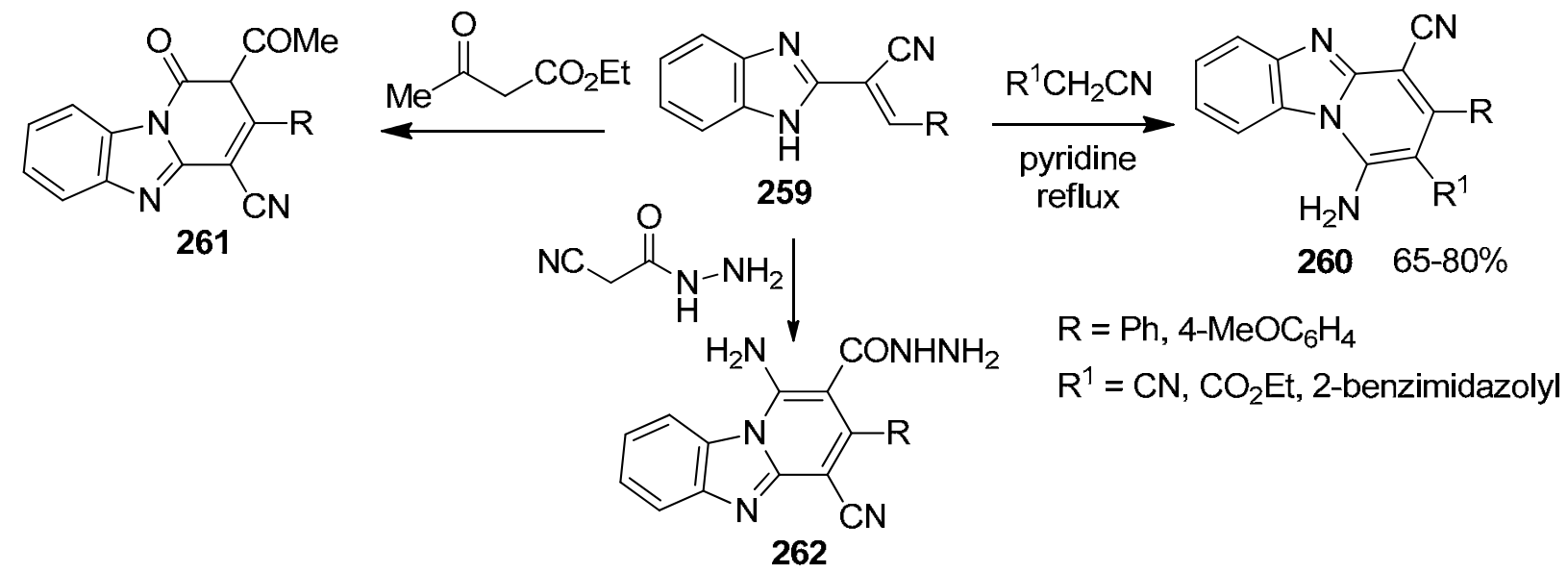

\section{Scheme 91}

Michael-type addition of 2-benzimidazoleacetonitrile 59 to chalcone 263 in ethanol and piperidine led to the formation of pyridobenzimidazole 264. Also, analogous reaction of $\mathbf{5 9}$ with ethyl 2-cyanoacrylate derivative 265 yielded the pyridobenzimidazole derivative $\mathbf{2 6 6}$ in $\mathbf{7 5 \%}$ yield (Scheme 92). ${ }^{151-153}$

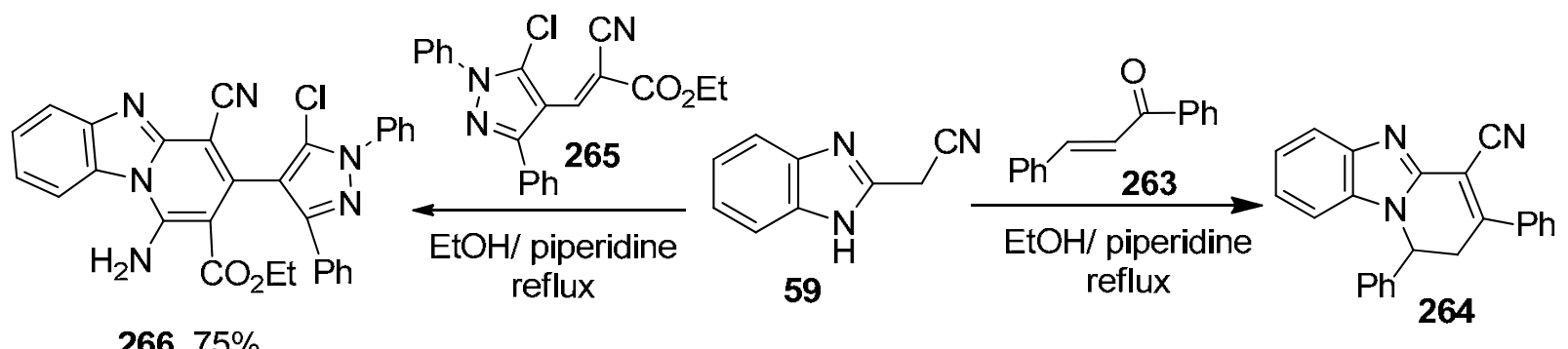

\section{Scheme 92}

Treatment of 2-benzimidazoleacetonitrile 59 and benzylidinemalononitriles 267 in acetonitrile containing piperidine under reflux afforded the polysubstituted pyrido[1,2a] benzimidazoles $\mathbf{2 6 9}$ in moderate to good yields via cyclization followed by loss of hydrogen from the intermediate $\mathbf{2 6 8}$ (Scheme 93). ${ }^{154,155}$

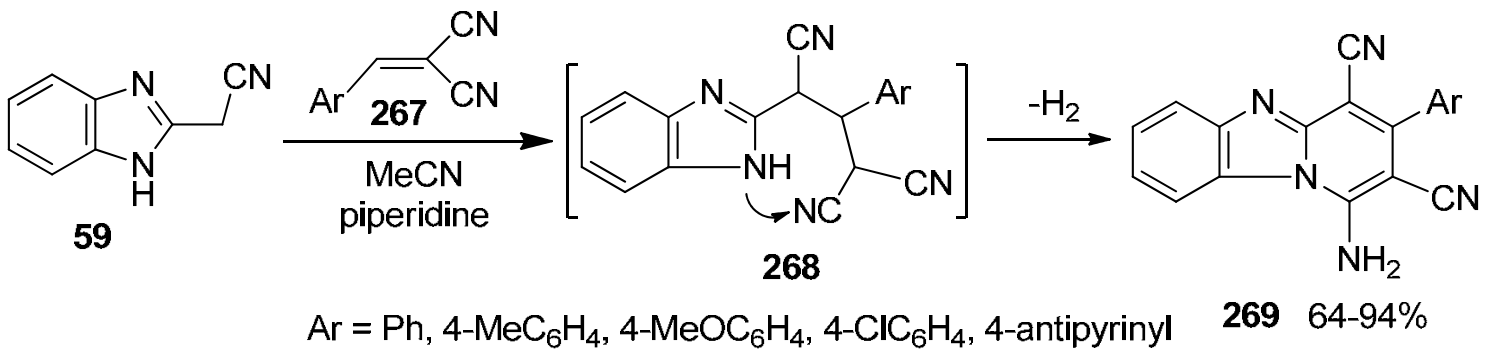

\section{Scheme 93}


Heating a mixture of 2-benzimidazoleacetonitrile 59 and $\beta$-aminocrotononitrile 270 in the presence of ammonium acetate at $130-140{ }^{\circ} \mathrm{C}$ afforded 1-amino-3-methylpyrido[1,2a]benzimidazole-4-carbonitrile 271 (Scheme 94). ${ }^{156}$

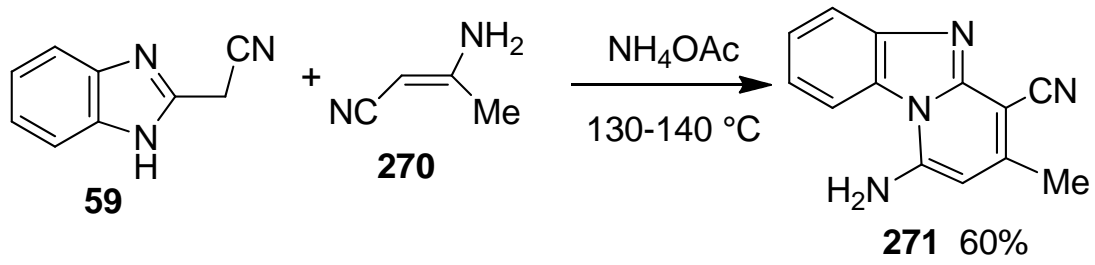

\section{Scheme 94}

Treatment of 2-benzimidazoleacetonitrile 59 with the phenylacetylene derivative 272 produced the pyrido[1,2- $a$ ] benzimidazole-4-carbonitrile derivative 273 (Scheme 95). ${ }^{157}$<smiles>[R2]#CC(=O)C[C@H]1[C@H](OCc2ccccc2)[C@@H](OC)O[C@@H]2COC(c3ccccc3)O[C@H]21</smiles><smiles>N#CCc1nc2ccccc2[nH]1</smiles>

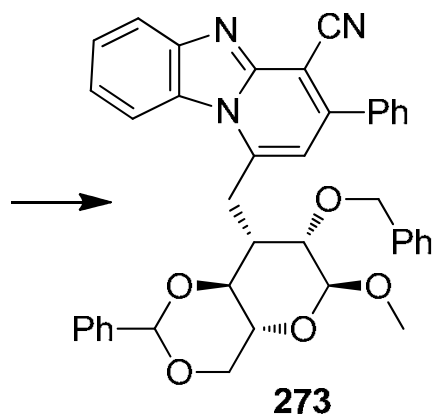

\section{Scheme 95}

The reaction of heteroaryl enamines 274, 275 and 276 with 2-benzimidazoleacetonitrile 59 was conducted in refluxing ethanol in the presence of piperidine to afford the corresponding pyrido[1,2-a] benzimidazoles 277-279 (Scheme 96). ${ }^{158-162}$ 
<smiles>[R]C(=O)c1cn2c(nc3ccccc32)c(C#N)c1N</smiles><smiles>[R]=C=Cc1csc(C)n1</smiles><smiles>CCOC(=O)C(C)(C)C(=O)C(C#N)=CN(C)C</smiles>

59<smiles>[R]C(=O)/C=C/N(C)Cc1ccc2nc3c(C#N)c([R])ccn3c2c1</smiles>

$27780-86 \%$

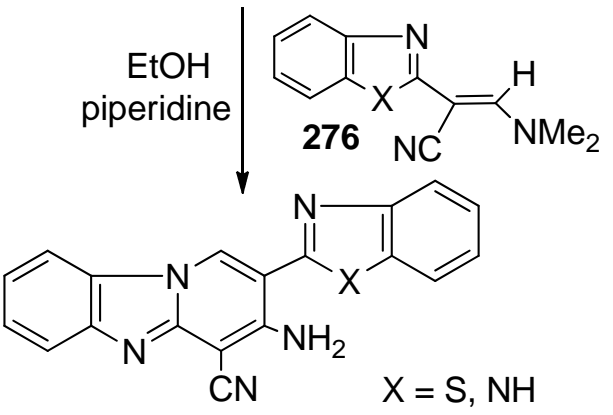<smiles>[R]=C=C1CC=Cc2nc(C)sc21</smiles><smiles>Cc1c(-c2ccccc2)nn(-c2ccccc2)c1C</smiles>

$27958-81 \%$

\section{Scheme 96}

Pyrido[1,2-a]benzimidazoles $\mathbf{2 8 2}$ and $\mathbf{2 8 3}$ were synthesized by reacting 2benzimidazoleacetonitrile $\mathbf{5 9}$ with the enaminones $\mathbf{2 8 0}$ and 281, respectively, in refluxing pyridine or ethanol/piperidine (Scheme 97). ${ }^{163-166}$

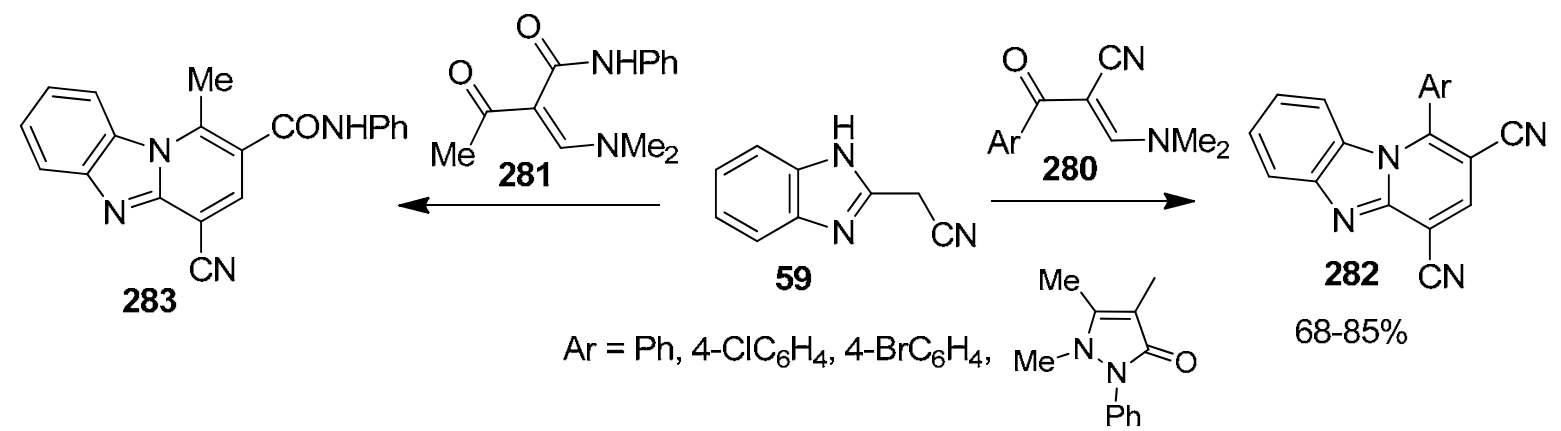

\section{Scheme 97}

Reaction of methyl 2-benzoyl-3-dimethylaminopropenoate $\mathbf{2 8 4}$ with 2benzimidazoleacetonitrile 59 in refluxing acetic acid in the presence of ammonium acetate gave methyl 4-cyano-3-phenylbenzimidazo[1,2-a]pyridine-2-carboxylate 285. ${ }^{167}$ Heating a mixture of 3-(dimethylamino)-2-(phenylsulfonyl)acrylonitrile 286 with 2-benzimidazoleacetonitrile 59 in ethanol and piperidine afforded the pyrido[1,2-a] benzimidazole derivative 287 (Scheme 98). ${ }^{168}$ 


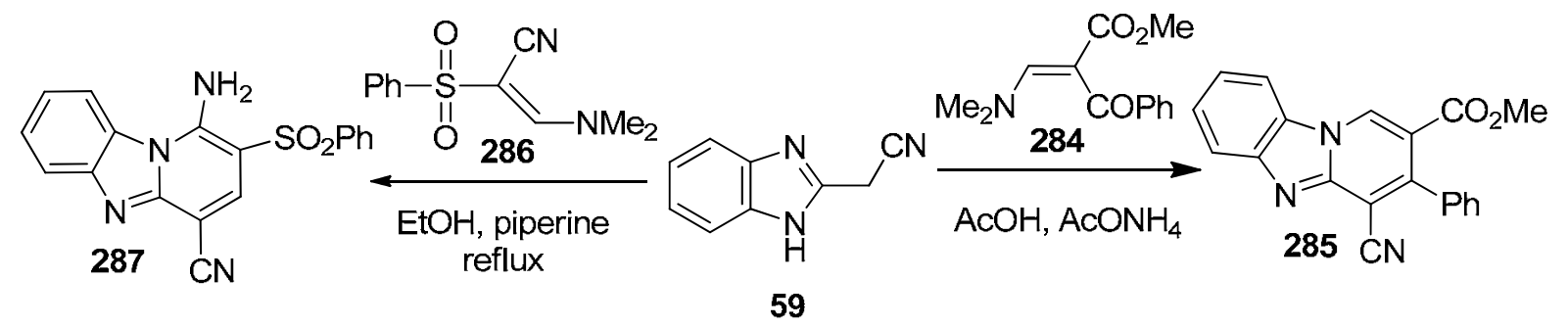

\section{Scheme 98}

Treatment of 2-benzimidazoleacetonitrile 59 with cyanamide in the presence $s$-triazine gave the enaminonitrile derivative $\mathbf{2 8 8}$ which reacted again with 59 to give pyridobenzimidazole derivative 270 (Scheme 99). ${ }^{169}$<smiles>N#C/C(=C\N)c1nc2ccccc2[nH]1</smiles>

\section{Scheme 99}

Reaction of 6-aryl-3-cyano-4-methylthio-2H-pyran-2-ones $\mathbf{2 8 9}$ with 2benzimidazoleacetonitrile 59 in DMF and $\mathrm{KOH}$ at $30{ }^{\circ} \mathrm{C}$ led to the formation of the pyrido[1,2a] benzimidazole derivatives 290 in moderate yields (Scheme 100). ${ }^{170}$

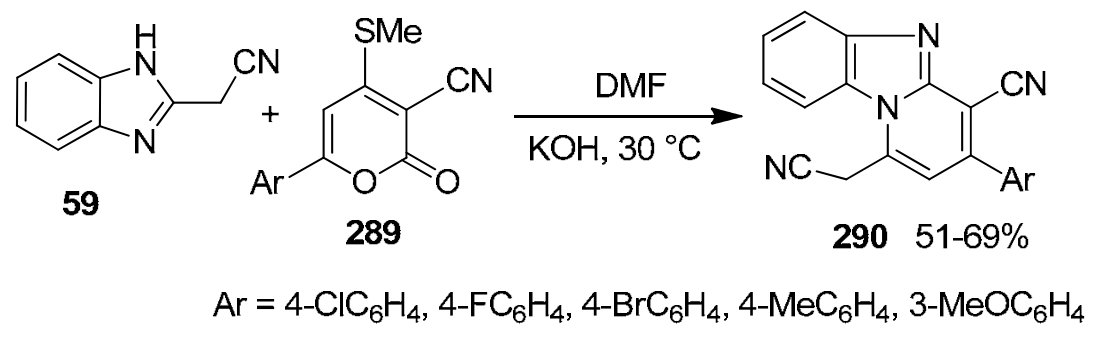

\section{Scheme 100}

3-Formylchromenes 291 underwent ring opening when heated with 2benzimidazoleacetonitrile 59 in ethylene glycol at $200-210{ }^{\circ} \mathrm{C}$ to give the pyridobenzimidazoles 292 in good yields. ${ }^{171}$ Similar ring transformation occurred on the reaction of 2-formylglycals 293 with 59 when heated in chlorobenzene/AcOH in the presence of piperidine, to furnish the pyridobenzimidazoles 294 in moderate yields (Scheme 101). ${ }^{172,173}$ 

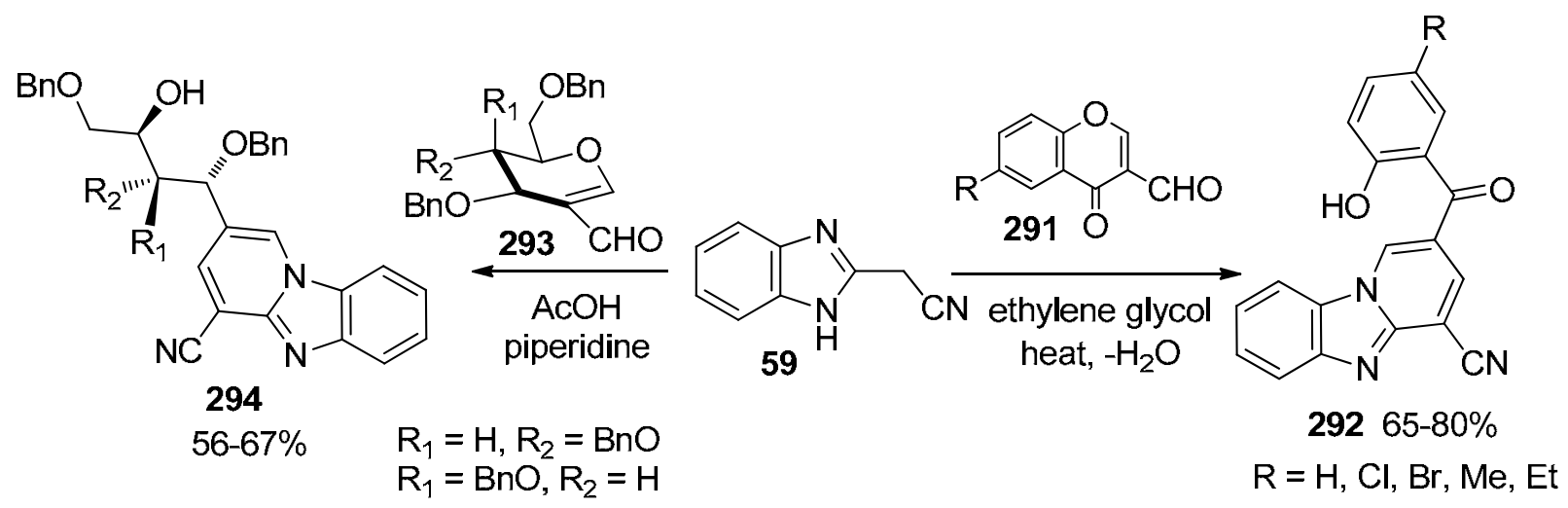

Scheme 101

7,8-Difluoro-3-methyl-1-oxo-4-cyano-1H,5H-pyrido[1,2-a]benzimidazole $\quad$ 295A was obtained in high yield by heating a mixture of 2-benzimidazoleacetonitrile 59 with ethyl acetoacetate at $140{ }^{\circ} \mathrm{C}$ in the presence of ammonium acetate. ${ }^{174,175}$ Pyrido[1,2- $a$ ] benzimidazol-1ones 295B $\left(\mathrm{R}^{1}=\mathrm{H}, \mathrm{Bz}\right)$ were obtained by fusing 2-benzimidazoleacetonitrile 59 with ethyl $\beta$ aminocrotonates 296 in the presence of $\mathrm{NH}_{4} \mathrm{OAc}$ at $140{ }^{\circ} \mathrm{C}$ (Scheme 102). ${ }^{176}$

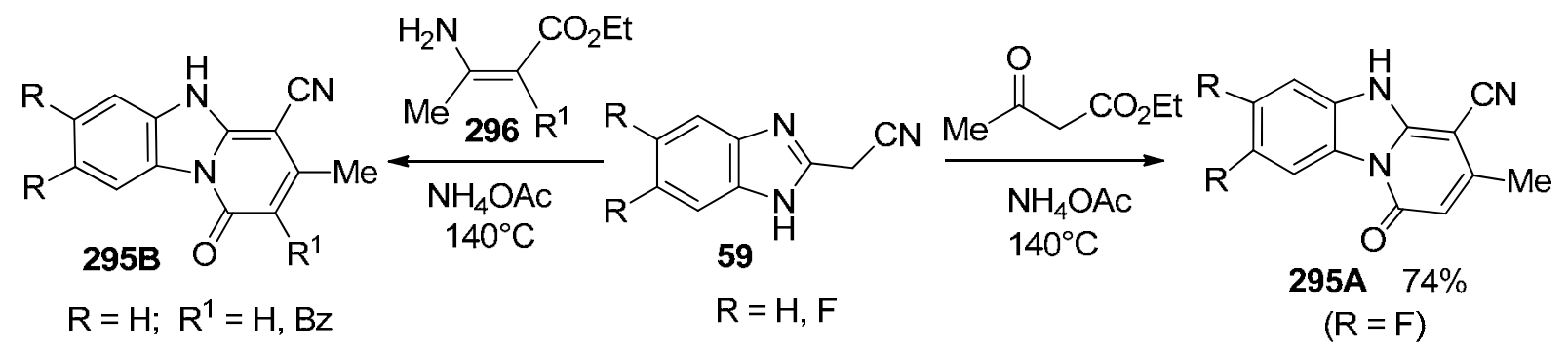

\section{Scheme 102}

Graebe-Ullmann thermolysis of 5-(1-benzotriazolyl)-spiro[2H-imidazo[4,5-b]pyridine-2,1'cyclohexane] 297 followed by treatment with $\mathrm{Na}_{2} \mathrm{~S}_{2} \mathrm{O}_{4}$ in aq. THF gave 1,2-diaminopyrido[1,2a] benzimidazole 298 in low yield (Scheme 103). ${ }^{177}$

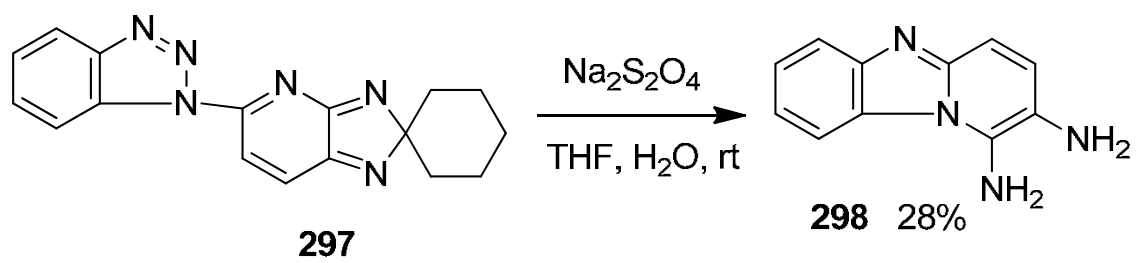

Scheme 103 
Condensation of 2-benzimidazoleacetonitrile 59 with diethyl 2-oxosuccinate 299, in ethanol and DMF in the presence of piperidine produced pyrido[1,2- $a$ ] benzimidazole derivative 300. In addition, thermal condensation of 59 with diethyl ethoxymethylenemalonate 301 in diphenyl ether at 240-250 ${ }^{\circ} \mathrm{C}$ gave the pyrido[1,2-a]benzimidazole 302 (Scheme 104). ${ }^{178}$ 3Hydroxypyrido[1,2-a]benzimidazol-1-ones 304 were prepared by heating 2benzimidazoleacetonitrile 59 with substituted malonate esters 303 (Scheme 104). ${ }^{179,180}$

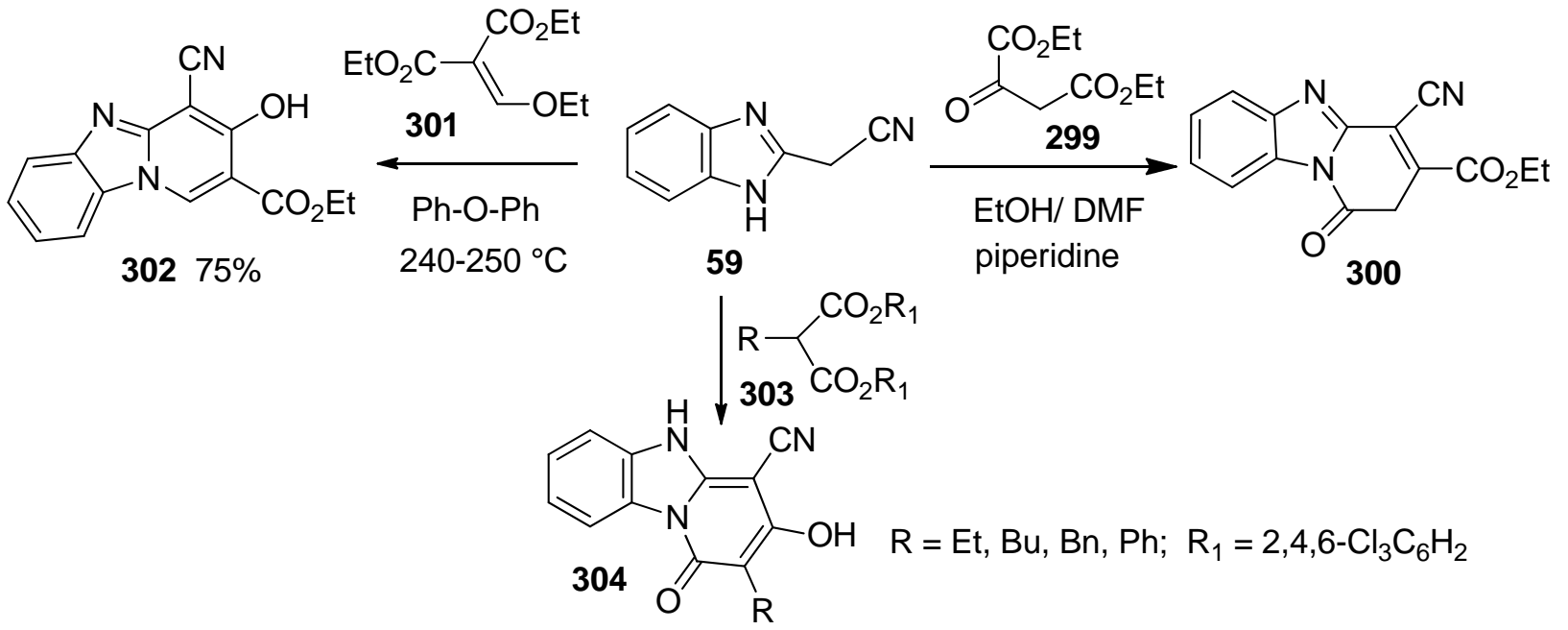

\section{Scheme 104}

Treatment of 1-aminobenzimidazoles 305 with $\alpha, \beta$-unsaturated ketones 306 in the presence of zinc chloride as catalyst in refluxing acetone gave the corresponding pyridobenzimidazoles 307 via an intramolecular rearrangement of the intermediates $\mathbf{A}$ (Scheme 105). ${ }^{181}$

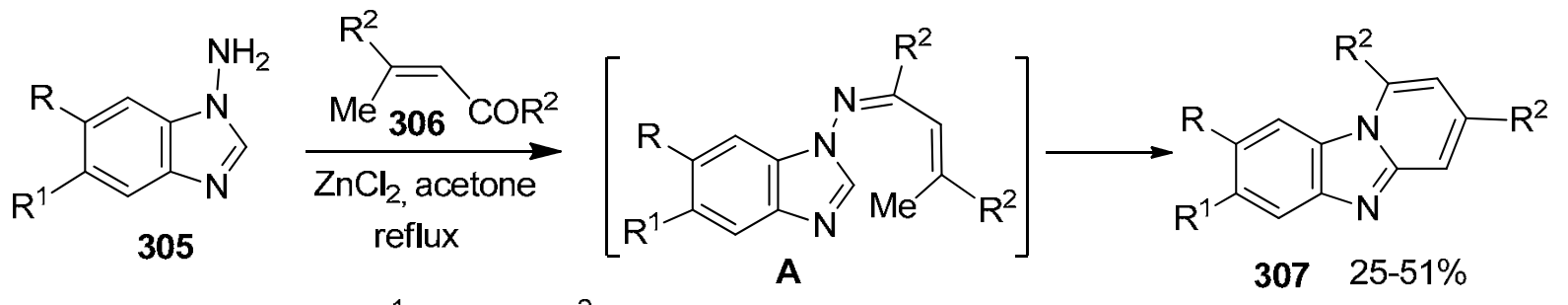

$\mathrm{R}=\mathrm{R}^{1}=\mathrm{H}, \mathrm{Me} ; \mathrm{R}^{2}=\mathrm{Me}, \mathrm{Ph}, 4-\mathrm{ClC}_{6} \mathrm{H}_{4}, 4-\mathrm{BrC}_{6} \mathrm{H}_{4}, 3,4-\mathrm{Cl}_{2} \mathrm{C}_{6} \mathrm{H}_{3}$

\section{Scheme 105}

Formation of 2-benzamido-1-oxo-1H,5H-pyrido[1,2-a]benzimidazoles $\mathbf{3 1 0}$ was achieved by the neat heating of 2-benzimidazoleacetonitrile 59 or ethyl 2-benzimidazoleacetate 308 with 4ethoxymethylene-2-phenyl-5-oxazolinone 309 via loss of ethanol from the intermediates A (Scheme 106). ${ }^{8 b, 182}$ 


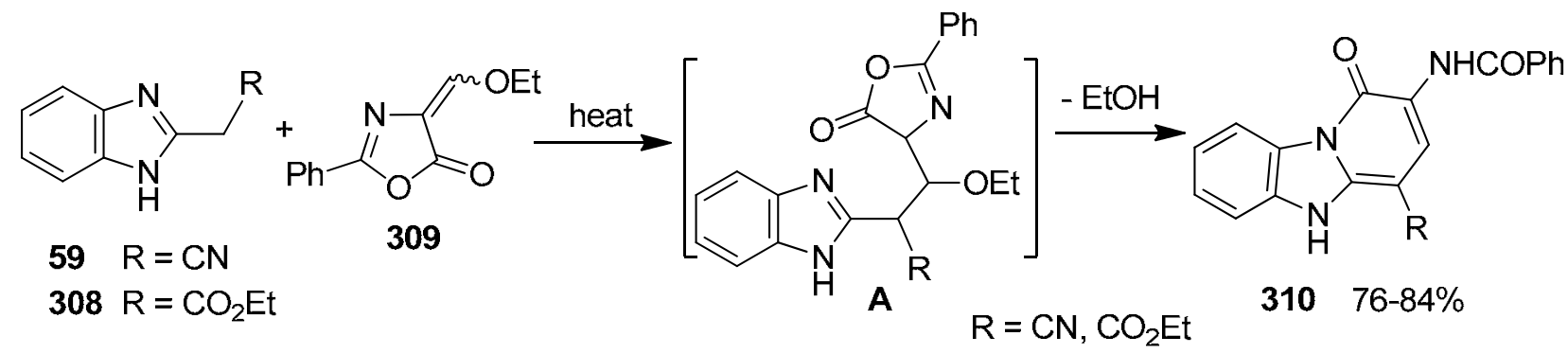

\section{Scheme 106}

Reaction of 2-benzimidazoleacetonitrile 59 with sodium salts of 3-hydroxymethylene-2alkanones $\mathbf{3 1 1}$ in piperidine acetate and aq. ethanol yielded the pyrido[1,2-a]benzimidazoles 312. The other isomeric structure 313 was excluded based on the X-ray analysis (Scheme 107). ${ }^{183}$

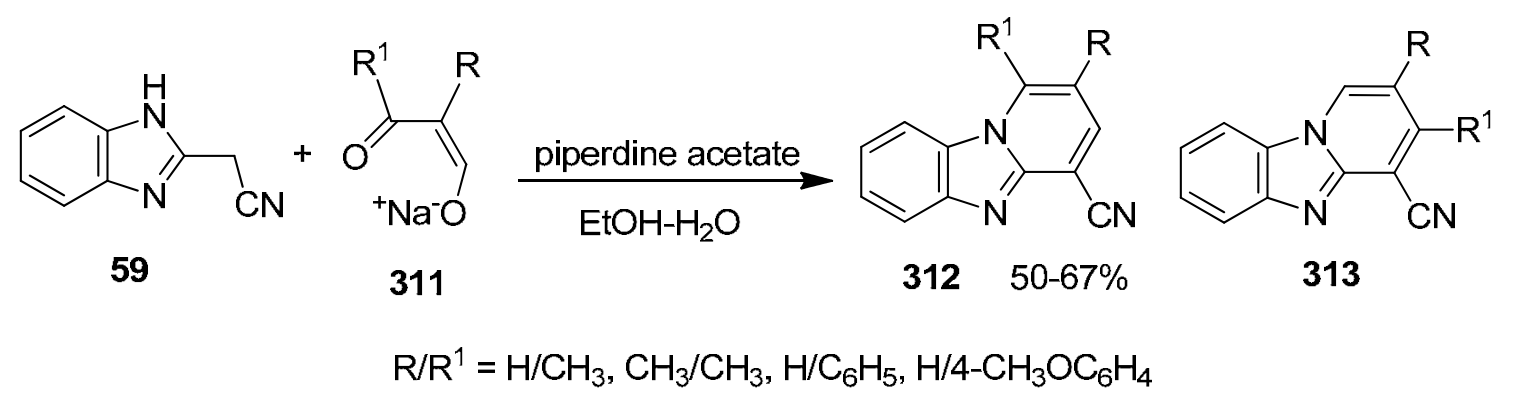

\section{Scheme 107}

2-(2-Hydroxyethyl)pyrido[1,2-a] benzimidazole-4-carbonitriles 315 were prepared from heating 2-benzimidazoleacetonitriles 59 with 2-acetylbutyrolactone 314 in the presence of ammonium acetate. ${ }^{184}$ Condensation of 59 with ethyl 4-chloro-3-oxobutanoate $\mathbf{3 1 6}$ in refluxing $\mathrm{DMF}$ and $\mathrm{ZnCl}_{2}$ led to 3-chloromethylpyrido[1,2-a] benzimidazol-1-one-4-carbonitrile 317 (Scheme 108). ${ }^{185}$

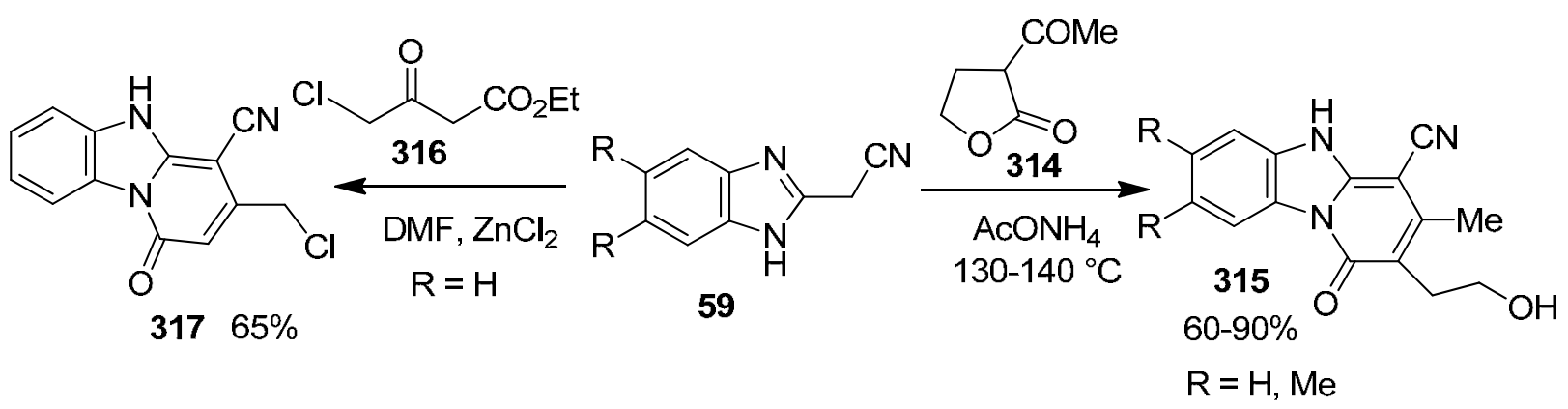

Scheme 108 
A highly efficient and regioselective annulation protocol for a series of pyrido[1,2a]benzimidazoles 320 involving [3+3] cyclocondensation of 2-benzimidazoleacetonitrile 59 with a variety of $\alpha$-oxoketene dithioacetals 318 has been reported (Scheme 109). ${ }^{186}$

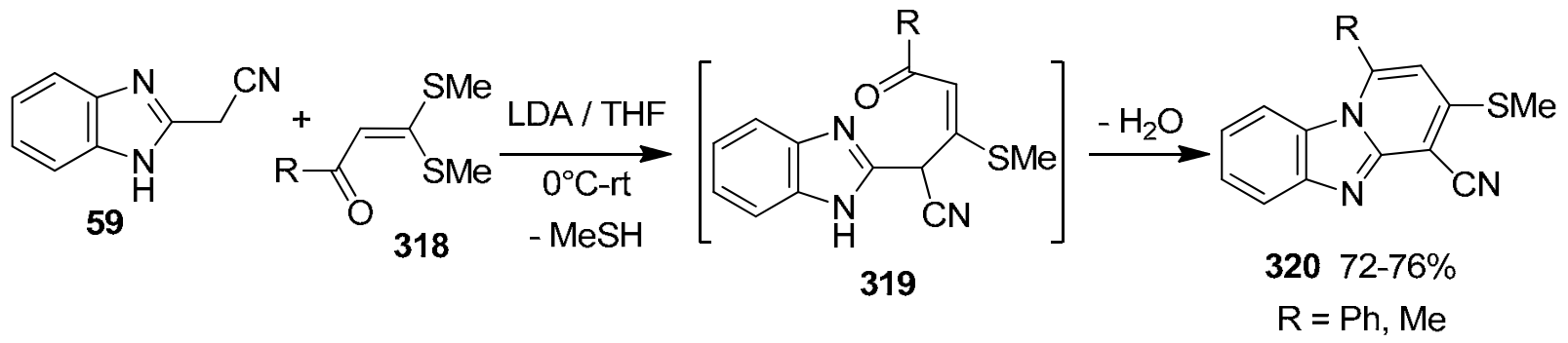

\section{Scheme 109}

Reaction of chloromethylenemalononitriles 321 with 2-(nitromethylene)-benzimidazole 322 yielded the 4-nitropyrido[1,2-a]benzimidazole derivative 323 (Scheme 110). ${ }^{187}$

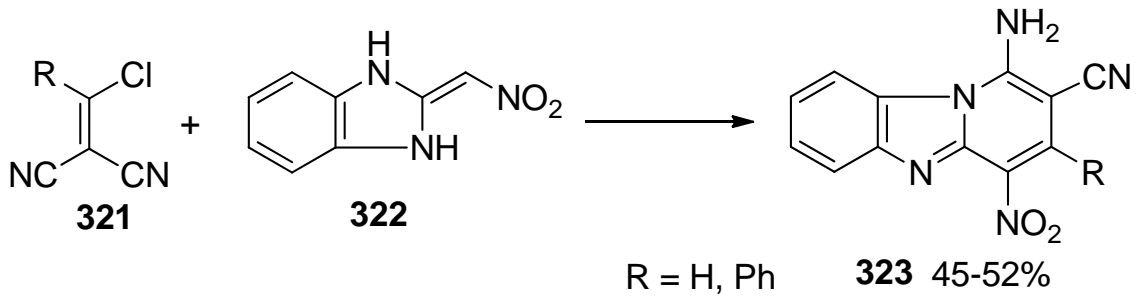

\section{Scheme 110}

Heating a mixture of 2-(2-arylhydrazono)malononitrile 324 with 2-benzimidazoleacetonitrile 59 in refluxing ethanol yielded the 2-arylazopyrido[1,2-a]benzimidazoles $325 .{ }^{188}$ However, condensation of the arylhydrazones 326 with 2-benzimidazoleacetonitrile 59 in refluxing acetic acid gave the 3-methyl-2-arylazopyrido[1,2-a]benzimidazoles 327 (Scheme 111). ${ }^{189}$

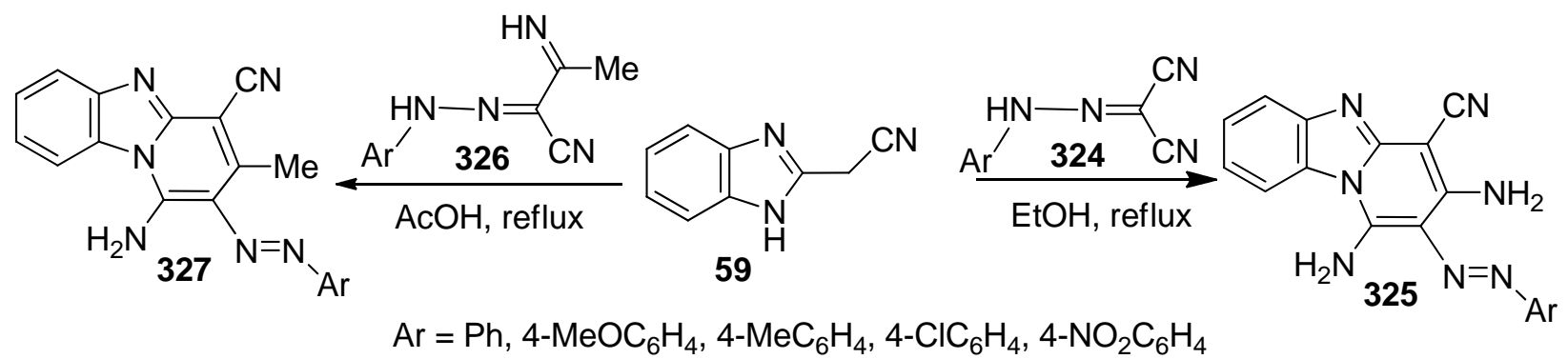

\section{Scheme 111}


Heating of 2-benzimidazoleacetonitrile 59 with triethyl orthoformate gave the intermediate ethoxyacrylonitrile derivative $\mathbf{3 2 8}$ which upon treatment with hippuric acid derivatives $\mathbf{3 2 9}$ in refluxing acetic anhydride afforded the pyrido[1,2- $a$ ] benzimidazole derivatives 331 in high yields via loss of water molecule from the intermediate 330 (Scheme 112). ${ }^{190}$<smiles>N#CCc1nc2ccccc2[nH]1</smiles>

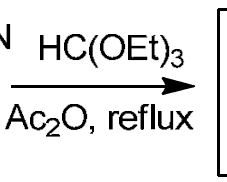<smiles>CCO/C=C(\C#N)c1nc2ccccc2[nH]1</smiles>
328 $\mathrm{Ar}=\mathrm{Ph}, 4-\mathrm{MeOC}_{6} \mathrm{H}_{4}, 4-\mathrm{MeC}_{6} \mathrm{H}_{4}, 4-\mathrm{ClC}_{6} \mathrm{H}_{4}$<smiles>CCOC(=O)CCCC(=O)NCC(=O)OCC(=O)O</smiles>
330<smiles>N#Cc1cc(NC(=O)OCc2ccccc2)c(O)n2c1nc1ccccc12</smiles>

$33184-91 \%$

\section{Scheme 112}

Polysubstituted pyrido[1,2-a]benzimidazoles 332 were efficiently produced in moderate yields in a one-pot, four-component reaction of pyridine or 3-picoline, chloroacetonitrile, malononitrile, and aromatic aldehydes in refluxing acetonitrile as outlined in Scheme 113. ${ }^{191}$

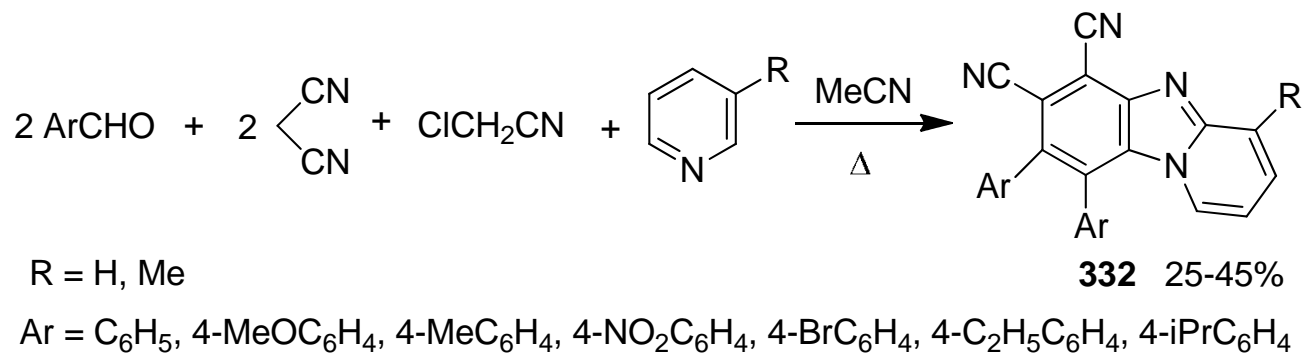

\section{Scheme 113}

Alkylation of 4,7-dimethoxy-1H-benzimidazole 333 using 1-iodo-4-(phenylselenanyl)butane and sodium hydride gave the phenylselenide derivative 334. Radical cyclisation of 334 gave the pyrido[1,2-a]benzimidazole derivative 335 using $\mathrm{Bu}_{3} \mathrm{SnH}, \quad 1,1^{\prime}$ azobis(cyclohexanecarbonitrile) (ACN) and camphorsulfonic acid (CSA) under reflux in toluene (Scheme 114). ${ }^{192}$ 


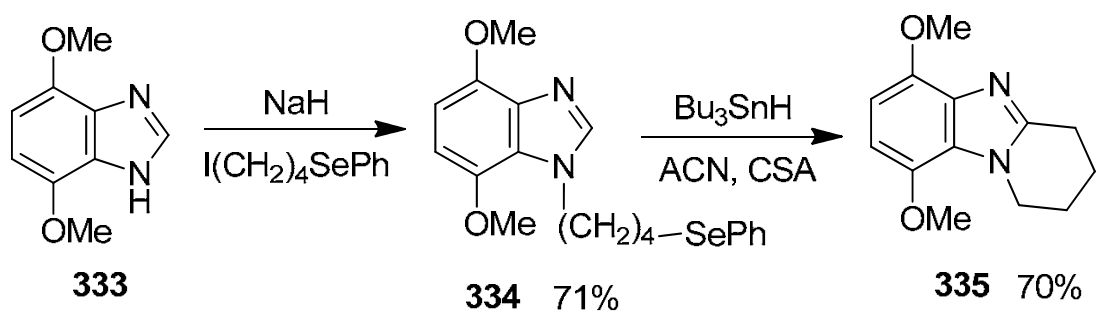

\section{Scheme 114}

Pyrido[1,2-a]benzimidazole derivatives 339 were prepared by reaction of the 2bromopyridinium salts $\mathbf{3 3 6}$ with pyridine to give the fused heterocyclic bromide salt $\mathbf{3 3 8}$ which upon heating in basic solution underwent recyclization to form 339 (Scheme 115). ${ }^{193}$

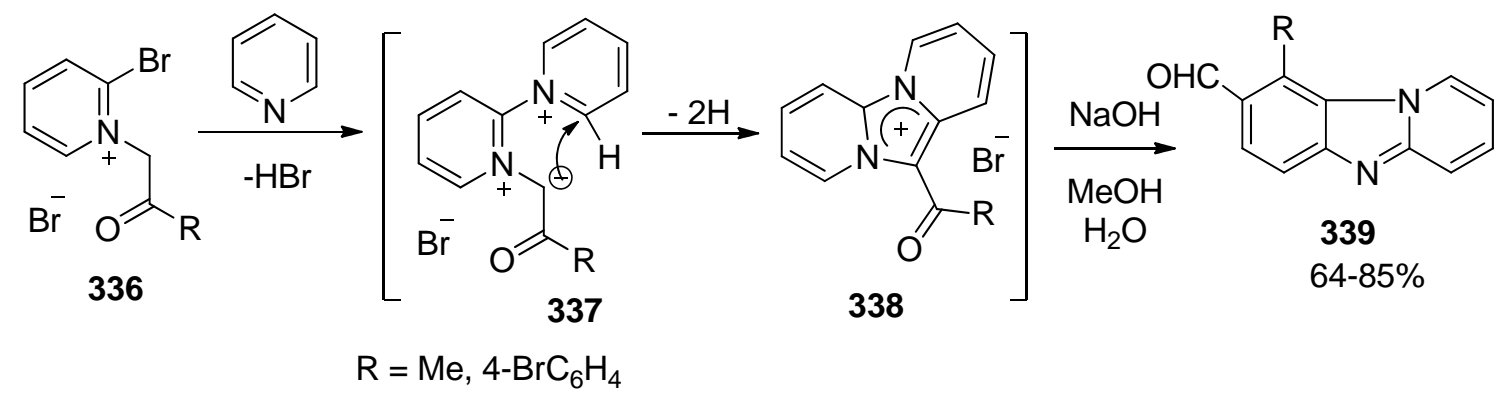

\section{Scheme 115}

3-(N-Piperidyl)-2-nitroaniline 340 underwent Michael-type addition with acrylonitrile, followed by hydrogenation then condensation with 3-ethoxy-3-iminopropanoate hydrochloride 109 to give 1-(2-cyanoethyl)-2-(ethoxycarbonylmethyl)-4-( $N$-piperidinyl)benzimidazole 341. Ethanolysis of the nitrile function and base-catalyzed cyclization of the resulted diester followed by amidation with 2,6-difluoroaniline gave the pyrido[1,2-a]benzimidazole derivative 342 (Scheme 116). ${ }^{194,195}$
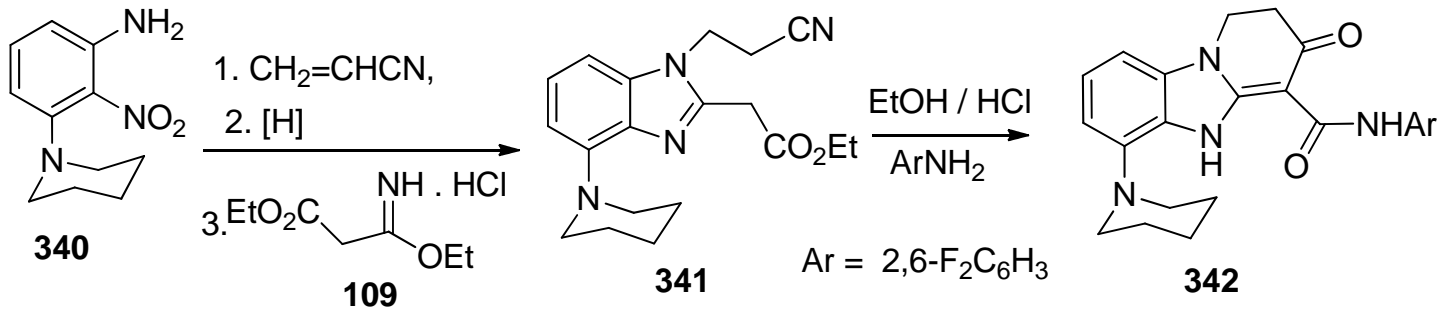

\section{Scheme 116}

Catalytic hydrogenation of $N$-cyanoethyl-2-nitroaniline 343 and subsequent reaction with ethyl 3-amino-3-ethoxyacrylate hydrochloride $\mathbf{1 0 9}$ followed by ethanolysis of the cyano group in 
ethanolic $\mathrm{HCl}$ gave the diester intermediate 344. The latter upon treatment with sodium ethoxide underwent Dieckmann cyclization to afford pyrido[1,2-a]benzimidazoles 345 (Scheme 117). ${ }^{196,197}$<smiles>[X]c1ccc(NCCC#N)c([N+](=O)[O-])c1</smiles><smiles>CCOC(=O)C=C(N)OCC</smiles><smiles>[X]c1ccc2c(c1)nc(CC(=O)O)n2CCC(=O)OCC</smiles>
344<smiles>[X]c1ccc2c(c1)NC1=C(C(=O)OCC)C(=O)CCN12</smiles>

3. $\mathrm{HCl} / \mathrm{EtOH}$

\section{Scheme 117}

The reaction of 2-amino-5-methylpyridine 346 with 1,2-cyclohexanediol 347 in the presence of a catalytic amount of $\mathrm{RuCl}_{2}\left(\mathrm{PPh}_{3}\right)_{3} 348$ under reflux in diglyme for $24 \mathrm{~h}$ afforded 2-methyl6,7,8,9-tetrahydropyrido[1,2-a]benzimidazole 349 in 74\% yield (Scheme 118). ${ }^{198}$

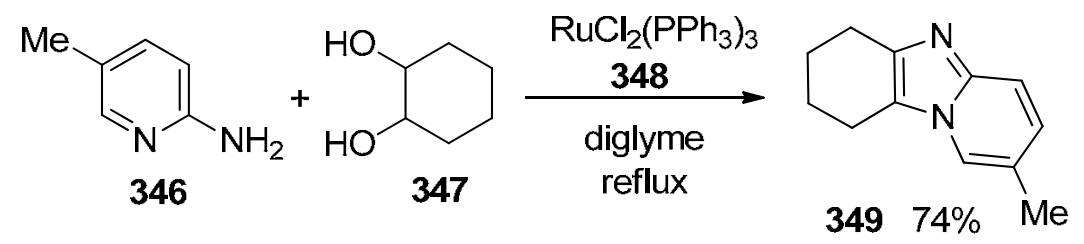

\section{Scheme 118}

Pyrido[1,2-a]benzimidazole derivative 351 was obtained by photochemical cyclization of 2chloro- $N, N^{\prime}$-di(2-pyridyl)-1,4-phenylenediamine 350 (Scheme 119). ${ }^{199}$

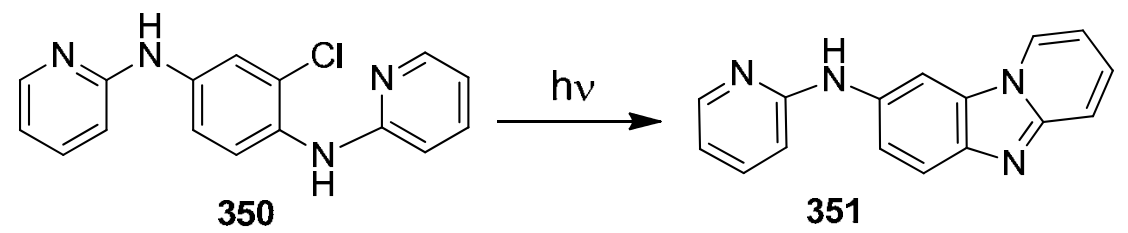

\section{Scheme 119}

Photo-induced cyclization of haloarylpyridylamines 352 gave the pyrido[1,2a]benzimidazoles 353 (Scheme 120). ${ }^{200,201}$ 


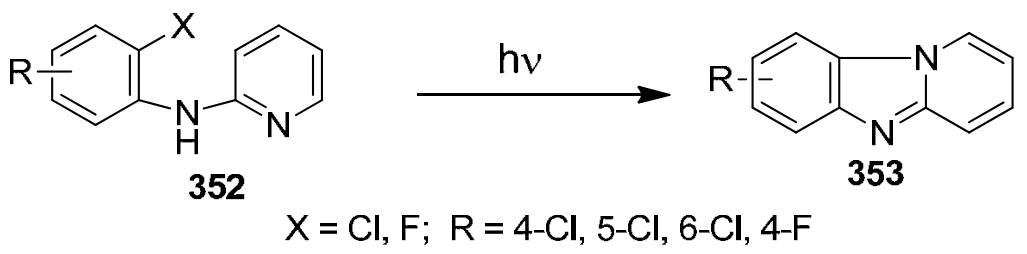

\section{Scheme 120}

The $N$-heterocyclic carbene of complex 355 was found to be an active catalyst in the Rh(I)catalyzed intramolecular coupling of the alkenyl group of 1-(2,2-dimethylbut-3-enyl)-1Hbenzimidazole 354 to the $\mathrm{C}-\mathrm{H}$ bond of the benzimidazole moiety to give 2,2-dimethyl-1,2,3,4tetrahydropyrido[1,2-a] benzimidazole 356 (Scheme 121). ${ }^{202,203}$
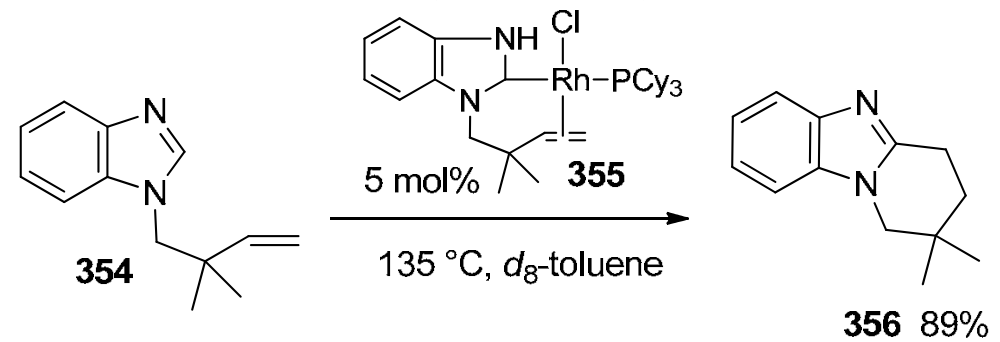

\section{Scheme 121}

Intramolecular radical addition of 2-thiophenoxybenzimidazole 357 was reported in the presence of cobaloxime 358 or $\mathrm{Ph}_{3} \mathrm{SnH} / \mathrm{AIBN}$ to give 3,3-dimethyl-1,2,3,4-tetrodydropyrido[1,2a] benzimidazole 360. The yield of $\mathbf{3 6 0}$ was higher (81\%) with using cobaloxime $\mathbf{3 5 8}$ than with $\mathrm{Ph}_{3} \mathrm{SnH} / \mathrm{AIBN}(64 \%)$ (Scheme 122). ${ }^{204}$

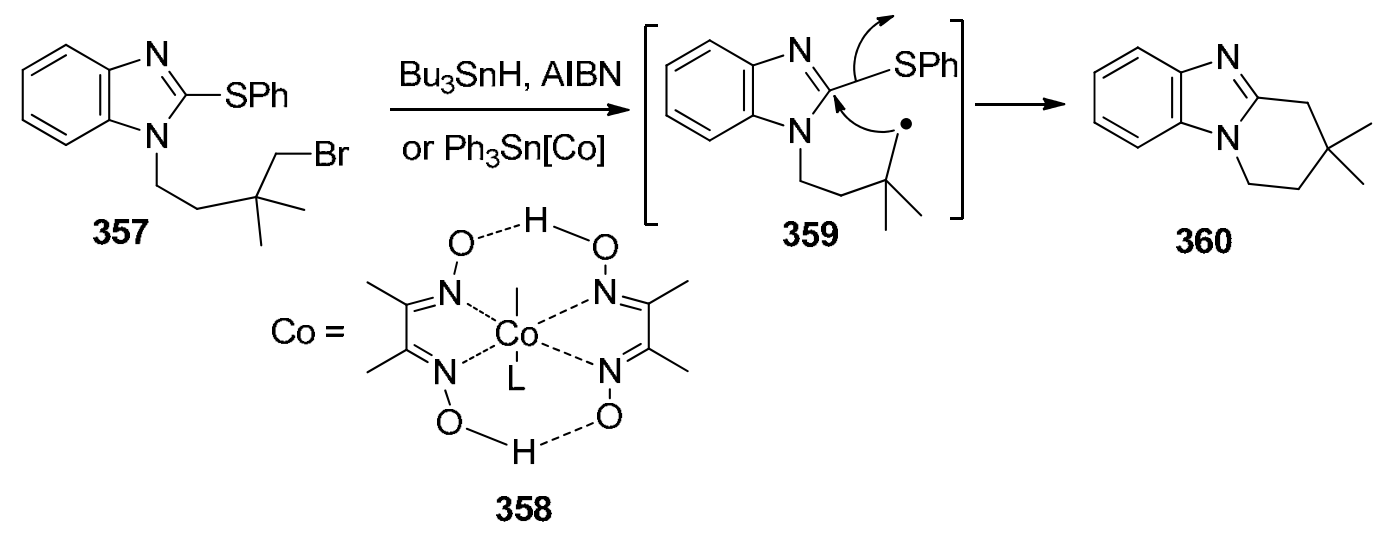

\section{Scheme 122}

Palladium-catalyzed intramolecular cyclization of 2-anilinopyridine $361(\mathrm{X}=\mathrm{Br} ; \mathrm{R}=\mathrm{H})$ using palladium acetate and $\mathrm{Na}_{2} \mathrm{CO}_{3}$ in $\mathrm{DMF}$ at reflux gave pyrido[1,2-a] benzimidazole $362(\mathrm{R}$ 
$=\mathrm{H})$ in $59 \%$ yield. Also, catalytic cyclization of $\mathbf{3 6 1}(\mathrm{X}=\mathrm{H} ; \mathrm{R}=\mathrm{H}, \mathrm{Me})$ in a continuous-flow quartz reactor containing $\mathrm{K}-16$, as a dehydrogenating catalyst, at $560-580{ }^{\circ} \mathrm{C}$ gave the pyridobenzimidazoles $362(\mathrm{R}=\mathrm{H}, \mathrm{Me})$ in $10-27 \%$ yields (Scheme 123$){ }^{206}$

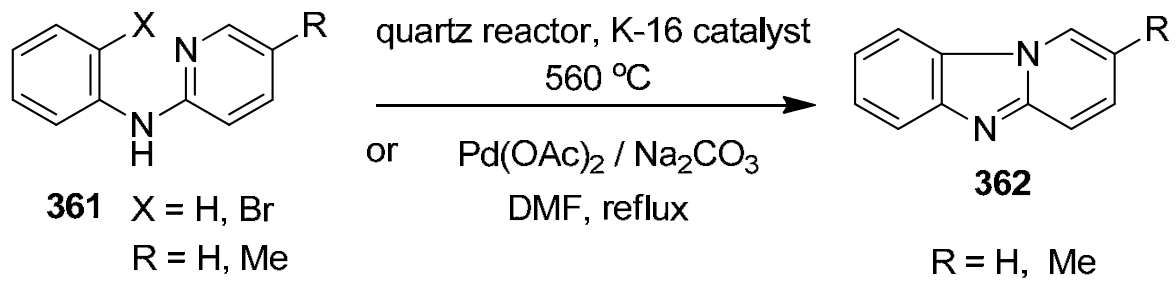

\section{Scheme 123}

Condensation of 1,2-diaminobenzene 36 with the $5 H$-pyran-2,6-dione 363 gave the pyrido[1,2-a]benzimidazol-1-one $364,{ }^{207}$ while condensation of 36 with 6-hydroxy-4-methyl-2oxo-3-pyridine-carbonitrile 365 in 85\% orthophosphoric acid afforded 3-methyl-1-oxo- $1 \mathrm{H}, 5 \mathrm{H}$ pyrido[1,2-a] benzimidazole 366 (Scheme 124). ${ }^{208}$
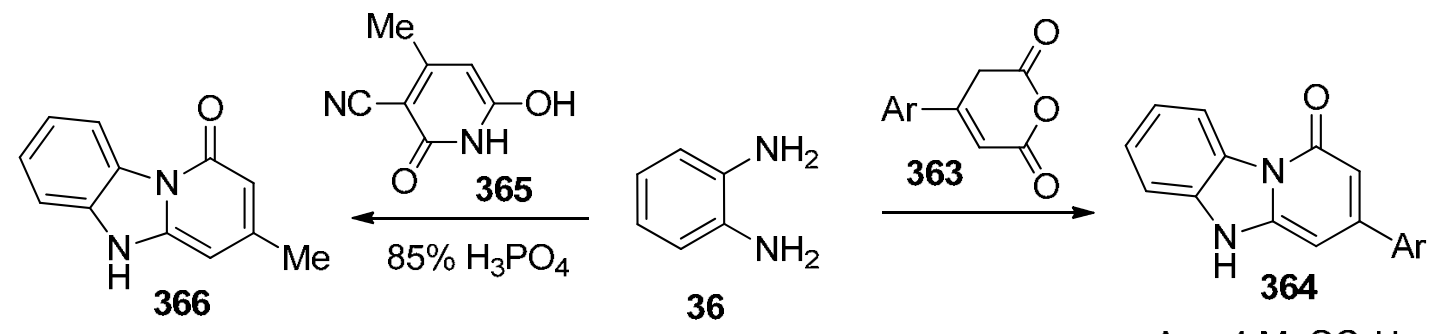

$\mathrm{Ar}=4-\mathrm{MeOC}_{6} \mathrm{H}_{4}$

\section{Scheme 124}

\subsection{Pyrimidobenzimidazoles}

Treatment of 2-aminobenzimidazole 117 with variety of enaminones 367, 368 and 369 in refluxing pyridine gave the corresponding pyrimido[1,2-a]benzimidazoles 370, 371 and 372, respectively (Scheme 125). ${ }^{160,163,165,168,209-213}$ 


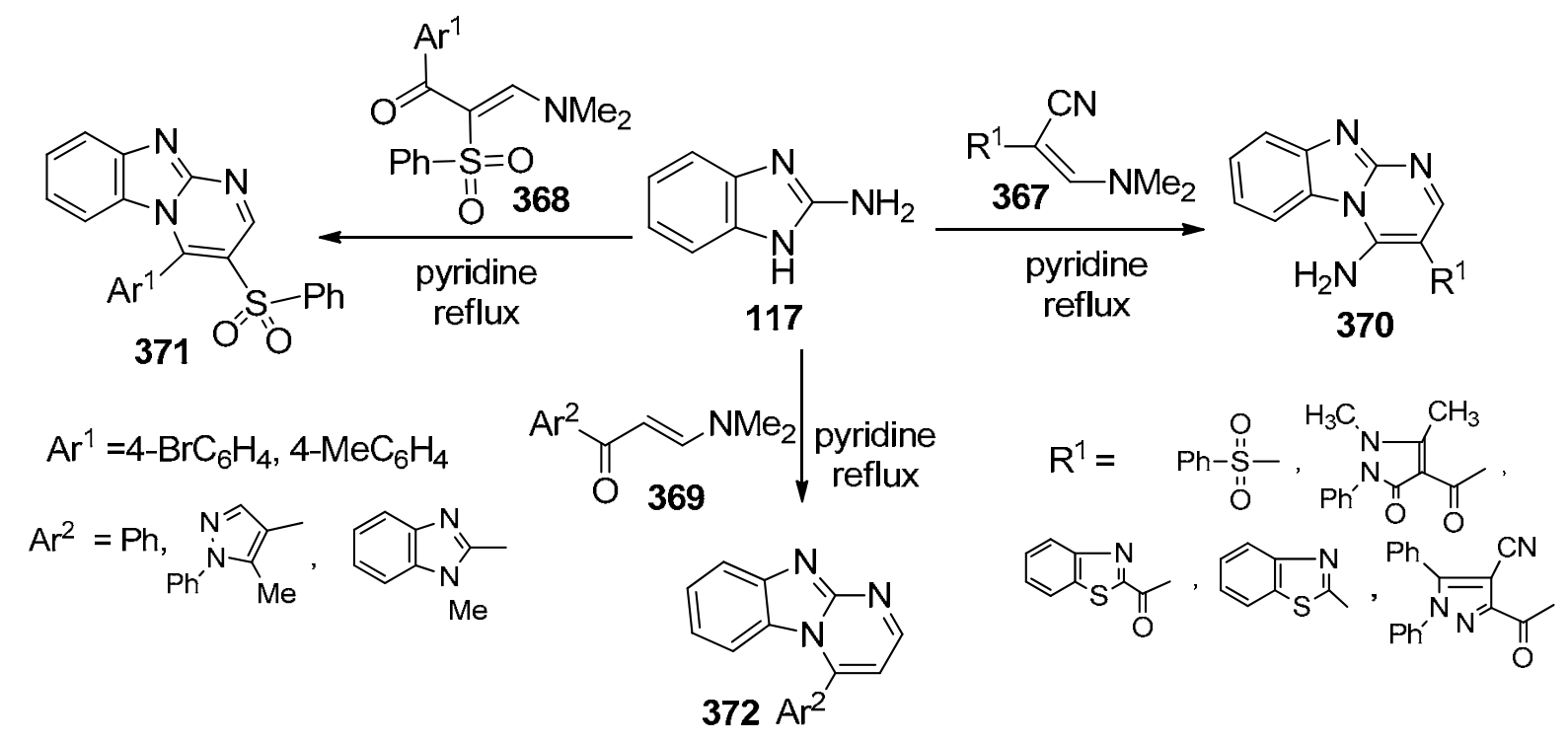

\section{Scheme 125}

Meziane et al reported the microwave-assisted synthesis of the pyrimido[1,6a]benzimidazoles $376 .^{214}$ Thus, heating of ethyl 2-(benzimidazol-2-yl)acetate 308 with $N, N$ dimethylformamide diethylacetal (DMF-DEA) at $90^{\circ} \mathrm{C}$ under microwave irradiation for 15 minutes gave the enamine derivative 373 which on treatment with the isocyanates or isothiocyanates $\mathbf{3 7 4}$ led to the formation of the pyrimido[1,6-a]benzimidazole $\mathbf{3 7 6}$ in good yields (Scheme 126). ${ }^{214}$

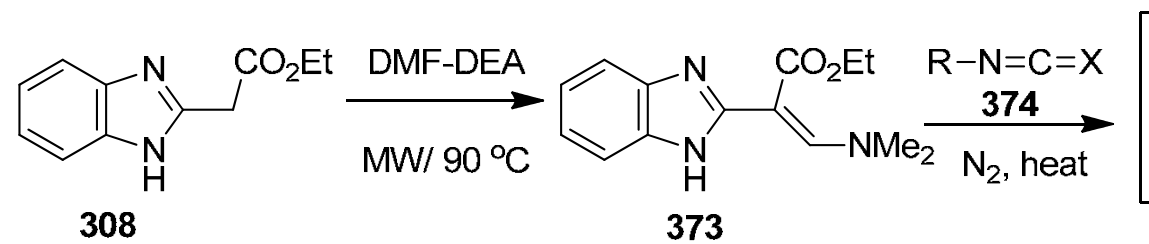<smiles>[Y]C(NC)/C(=C\N(C)C)C(C(=O)OCC)c1nc2ccccc2n1C</smiles>

$$
\begin{aligned}
& \mathrm{R}=\mathrm{Me}, \mathrm{Et}, \mathrm{CH}_{2} \mathrm{CO}_{2} \text { Et, Ph, 4-ClC } \mathrm{CH}_{4}, 4-\mathrm{NO}_{2} \mathrm{C}_{6} \mathrm{H}_{4} \\
& X=\mathrm{O}, \mathrm{S}
\end{aligned}
$$

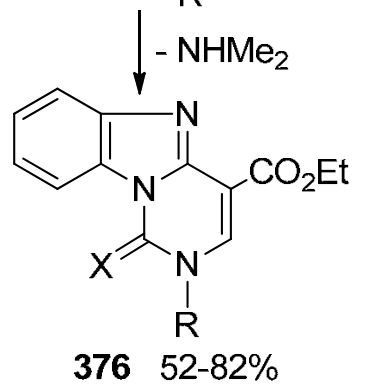

\section{Scheme 126}

Microwave assisted one-pot three component synthesis of 1,2-dihydro-pyrimido[1,2a]benzimidazole-3-carbonitrile derivatives $\mathbf{3 7 9}$ were achieved in high yields. Thus, reaction of 
carbonyl compounds 378, malonodinitrile and 2-aminobenzimidazole 117 in water under microwave gave pyrimido[1,2-a]benzimidazoles 379 (Scheme 127). ${ }^{215-217}$

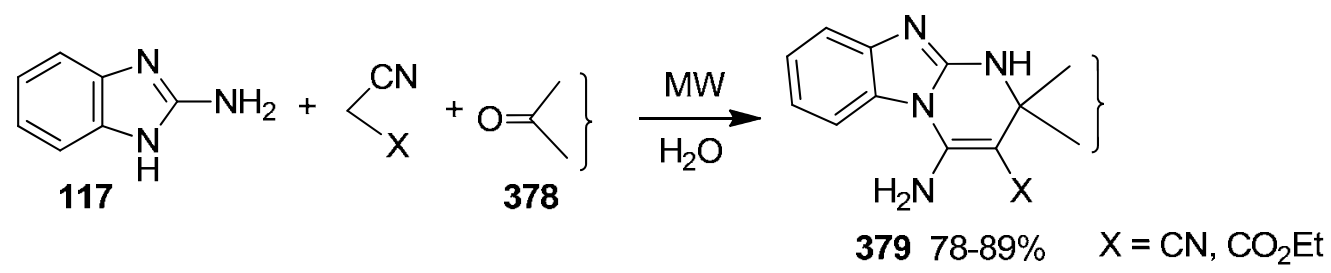

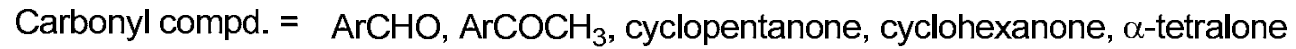
$\mathrm{Ar}=\mathrm{Ph}, 4-\mathrm{ClC}_{6} \mathrm{H}_{4}, 4-\mathrm{BrC}_{6} \mathrm{H}_{4}, 4-\mathrm{FC}_{6} \mathrm{H}_{4}, 4-\mathrm{MeOC}_{6} \mathrm{H}_{4}, 4-\mathrm{MeC}_{6} \mathrm{H}_{4}, 2-\mathrm{ClC}_{6} \mathrm{H}_{4}, 2,4-\mathrm{Cl}_{2} \mathrm{C}_{6} \mathrm{H}_{3}$

\section{Scheme 127}

The pyrimido[1,2-a]benzimidazoles $\mathbf{3 8 1}$ were synthesized through reaction of 2aminobenzimidazole 117 with tetracyanoethylene $\mathbf{3 8 0}$ in ethyl acetate at room temperature via loss of HCN and heterocyclization. ${ }^{218}$ When 2-aminobenzimidazole 117 was treated with $(E)-3$ (diethylamino)acrylonitrile 382 in refluxing pyridine it gave pyrimido[1,2-a]benzimidazol-4amine 383 in 57\% yield (Scheme 128). ${ }^{219}$

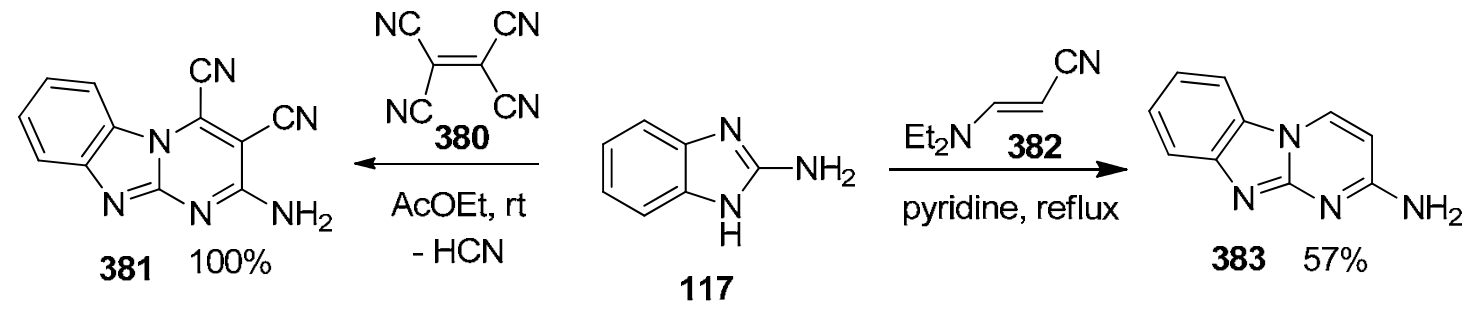

\section{Scheme 128}

Fusion of 2-aminobenzimidazole 117 with methyl cinnamates 384 gave the pyrimido[1,2a]benzimidazoles 385 (Scheme 129). ${ }^{220}$ The acetylenic aldehydes 386 and 3phenylpropynenitrile 388 reacted by conjugate addition to 117 giving the pyrimido[1,2a]benzimidazoles $\mathbf{3 8 7}$ and 389, respectively (Scheme 129). ${ }^{221}$ 


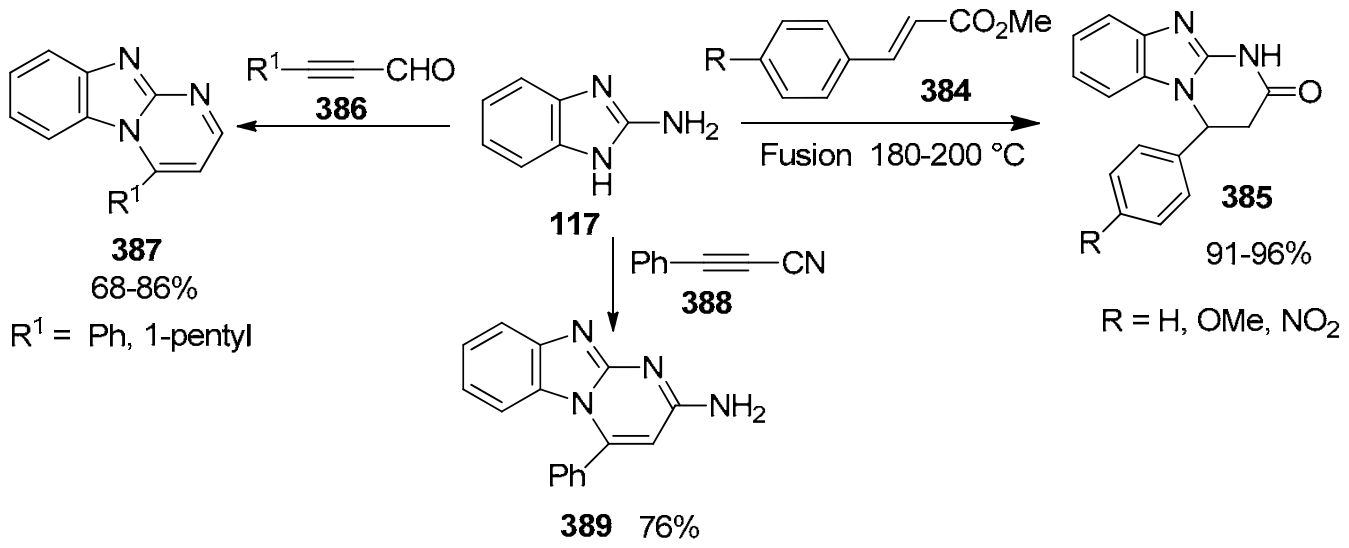

\section{Scheme 129}

Refluxing chlorooxazinediones $\mathbf{3 9 0}$ with $o$-phenylenediamines $\mathbf{3 6}$ in THF in the presence of acetic acid gave pyrimidobenzimidazolediones 391 in low yields (Scheme 130). ${ }^{22}$

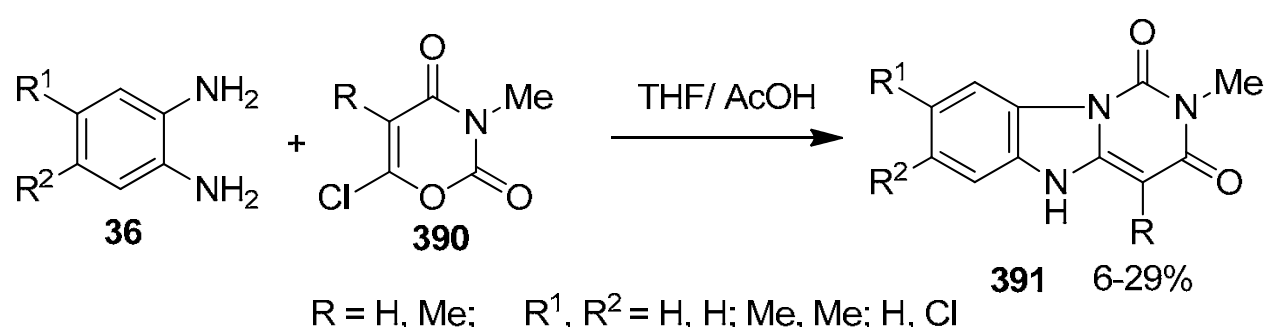

\section{Scheme 130}

Photo-irradition of $\quad N, N^{\prime}$-(chlorophenylene)bis[dimethylpyrimidinamines] 392 gave pyrimidobenzimidazoles 393 (Scheme 131). ${ }^{223}$<smiles></smiles>

\section{Scheme 131}

Photochemical cyclization of (2-chloroanilino)pyrimidines 394 in aqueous acetonitrile gave pyrimido[1,2-a]benzimidazoles 395 (Scheme 132). ${ }^{224,225}$ 


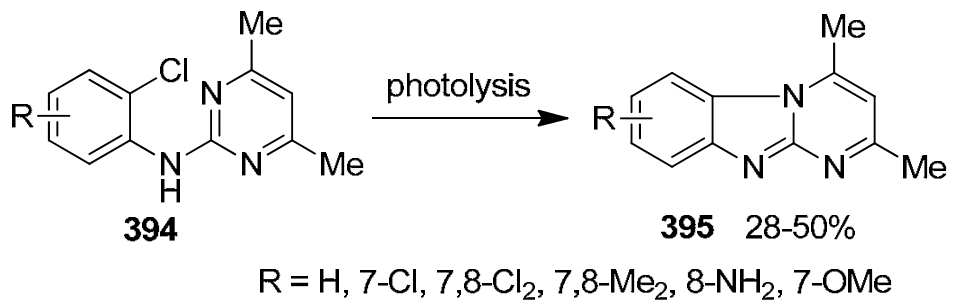

\section{Scheme 132}

Reaction of ethyl 2-[(1H-benzimidazol-2-yl)sulfinylmethyl]-4-dimethylamino-5-pyrimidinecarboxylate 396 with alkanethiols in the presence of hydrochloric acid gave the pyrimido[1,2a] benzimidazole-3-carboxylate $\mathbf{4 0 3}$ according to the mechanism shown in Scheme $133 .{ }^{226}$

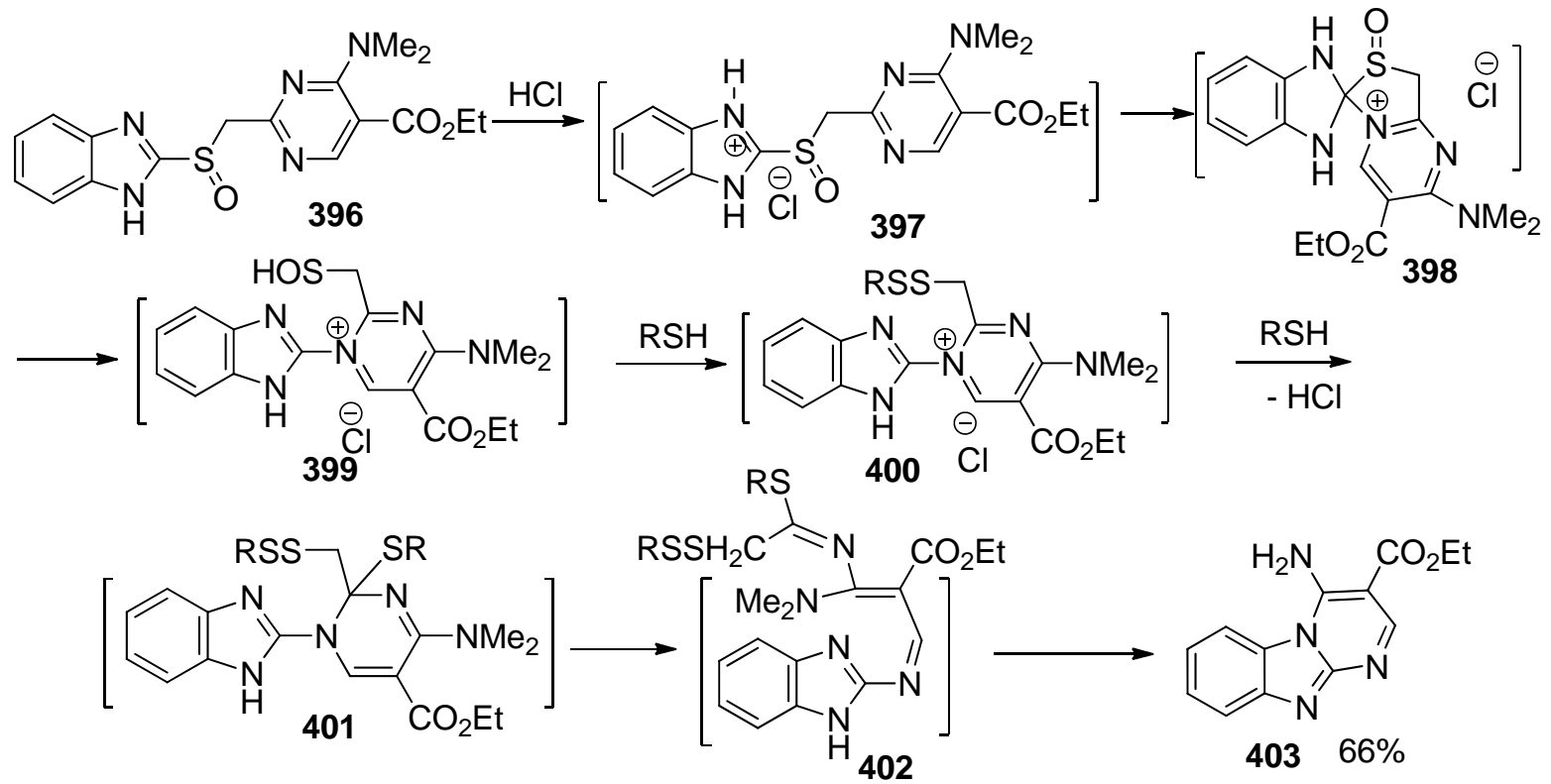

\section{Scheme 133}

Treatment of 2-vinylbenzimidazoles $\mathbf{4 0 4}$ with bromine in chloroform gave 2-(1,2dibromoethyl)- $1 H$-benzimidazoles 405 . Reaction of the latter compounds with benzonitriles and with aryl isocyanates under basic conditions yielded 1-phenylpyrimido[1,6-a]benzimidazole 407 and 2-phenylpyrimido[1,6-a]benzimidazole-3-one 408, respectively (Scheme 134). ${ }^{227}$ 


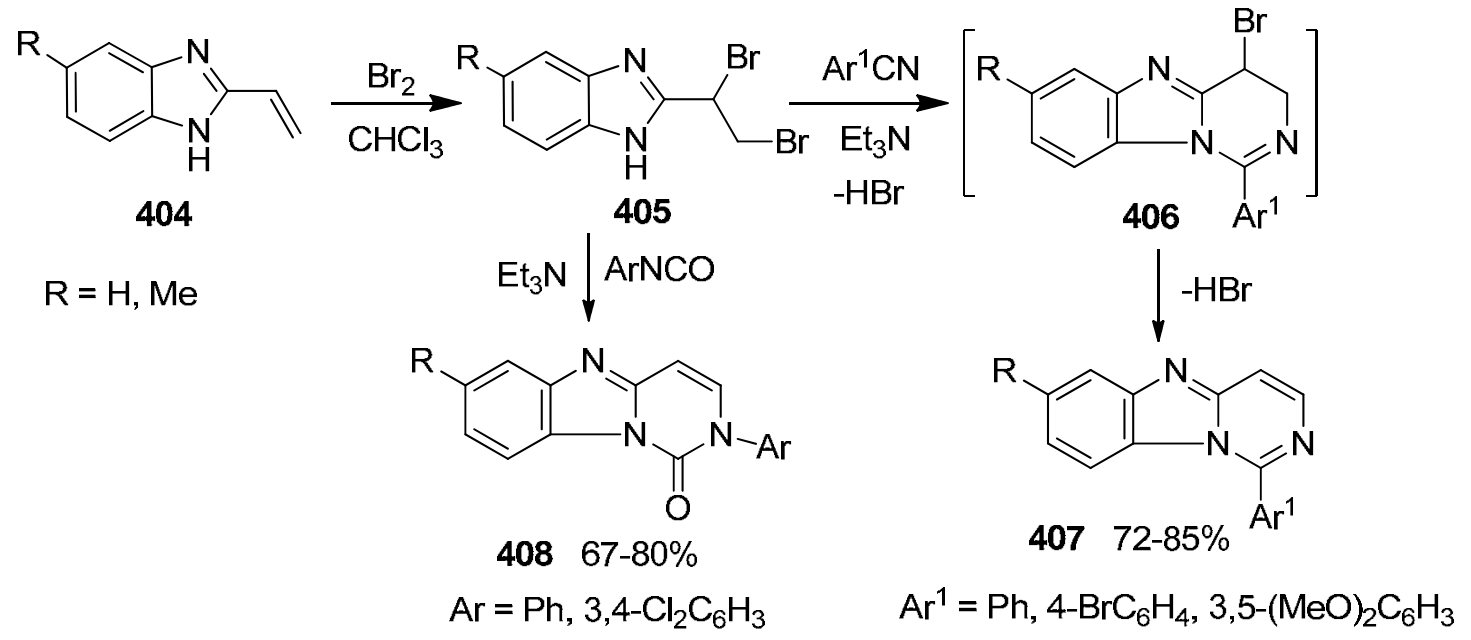

\section{Scheme 134}

Reaction of ethyl benzimidazole-2-acetate 308 with alkyl isocyanates gave the corresponding pyrimido[1,6-a]benzimidazoles 410 in excellent yields via loss of ethanol from 409 (Scheme $135)^{228}$

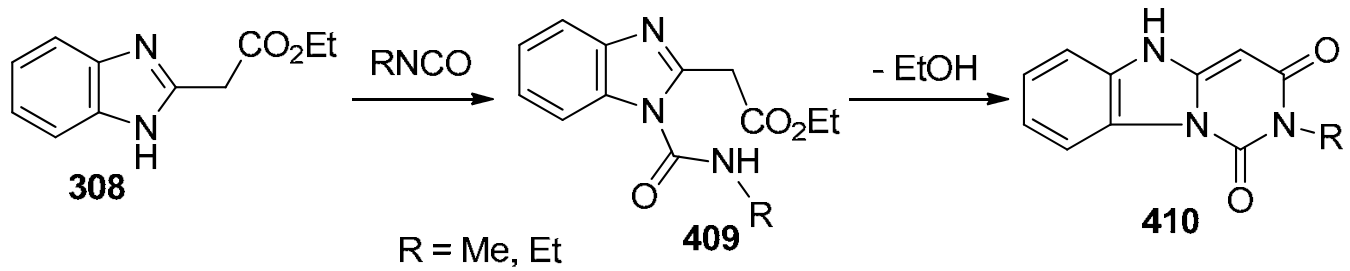

\section{Scheme 135}

Abdelhamid et al. reported the synthesis of pyrimido[1,6-a]benzimidazole-4-carbonitriles 413 from the reaction of 2-(1-ethoxycarbonyl)benzimidazolylacetonitrile $\mathbf{4 1 1}$ with isothiocyanates in the presence of $\mathrm{KOH}$ followed by $\mathrm{HCl}$ (Scheme 136). ${ }^{229,230}$

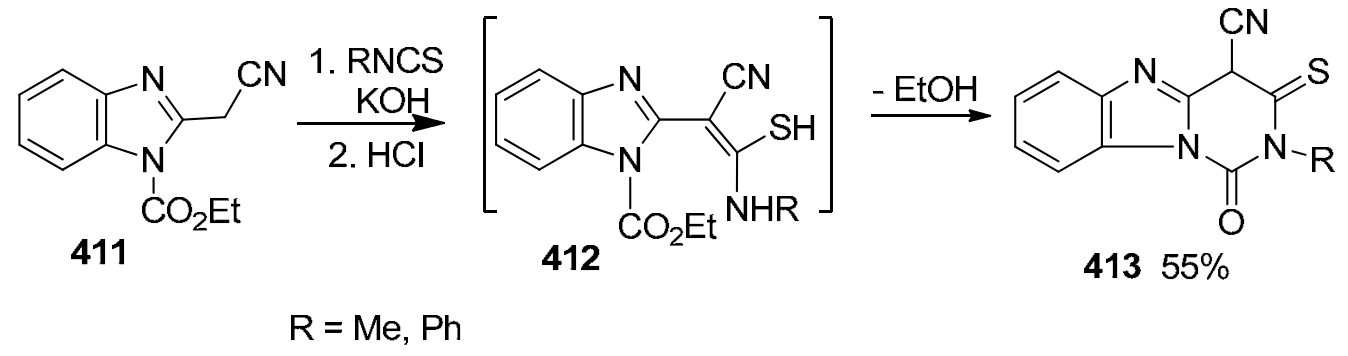

Scheme 136 
Treament of 2-benzimidazoleacetonitriles 59 or methyl 2-benzimidazoleacetate 308 with chloroalkyl isocyanates or carbodiimides $414\left(\mathrm{Y}=\mathrm{O}, \mathrm{N}-\mathrm{Ar}^{\prime}\right)$, in benzene in the presence of ethyl diisopropylamine furnished the pyrimido[1,6- $a$ ] benzimidazoles 416 via cyclization and loss of $\mathrm{HCl}$ from the benzimidazolium salt intermediate 415 (Scheme 137). ${ }^{231}$

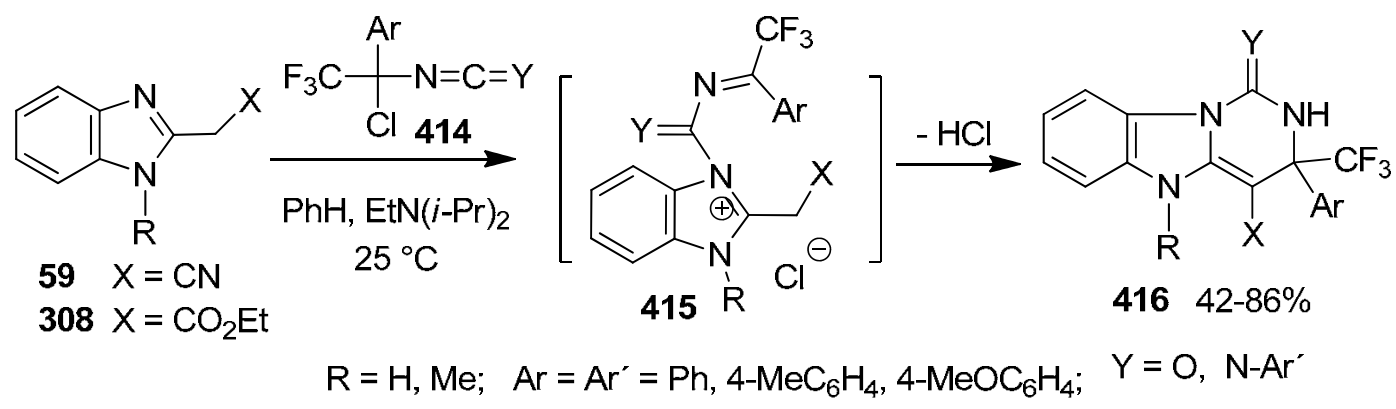

\section{Scheme 137}

Reaction of ethyl 2-(1H-benzimidazol-2-yl)-2-cyanoacetate 417 with guanidine sulfate 418 in dry pyridine and sodium methoxide gave 1-amino-3-hydroxypyrimido[1,6-a]benzimidazole-4carbonitrile 419 (Scheme 138). ${ }^{232}$<smiles>CCOC(=O)C(C#N)c1nc2ccccc2[nH]1</smiles>

417

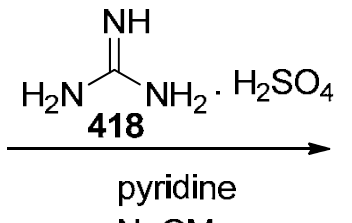

$\mathrm{NaOMe}$<smiles>N#Cc1c(O)nc(N)n2c1nc1ccccc12</smiles>

\section{Scheme 138}

2-Benzimidazoleacetonitrile 59 and its ester 308 reacted with $N$-acyl imidates 420 under microwave irradiation in open vessels to give the corresponding pyrimido[1,6- $a$ ]benzimidazoles 421 (Scheme 139). ${ }^{233}$

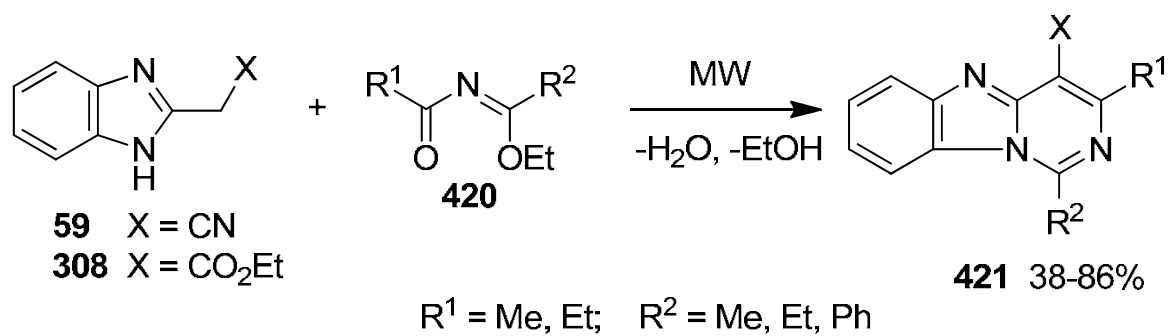

Scheme 139 
Badawey et al. reported the reaction of $1 H$-benzimidazoles 59 and $\mathbf{3 0 8}$ with ethoxycarbonyl isocyanate $\mathbf{4 2 2}$ at room temperature to afford the intermediate $\mathbf{4 2 3}$, which was readily cyclized in boiling bromobenzene to the corresponding 1,3-dioxopyrimido[1,6-a]benzimidazole-4carbonitrile 424 in excellent yields (Scheme 140). ${ }^{234}$

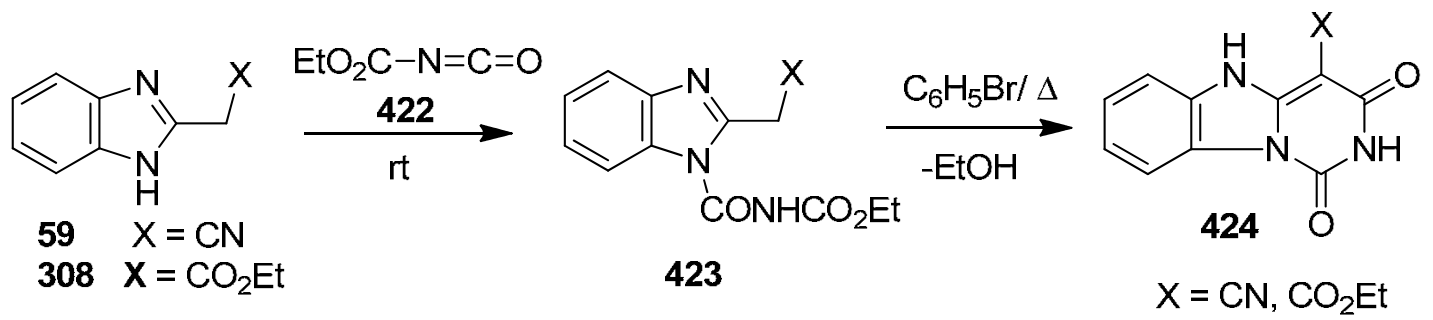

\section{Scheme 140}

The reaction of 2-aminobenzimidazole 117 with sulfones 425 proceeded at room temperature in acetonitrile to give tetrahydropyrimido[1,2-a]benzimidazol-2-ol 426. Aromatization of the latter compounds $\mathbf{4 2 6}$ was performed under reflux in acetic acid via elimination of water and sulfinic acid to give 427. One-step procedure for the preparation of 427 in high yields from 2aminobenzimidazole 117 and the sulfones 425 under reflux in water was also reported (Scheme 141). ${ }^{235}$ Condensation of 2-aminobenzimidazole 117 with diethyl ethoxymethylenemalonate 301 in dry methanol afforded 4-oxopyrimido[1,2-a]benzimidazole-3-carboxylate 428 (Scheme 141). ${ }^{236}$

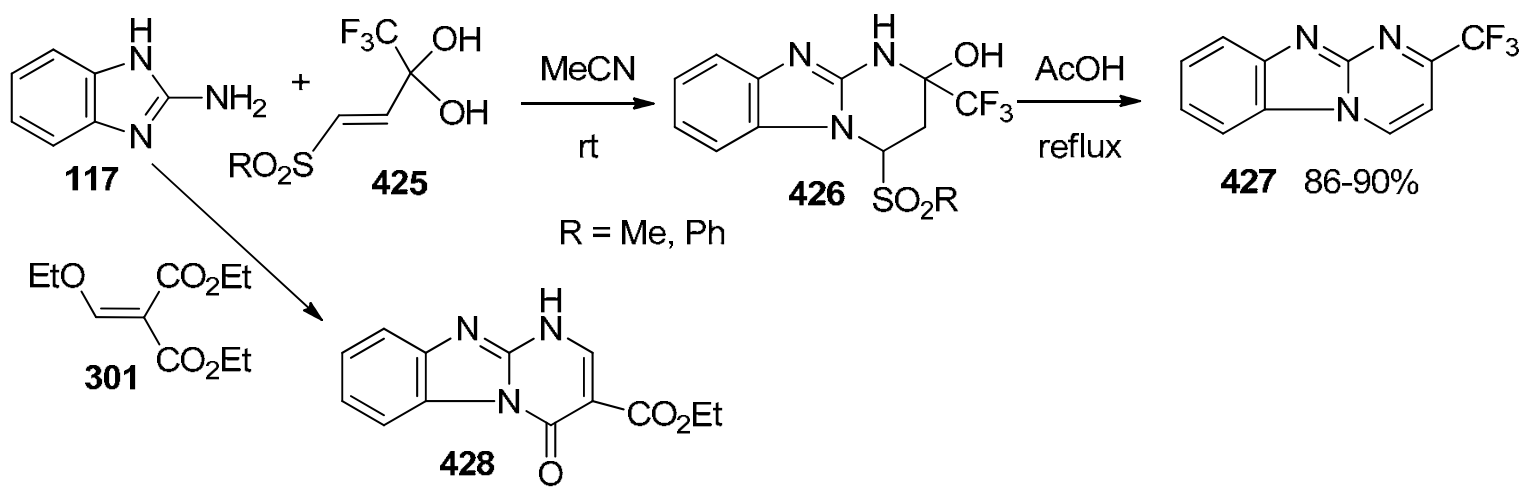

\section{Scheme 141}

3-(Trichloromethyl)pyrimido[1,6-a]benzimidazole-4-carbonitrile 429 was prepared by heating of 2-benzimidazoleacetonitrile 59 with trichloroacetonitrile followed by triethyl orthoformate (Scheme 142). ${ }^{237}$ Reaction of dimethyl N-cyanodithioiminocarbonate 430 with 2benzimidazoleacetonitrile 59 in the presence of $\mathrm{KOH}$ furnished 1-amino-4-cyano-3(methylthio)pyrimido[1,6-a] benzimidazole 432 (Scheme 142). ${ }^{238}$ 


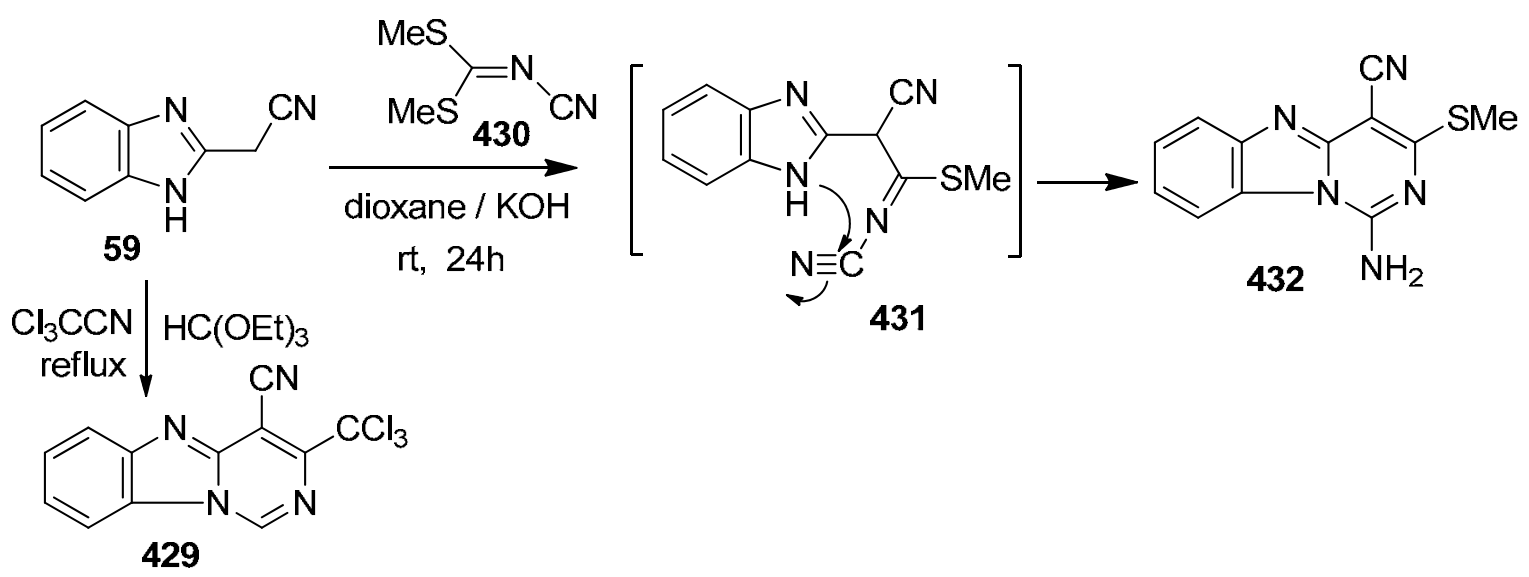

\section{Scheme 142}

The reaction of 2-aminobenzimidazole 117 with the benzylidene derivatives 433, 267 and 434 in ethanol containing a catalytic amount of piperidine gave the corresponding pyrimido[1,2a]benzimidazole derivatives 435, 436 and 437, respectively (Scheme 143). ${ }^{239-242}$

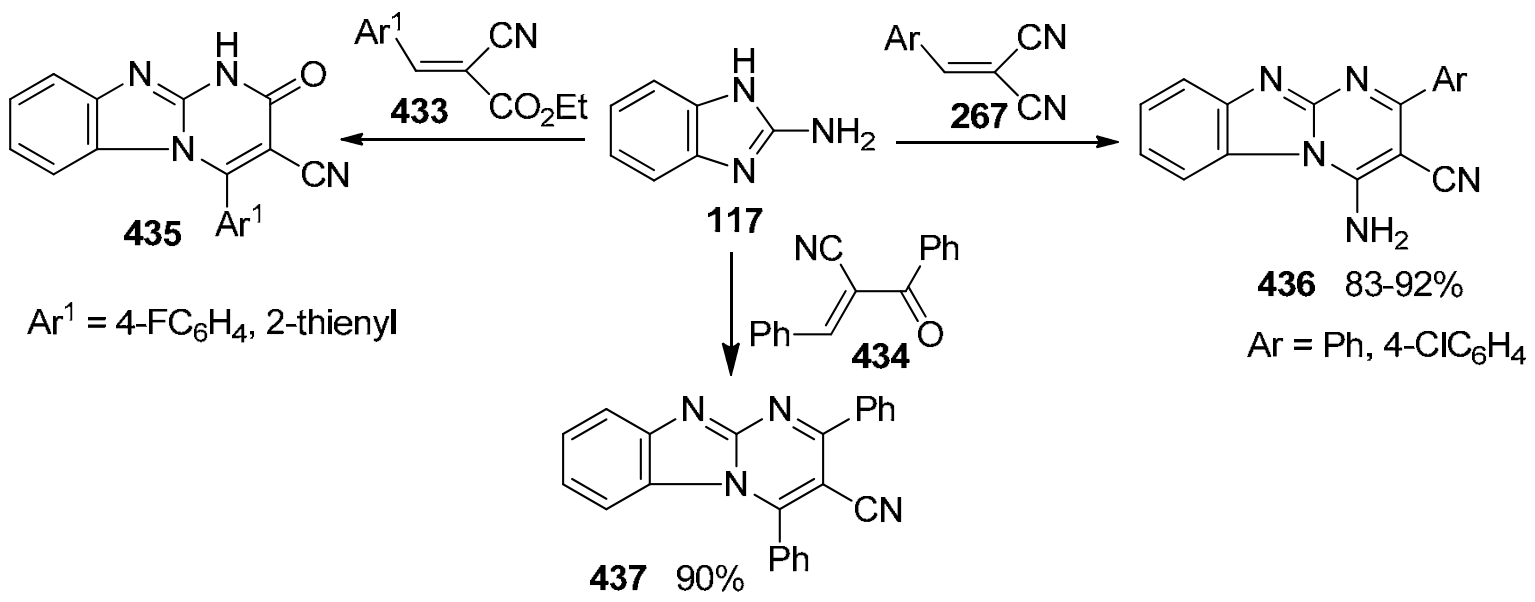

\section{Scheme 143}

The condensation of 2-aminobenzimidazole 117 with chalcones 263 and with phenylhydrazonomalononitrile $\mathbf{3 2 4}$ gave pyrimido[1,2-a]benzimidazoles $\mathbf{4 3 8}$ and $\mathbf{4 4 0 ,}$ respectively. ${ }^{243-246}$ Similar condensation of 117 with ethyl $\alpha$-( $p$-tolylazo)- $\beta$-oxobutyrate 441 in absolute ethanol afforded the pyrimido[1,2-a]benzimidazole-4-one 442 (Scheme 144). ${ }^{247}$ 


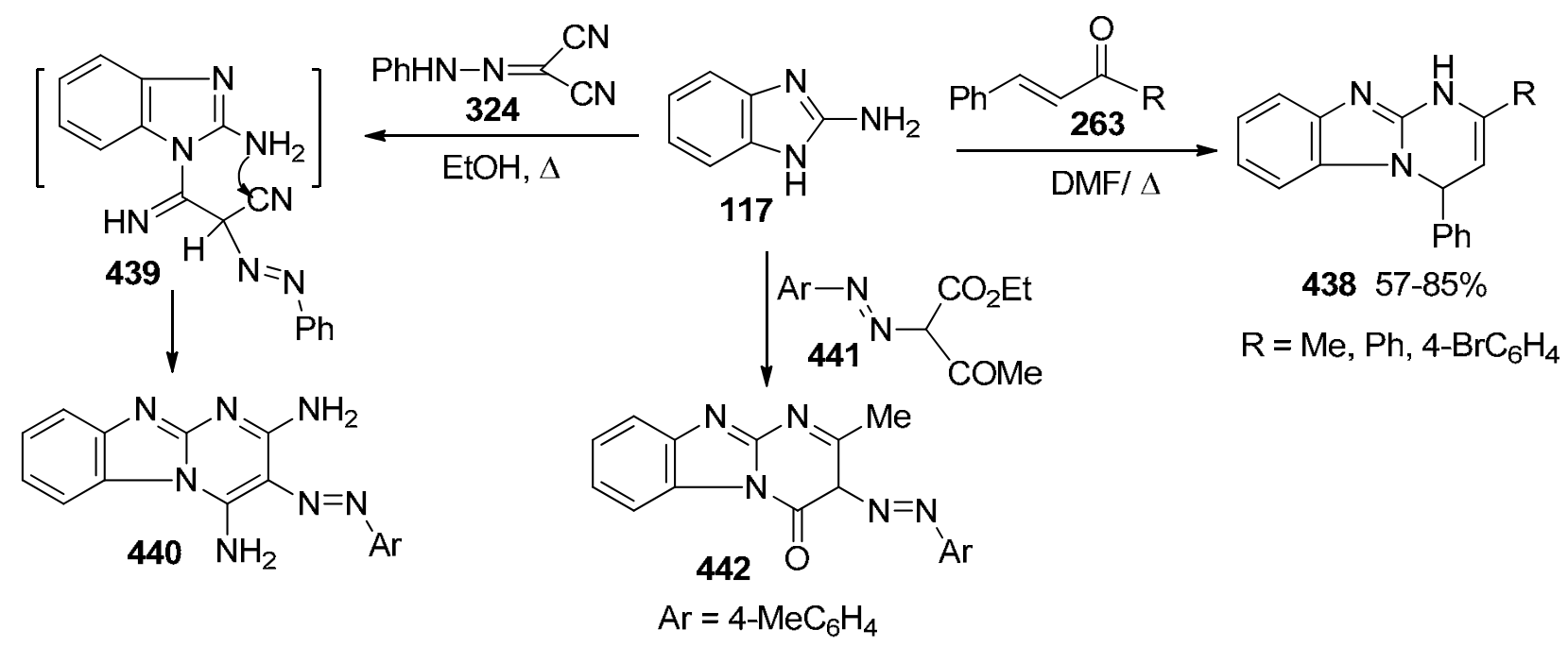

\section{Scheme 144}

The reaction of the allenic nitriles 443 with 2-aminobenzimidazoles 117 in refluxing DMF led to 2-aminopyrimido[1,2-a] benzimidazole 445 in high yields (Scheme 145). ${ }^{248}$

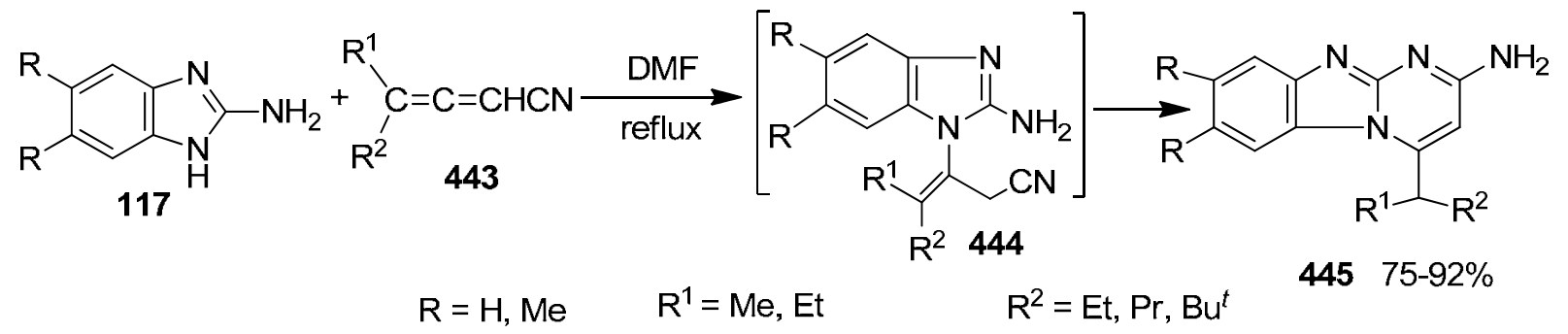

\section{Scheme 145}

Reaction of 1-ethyl-2-aminobenzimidazole 446 and dimethyl acetylenedicarboxylate 257 at $130{ }^{\circ} \mathrm{C}$ afforded the methyl pyrimido[1,2-a]benzimidazol-4-carboxylate 447 in 59\% yield. Similar treatment of $\mathbf{4 4 6}$ with diethyl (ethoxymethylene)malonate 301 gave ethyl 10-ethyl-4oxo-4H-pyrimido[1,2-a]benzimidazol-3-carboxylate 448 in $71 \%$ yield (Scheme 146). ${ }^{62}$<smiles>CCOC=C(C(=O)OCC)C(=O)OCC</smiles>

\section{Scheme 146}


Reaction of 2-aminobenzimidazole 117 with 4-hydroxy-2-alkynenitrile 152 in ethanol under reflux gave excellent yields of 2-amino-4-(1-hydroxyalkyl)pyrimido[1,2-a] benzimidazole 450 . $^{76}$ In addition, the pyrimidobenzimidazole-2,4-dione 452 was prepared in 30\% yield by treating 117 with diethyl diallylmalonate 451 (Scheme 147). ${ }^{249}$

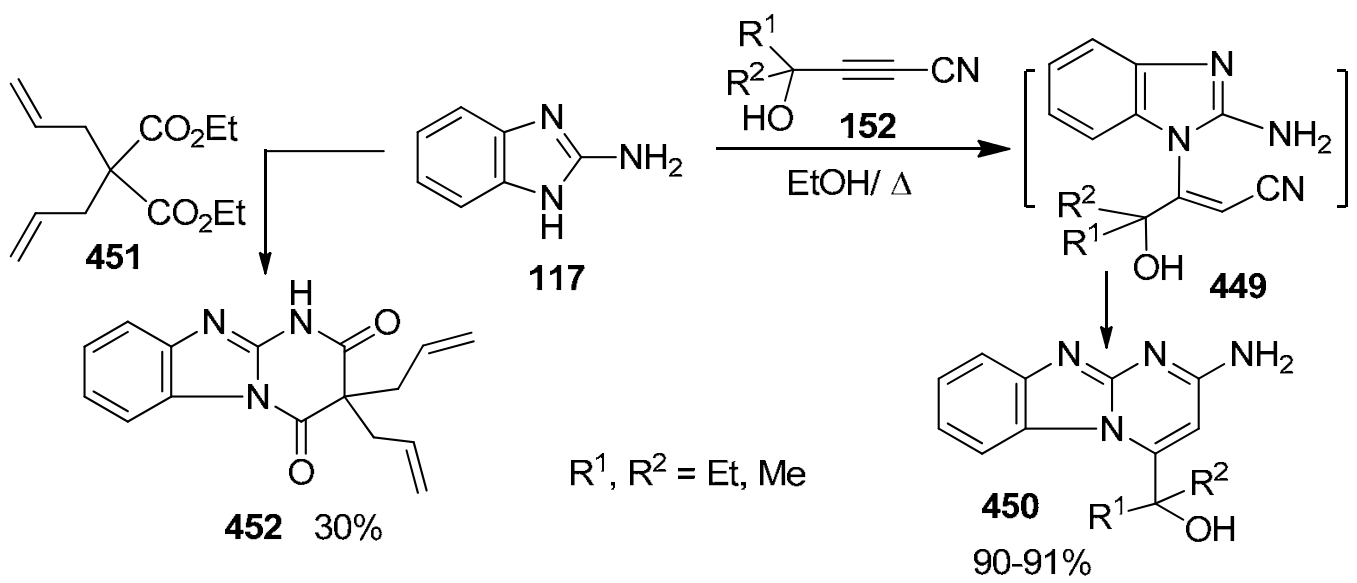

\section{Scheme 147}

Refluxing 3-isothiocyanatobutanal 453 with $o$-phenylenediamines 36 in methanol at $p \mathrm{H} 5$ gave the pyrimido[1,6- $a$ ] benzimidazole derivative 454 (Scheme 148). ${ }^{250,251}$

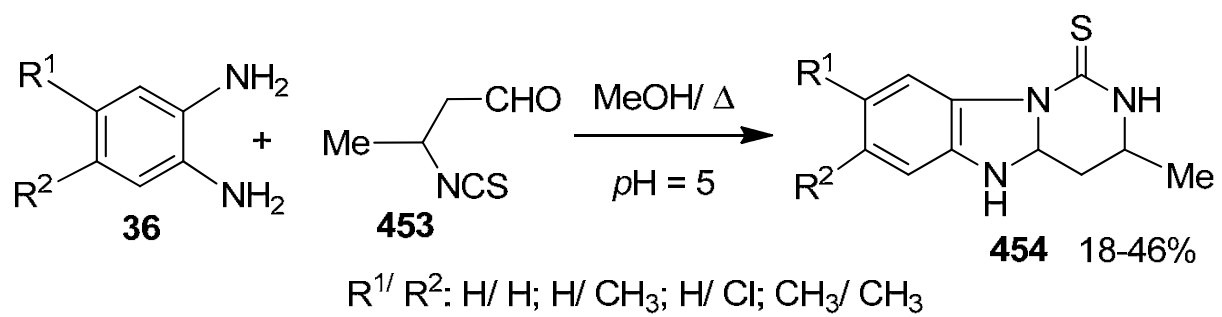

\section{Scheme 148}

Cyclocondensation of (2-benzimidazolylmethyl)triphenylphosphonium chloride 455 with benzoyl isothiocyanates in the presence of triethylamine gave pyrimido[1,6- $a$ ]benzimidazole derivative 456 (Scheme 149). ${ }^{252,253}$

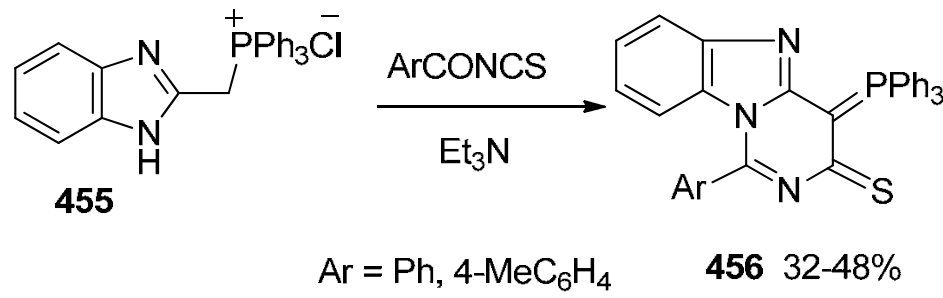

Scheme 149 
4-Amino-1H-1,5-benzodiazepine-3-carbonitrile 457 underwent ring opening when treated with hydroxylamine to yield 3-amino-3-(2-aminoanilino)-2-cyanopropenal oxime 458. Treatment of $\mathbf{4 5 8}$ with diluted hydrochloric acid gave 2-(2-benzimidazolinylidene)-2cyanoethanal-oxime 459. Refluxing of $\mathbf{4 5 9}$ in triethyl orthoformate resulted in the formation of the pyrimido[1,6-a] benzimidazole derivative $\mathbf{4 6 0}$ (Scheme 150). ${ }^{254}$<smiles></smiles>

\section{Scheme 150}

The pyrimido[1,2-a]benzimidazole derivative 461 was prepared in $75 \%$ yield by cyclocondensation of 4-(ethoxymethylene)-2-phenyloxazol-5(4H)-one $\mathbf{3 0 8}$ with 2aminobenzimidazole 117 under solventless domestic microwave heating via loss of ethanol from the intermediate 461A (Scheme 151). ${ }^{255}$

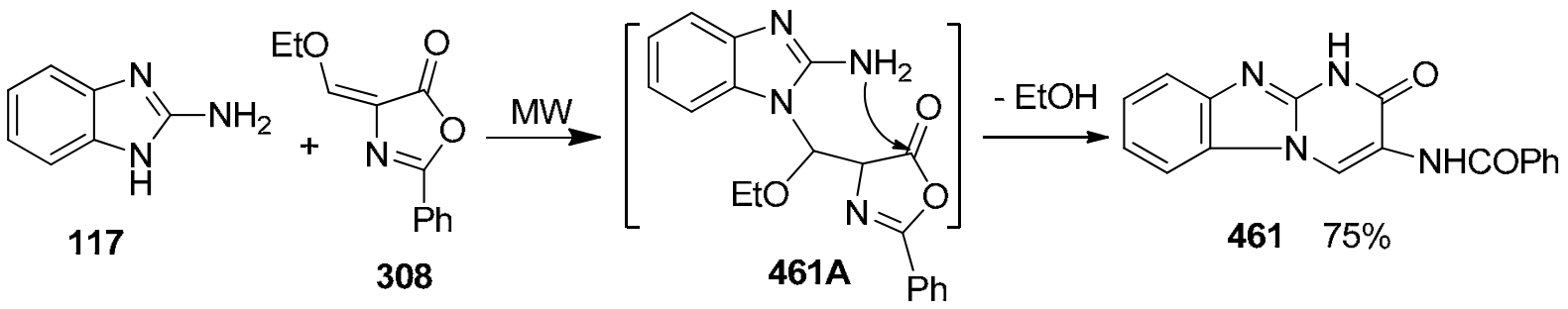

\section{Scheme 151}

1,2-Diaminobenzimidazole 462 reacted with diethyl ethoxymethylenemalonate 301 to give the pyrimido[1,2-a]benzimidazole derivative 463 (Scheme 152). ${ }^{256}$<smiles>CCOC=C(OCCc1ccc2c(c1)n1c(=O)c(C(=O)OCC)cnc1n2N)C(=O)OCC</smiles>

\section{Scheme 152}


Pyrimido[1,2-a]benzimidazole derivatives 467-470, which are useful as neoplasm inhibitors, immuno-modulators, and antiallergic agents, were prepared via reaction of 2aminobenzimidazole Schiff's base $\mathbf{4 6 4}$ with active methylene compounds and with the cinnamoyl chlorides 465 (Scheme 153). ${ }^{257-261}$

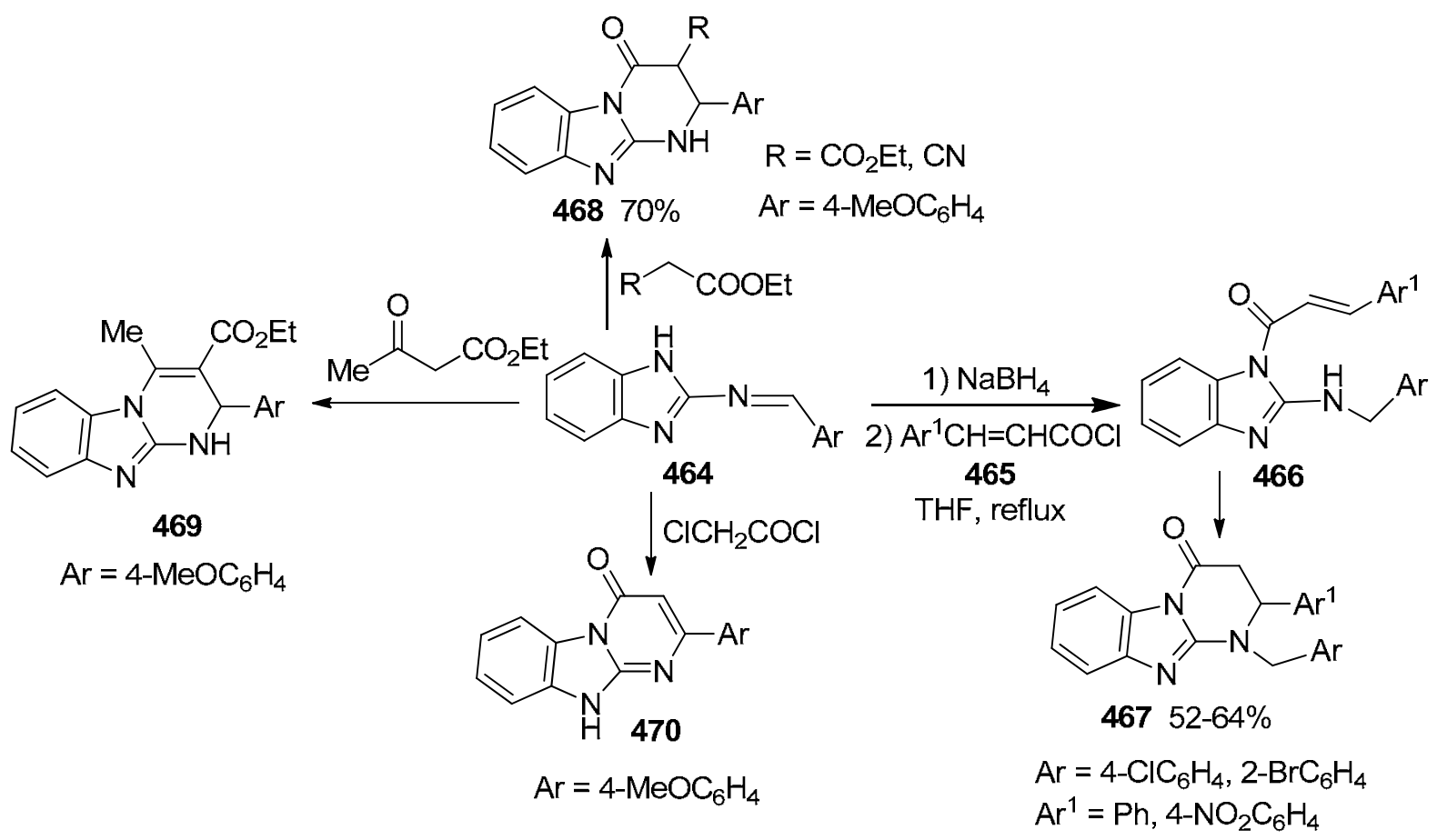

Scheme 153

\subsection{Pyrazinobenzimidazoles}

2-Acetylbenzimidazole 471 reacted with aromatic aldehydes to give 1-(benzimidazol-2-yl)-3aryl-2-propenone $\mathbf{4 7 2}$. Reaction of $\mathbf{4 7 2}$ with phenacyl bromides $\mathbf{5}$ in acetone in the presence of potassium carbonate gave 1-[1-(2-aryl-2-oxoethyl)benzimidazol-2-yl]-3-arylpropenones 473 which upon heating with ammonium acetate in acetic acid gave 1-(2-arylvinyl)-3arylpyrazino[1,2-a] benzimidazole derivative 474. Reaction of 471 with phenacyl bromides 5 gave 1-(2-aryl-2-oxoethyl)-2-acetylbenzimidazoles 475 , which were then reacted with anilines in acetic acid to give 1-methylene-2,3-diaryl-1,2-dihydropyrazino[1,2-a]benzimidazoles 476 (Scheme 154). ${ }^{262}$ 


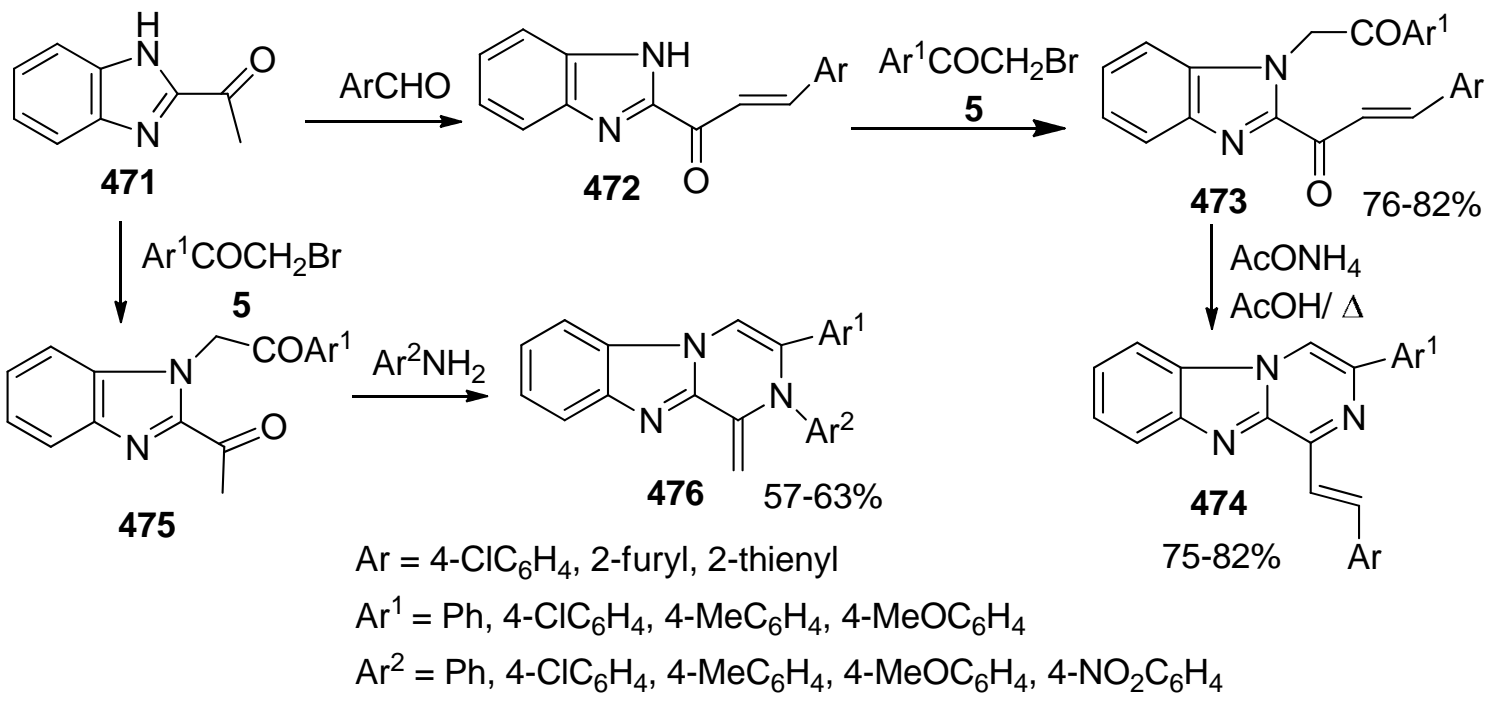

\section{Scheme 154}

Pyrazino[1,2-a]benzimidazole 478 was prepared by heating 1-(2-pyrazinyl)benzotriazole 477 with polyphosphoric acid (PPA) at $180{ }^{\circ} \mathrm{C}$ (Scheme 155). ${ }^{263}$<smiles>c1ccc2c(c1)nnn2-c1cnccn1</smiles>

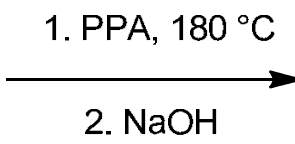<smiles>c1ccc2c(c1)nc1cnccn12</smiles>

$478 \quad 81 \%$

\section{Scheme 155}

Pyrazino[1,2-a]benzimidazole derivatives 479-481 were obtained from the reaction of 2aminomethylbenzimidazole 112 with diethyl oxalate, phenacyl bromide 5 and with dibromoethane, respectively (Scheme 156). ${ }^{60}$<smiles>Cc1ccccc1-n1cnc2ccccc21</smiles>

481

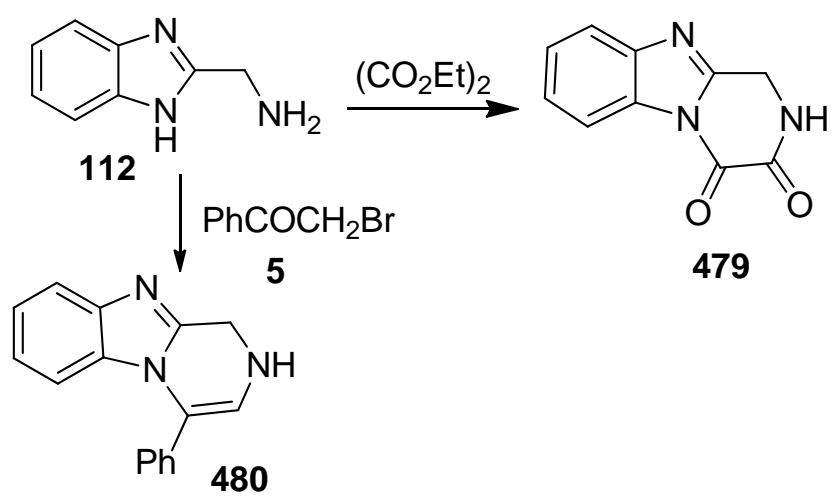

\section{Scheme 156}


Treatment of the 2-formylbenzimidazole $\mathbf{4 8 2}$ with primary amines and cyclohexyl isocyanide at $40{ }^{\circ} \mathrm{C}$ in methanol resulted in the formation of 3-oxo-1,2,3,4-tetrahydropyrazino[1,2a]benzimidazole-1-carboxamides $\mathbf{4 8 5}$ in good yields. Formation of $\mathbf{4 8 5}$ took place probably according to the mechanism depicted in Scheme $157 .^{264}$

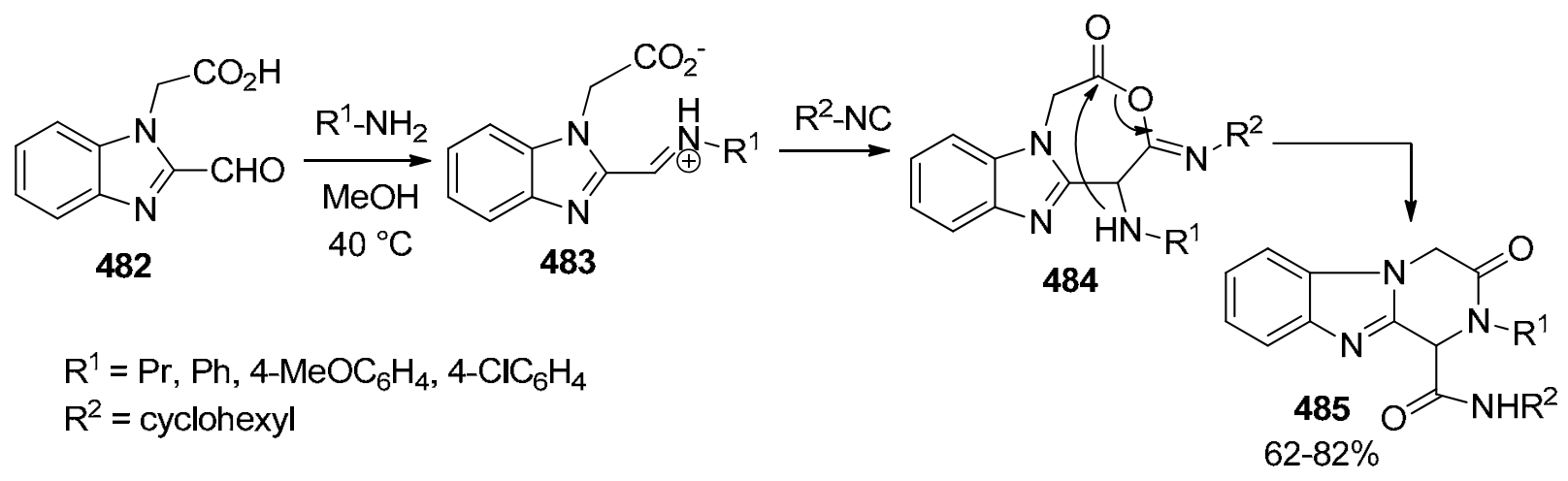

\section{Scheme 157}

3-Anilinopyrazinones 486 were easily converted into the pyrazino[1,2-a]benzimidazol1(2H)-ones 487 by applying a microwave assisted Buchwald-Hartwig type cyclization using $10 \% \mathrm{Pd}\left(\mathrm{PPh}_{3}\right)_{4}$ and anhydrous potassium carbonate in $\mathrm{DMF}$ at $150{ }^{\circ} \mathrm{C}$ and $150 \mathrm{Watts}$ (Scheme $158)^{265}$

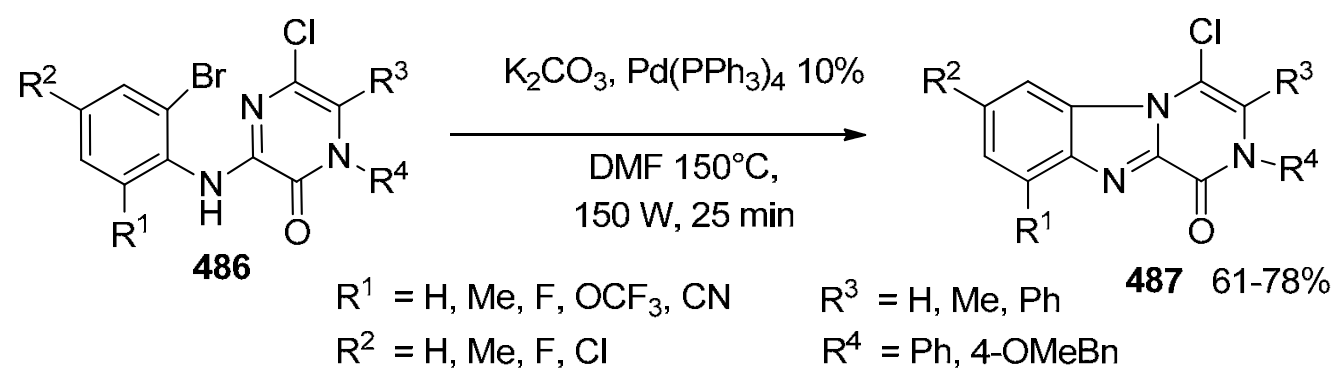

\section{Scheme 158}

\subsection{Triazinobenzimidazoles}

Treatment of ethyl 2-benzimidazolylacetate $\mathbf{3 0 8}$ with aryldiazonium salts in ethanolic sodium acetate solution yielded the arylhydrazones 488. Heating the latter hydrazones with ethyl chloroformate in pyridine afforded the 1,2,4-triazino[4,5-a]benzimidazole derivatives 489 (Scheme 159). ${ }^{266}$ 


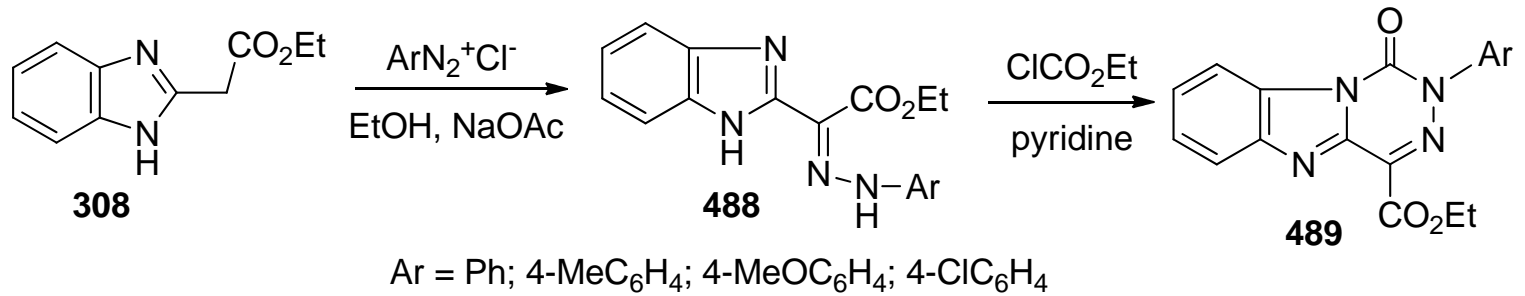

\section{Scheme 159}

1,2,4-Triazino[2,3-a]benzimidazole derivative 493 was obtained selectively by the reaction of diethyl $(E)$-2,3-dicyanobutenedioate 490 with 1,2-diamino-1H-benzimidazole 462 in dimethyl sulfoxide at room temperature as outlined in Scheme $160 .^{267}$

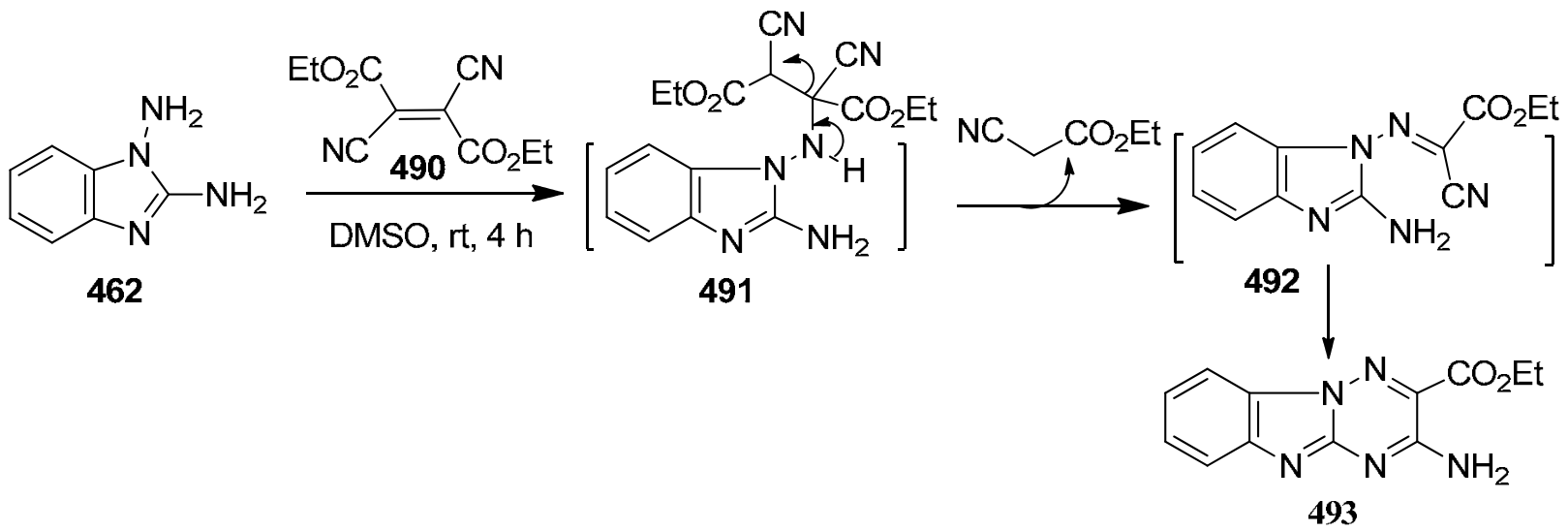

\section{Scheme 160}

3-Oxopropanenitriles 494 coupled smoothly with $1 H$-benzimidazole-2-diazonium sulfate 495 to afford the corresponding hydrazones 496. The latter hydrazones underwent intramolecular cyclization when heated in pyridine to give 1,2,4-triazino[4,3-a]benzimidazoles 497 in good yields (Scheme 161). ${ }^{268,269}$

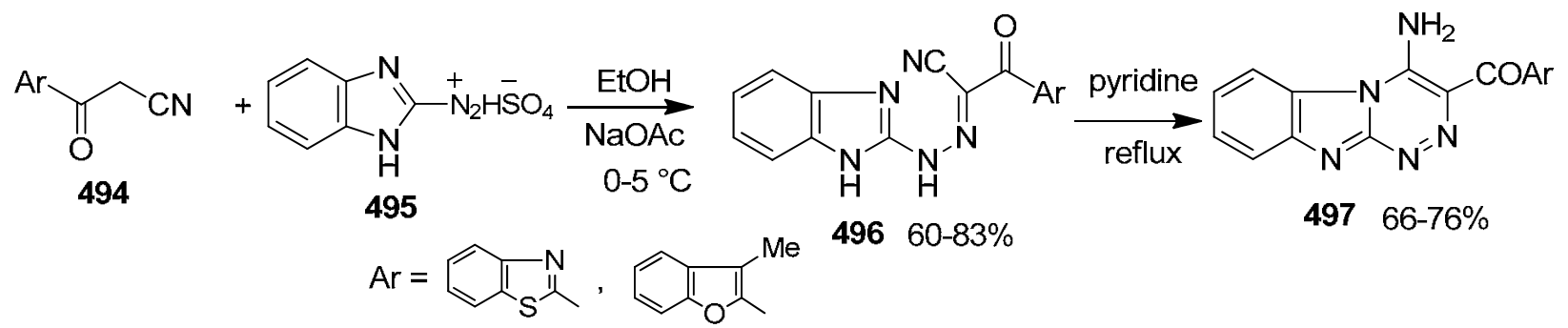

\section{Scheme 161}


Benzimidazole-2-diazonium salt 495 was coupled with 2-benzimidazoleacetonitrile 59 to yield the hydrazone 498 which was cyclized under refluxing pyridine to produce the 1,2,4triazino[4,3-a]benzimidazole 499 (Scheme 162). ${ }^{270}$<smiles></smiles>

\section{Scheme 162}

The diazotized 2-nitroanilines $\mathbf{5 0 0}$ were coupled with $N$-ethoxycarbonylcyanoacetamide $\mathbf{5 0 1}$ to afford the corresponding hydrazones 502 which were cyclized into the nitrophenyltriazinediones 503. The latter were reduced to the corresponding aminophenyltriazinedione derivatives 504 which were then converted into the 1,2,4-triazino[2,3a]benzimidazoles 505 (Scheme 163). ${ }^{271-274}$

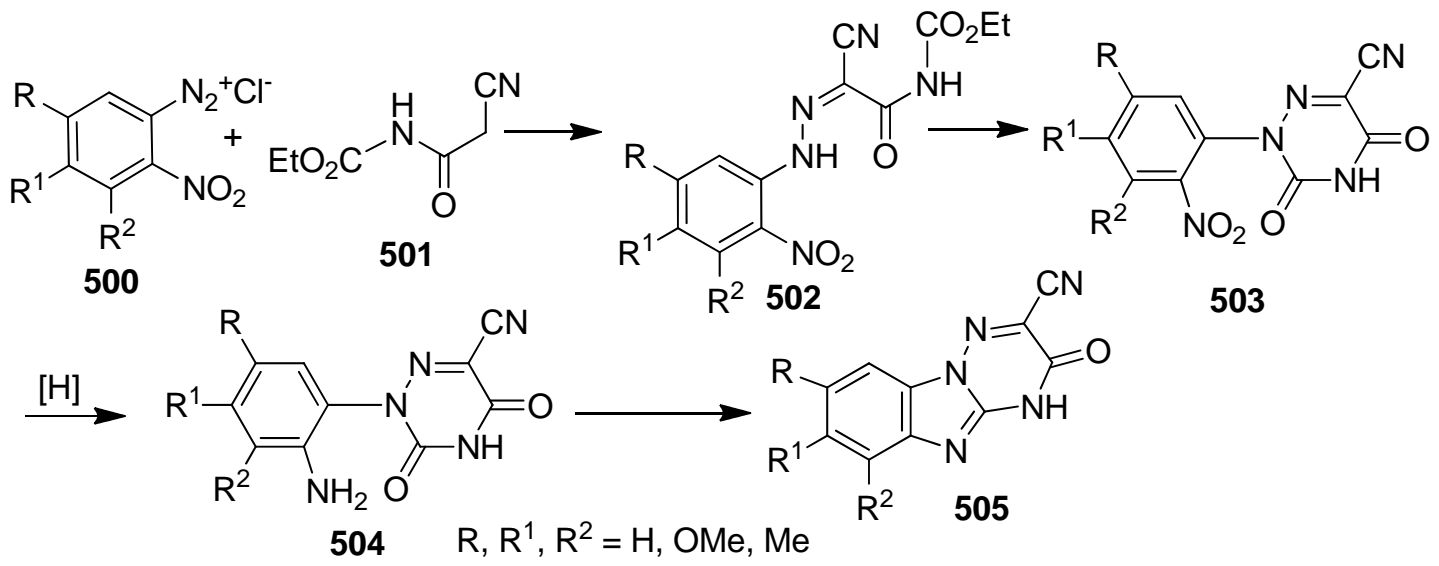

\section{Scheme 163}

Heating benzoylpyruvic acid $\mathbf{5 0 7}$ with 1-amino-2-( $N$-methylamino)benzimidazole 506 produced the 1,2,4-triazino[2,3-a]benzimidazole derivative 508 (Scheme 164). ${ }^{275}$

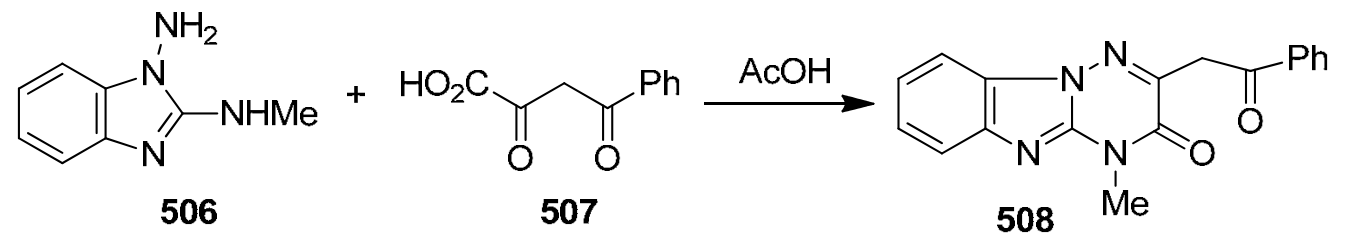

\section{Scheme 164}


Heating 2-chloro-1-phenacylbenzimidazole 158, in refluxing DMF, with aminoguanidine 509 or with hydrazine hydrate led to 3-phenyl-1,4-dihydro-1,2,4-triazino[4,3-a]benzimidazole 510 in 49 and $86 \%$ yields, respectively (Scheme 165). ${ }^{78}$<smiles>O=C(Cn1c(Cl)nc2ccccc21)c1ccccc1</smiles>

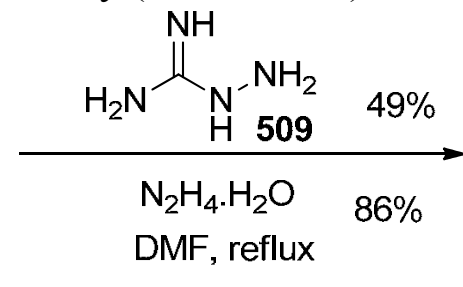<smiles></smiles>

\section{Scheme 165}

The reaction of 2-hydrazinobenzimidazoles 220 with diethyl 2-oxomalonate 511 and with $\alpha$ keto acids 513 in refluxing ethanol gave the corresponding 1,2,4-triazino[4,3-a]benzimidazol4(10H)-ones 412 and 514, respectively. ${ }^{276,277}$ Refluxing of 220 with diethyl oxalate in ethanol gave the 1,2,4-triazino[4,3-a]benzimidazole-3,4-dione 515 (Scheme 166). ${ }^{128}$

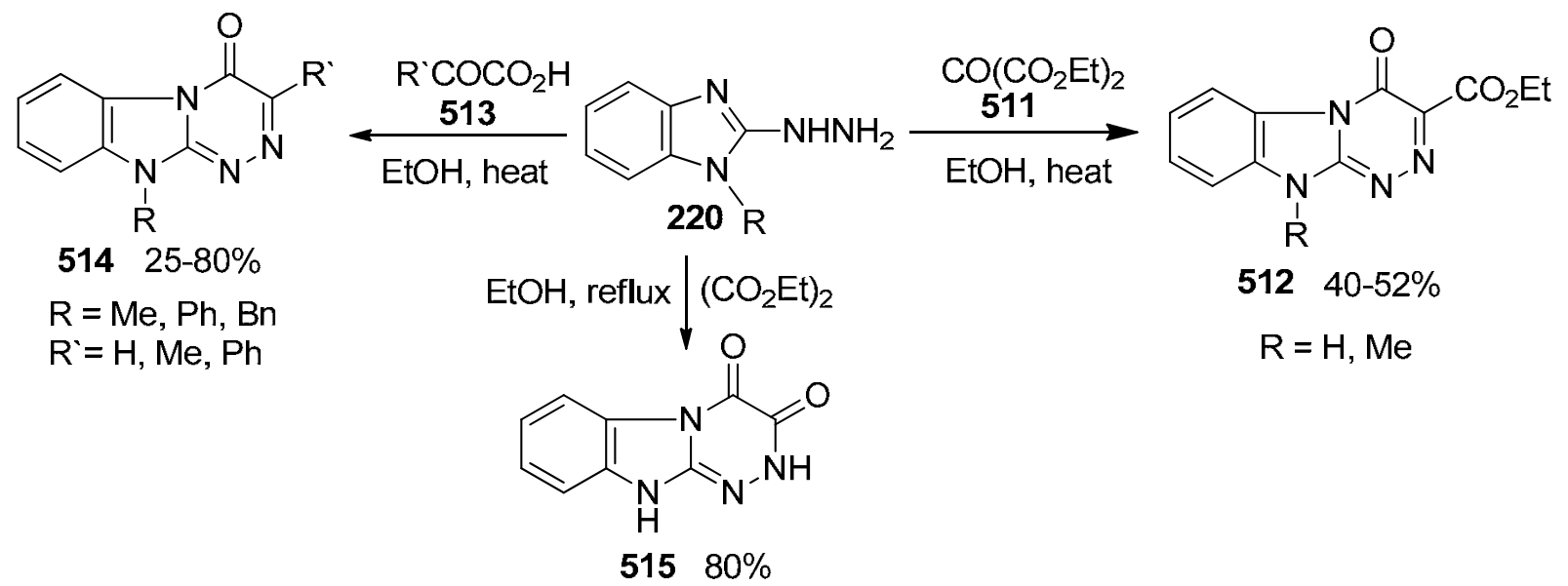

\section{Scheme 166}

Condensation of hydrazines with $N$-propargyl-2-chlorobenzimidazole 516 resulted in the formation of 1,2,4-triazino[4,3-a]benzimidazole derivatives 517 (Scheme 167). ${ }^{278}$

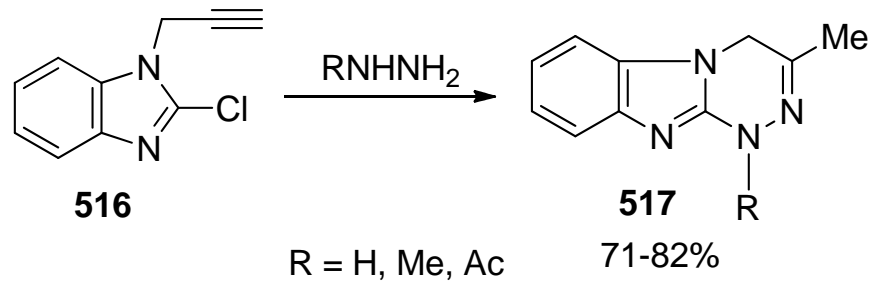

Scheme 167 
Heating benzimidazole-1-acetonitriles 518 and hydrazine in methanol gave 3-hydrazino1,2,4-triazino[4,3-a] benzimidazole 519 (Scheme 168). ${ }^{279,280}$

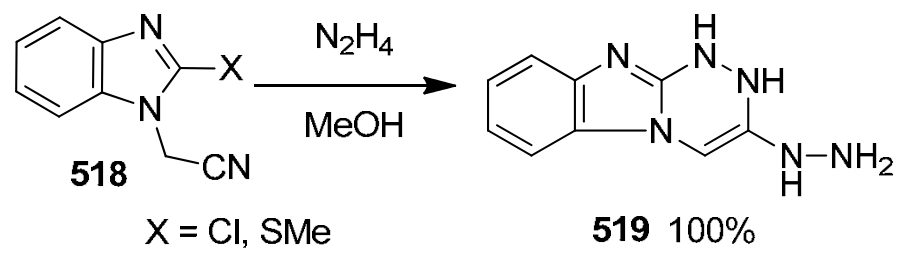

\section{Scheme 168}

\subsection{Thiazinobenzimidazoles}

Michael-type addition of 2-mercaptobenzimidazole 165 to ethyl propiolate in the presence of clay catalyst gave 4-oxothiazino[3,2-a]benzimidazole 520. ${ }^{281}$ Alkylation of 165 with epichlorohydrin 521 in aqueous base gave the thiazino[3,2-a]benzimidazole derivative $522{ }^{282}$ On the other hand, reaction of 2-mercaptobenzimidazole 165 with acryloyl chlorides 523 in pyridine and acetone afforded the $4 H$-[1,3]thiazino[3,2-a]benzimidazol-4-ones 524 (Scheme $169)^{283}$


$\mathrm{R}=\mathrm{H}, \mathrm{Me}$

Cl 521<smiles>O[C@H]1CSc2nc3ccccc3n2C1</smiles>

522

\section{Scheme 169}

Thiazino[3,2- $a$ ] benzimidazole derivatives 525 and $\mathbf{5 2 6}$ were prepared from the reaction of 2mercaptobenzimidazoles 165 with 3-chloropropanoic acid and 1,3-dibromopropane, respectively (Scheme 170). ${ }^{284,285}$<smiles>[R]1ccc2nc3n(c2c1)CCCS3</smiles>

525

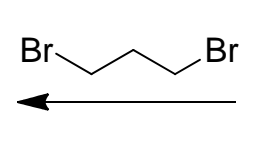

$\mathrm{R}=4-\mathrm{Me}, 6-\mathrm{Me}, 4-\mathrm{Cl}, 6-\mathrm{Br}$

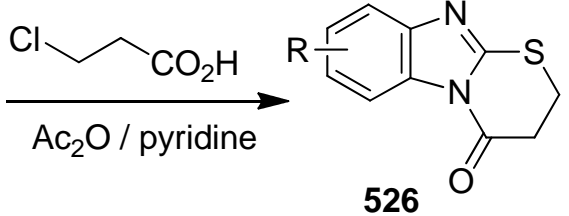

526

Scheme 170 
Bromination of 2-(allylthio)benzimidazoles 527 led to 2-[(2,3dibromopropyl)thio]benzimidazoles $\mathbf{5 2 8}$ which were converted into the thiazino[3,2a]benzimidazoles 529-531 in reasonable yields (Scheme 171). ${ }^{286,287}$

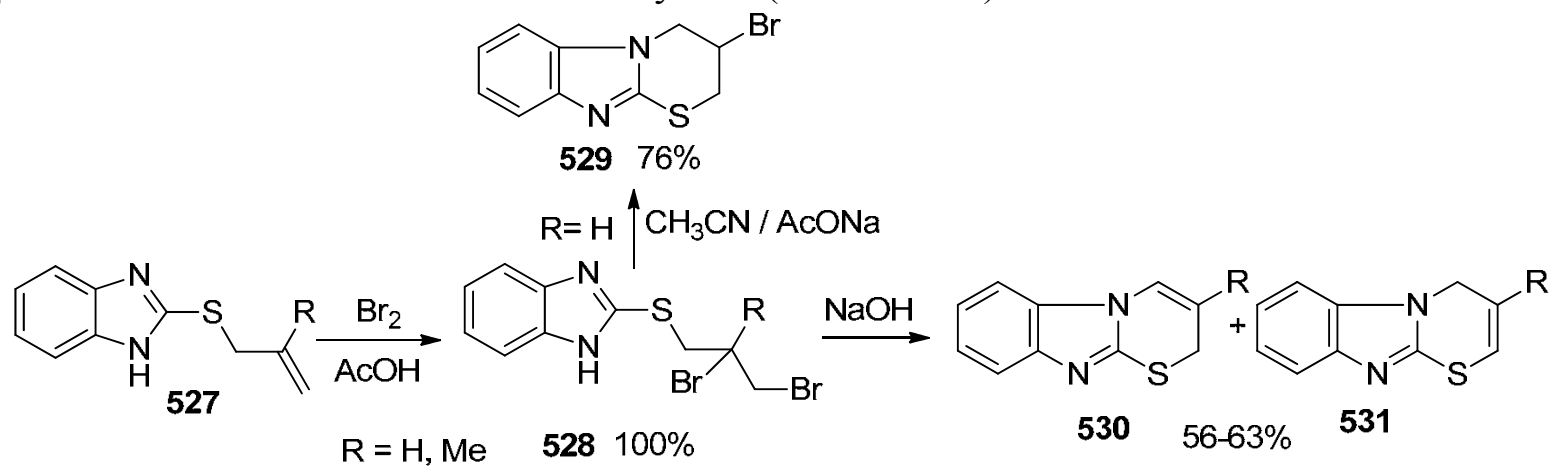

\section{Scheme 171}

Treatment of $1 H$-benzimidazol-2-ylmethanethiol 532 with tetracyanoethylene 380 gave 1cyanodihydrothiazino[4,3-a] benzimidazole-2-carboxamide 533 (Scheme 172). ${ }^{288}$

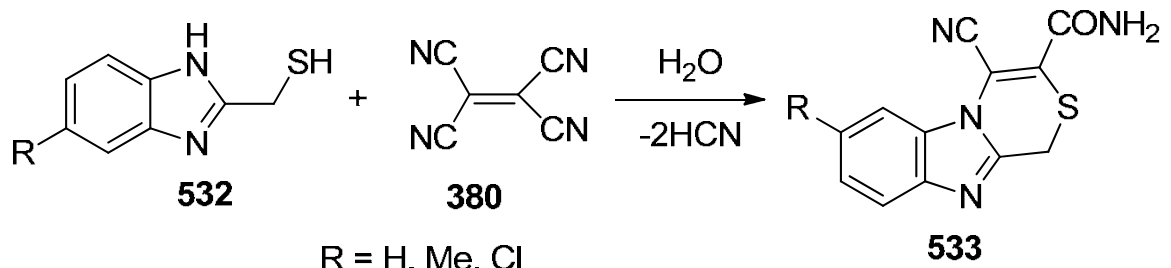

\section{Scheme 172}

Heating 2-mercaptobenzimidazoles 165 with acetylenedicarboxylate esters 257 under microwave irradiation gave a mixture of 4-oxothiazino[3,2-a]benzimidazole-2-carboxylates 534 and 535 (Scheme 173). ${ }^{289,290}$

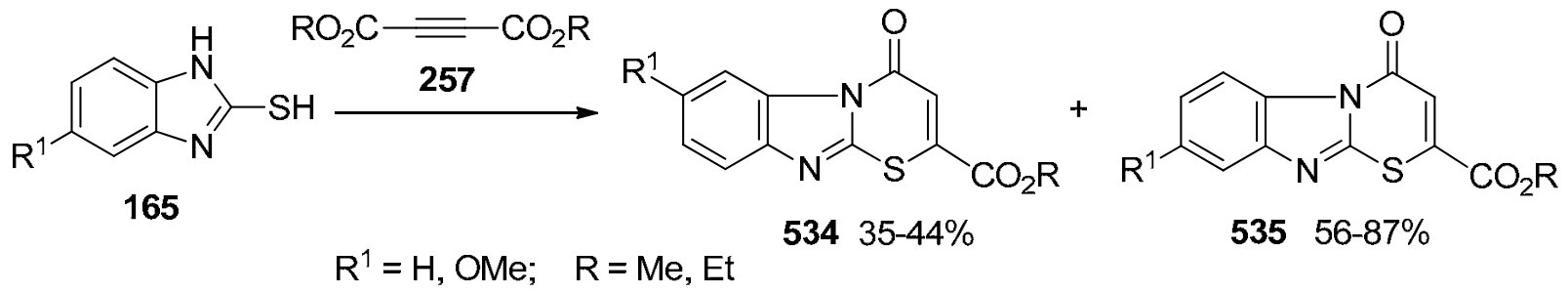

\section{Scheme 173}

Reaction of 3-methylthiazolo[3,2-a]benzimidazole 201 with two equivalents of methyl propiolate in refluxing acetonitrile gave the 1,4-thiazino[4,3-a]benzimidazole derivative 540 in reasonable yield and the mechanism of this reaction is depicted in Scheme 174. ${ }^{291}$ 


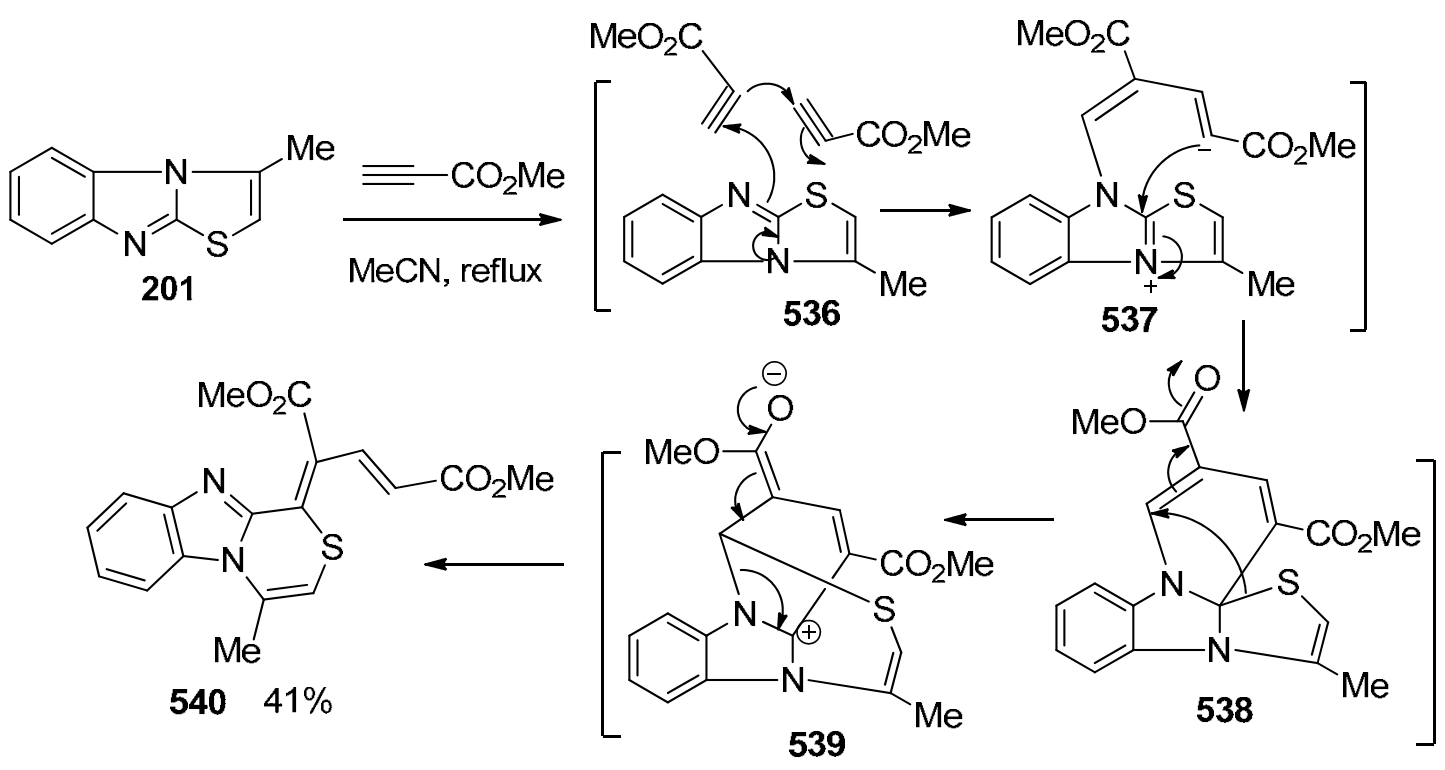

Scheme 174

\section{Synthesis of Azepino-fused-benzimidazoles}

\subsection{Azepinobenzimidazoles}

Treatment of 2-methylbenzimidazole 65 with ethyl 4-bromobutyrate in THF in the presence of $\mathrm{NaH}$ gave 1-(3-ethoxycarbonylpropyl)-2-methylbenzimidazole 541. Hydrolysis of the latter using $\mathrm{NaOH}$ followed by quaternization using alkyl halides gave the benzimidazolium salts $\mathbf{5 4 2}$. Treatment of the latter salts 542 with $N, N^{\prime}$-carbonyldiimidazole (CDI) in acetonitrile at room temperature followed by addition of $\mathrm{Et}_{3} \mathrm{~N}$ and heating the mixture at $70{ }^{\circ} \mathrm{C}$ gave $7,8,9,10$ tetrahydro-5H-azepino[1,2-a] benzimidazol-7-one derivatives 543 (Scheme 175). ${ }^{31,292}$

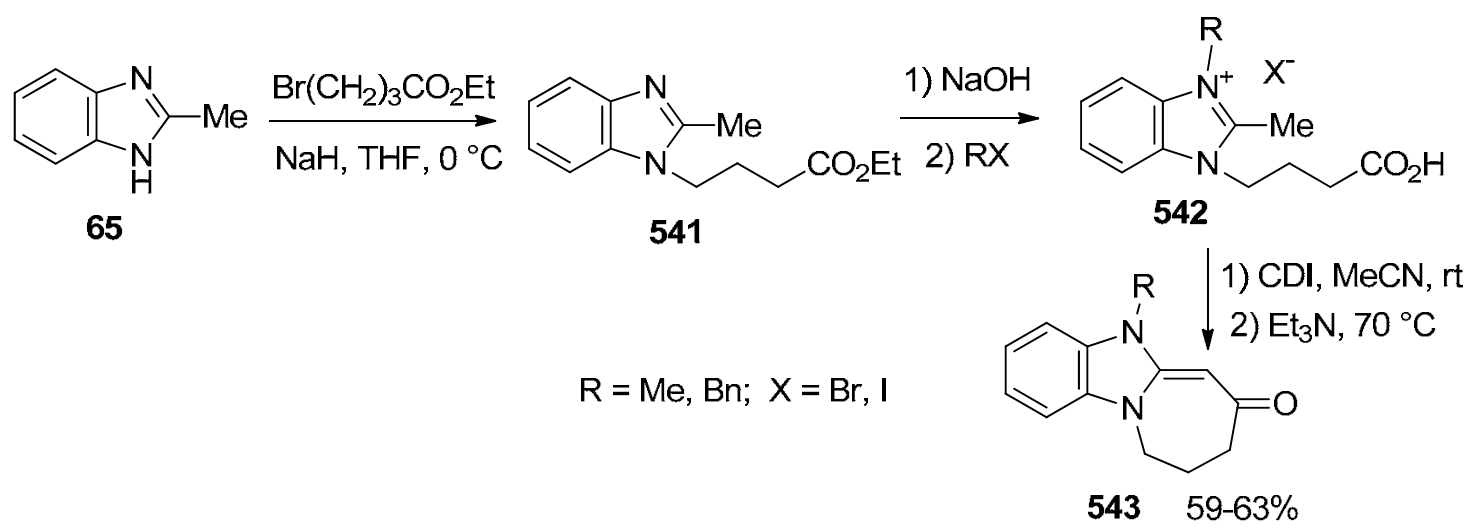

\section{Scheme 175}


$N$-(Haloaryl)amidines 544 underwent heterocyclization when heated in DMF in the presence of sodium methoxide to give the 7,8,9,10-tetrahydro- $6 H$-azepino[1,2-a]benzimidazole derivatives 545 in high yields (Scheme 176). ${ }^{25,293}$

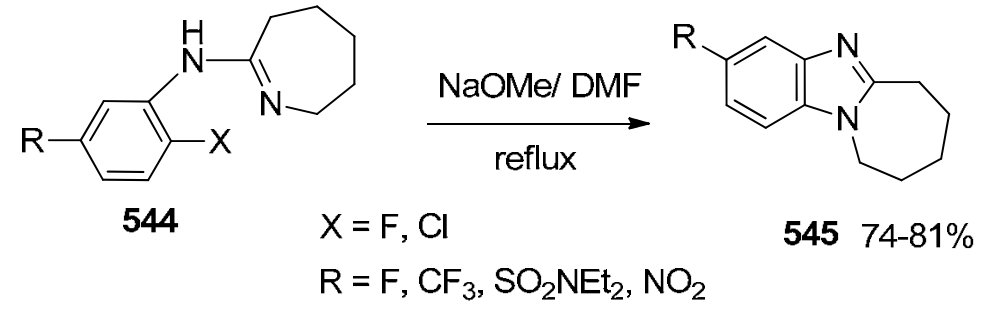

\section{Scheme 176}

3-Methoxy-7,8,9,10-tetrahydro-6H-azepino[1,2-a]benzimidazole 547 was prepared from the reaction of mixture of $\mathrm{N}$-(2-(azepan-1-yl)-5-methoxyphenyl)acetamide 546, formic acid and $\mathrm{H}_{2} \mathrm{O}_{2}$ at $40{ }^{\circ} \mathrm{C}$ as shown in Scheme $177 .{ }^{294}$

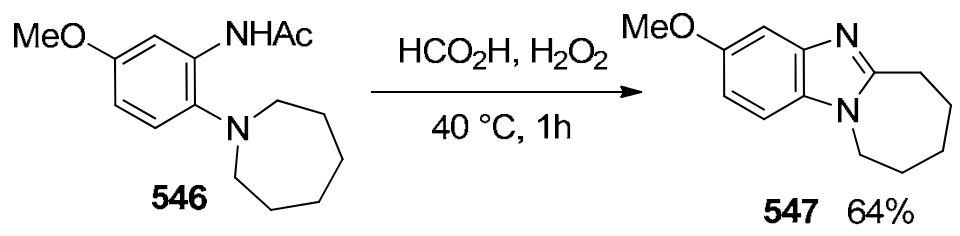

\section{Scheme 177}

Fusion of a mixture of $\gamma$-bromodipnone 549 and 1,2-dimethyl- $1 H$-benzimidazole 548 on an oil bath at $110{ }^{\circ} \mathrm{C}$ for $30 \mathrm{~min}$ afforded 11 -methyl-7,9-diphenyl-6H,11H-azepino[1,2- $a$ ]-5benzimidazolium bromide 550 in reasonable yield (Scheme 178). ${ }^{295}$

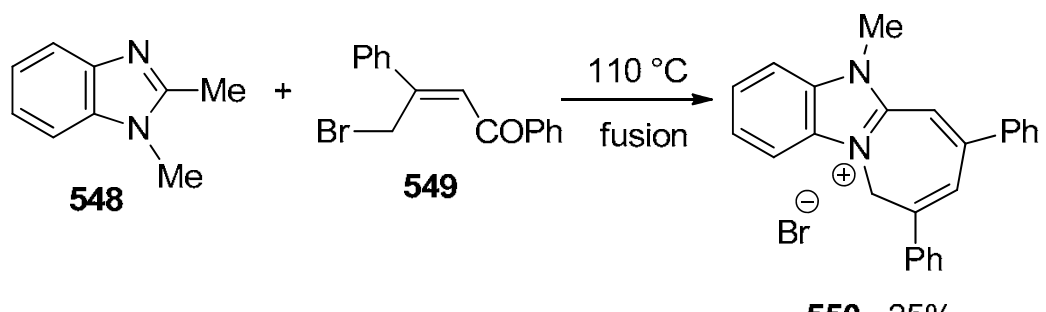

$55025 \%$

\section{Scheme 178}

Treatment of 1H-2-phenylthiobenzimidazole 551 with $\mathrm{NaH}$ in THF followed by adding 5iodo-1-(phenylselenyl)pentane 552 under reflux gave 1-[5-(phenylselenyl)pentyl]-2(phenylthio)-1H-benzimidazole 553. Refluxing the latter 553 in toluene using $\mathrm{Bu}_{3} \mathrm{SnH}$ and $\mathrm{AIBN}$ 
resulted in an intramolecular radical substitution of the intermediate 554 to give the 7,8,9,10tetrahydro-6H-azepino[1,2-a]benzimidazole 555 in low yield (Scheme 179). ${ }^{296}$

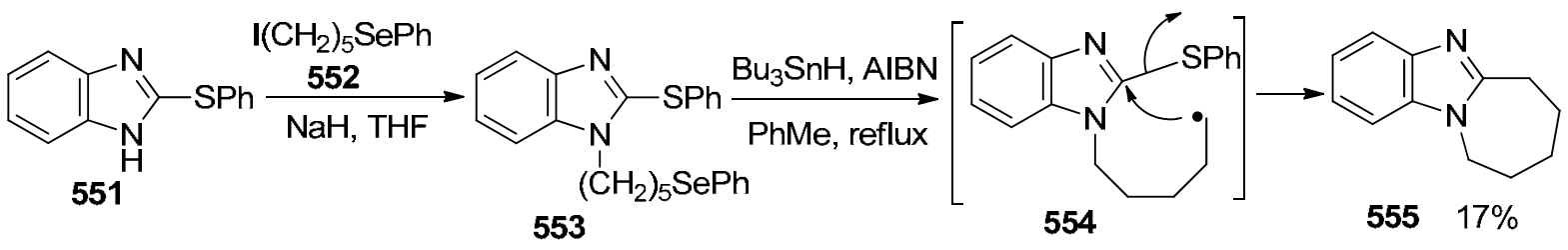

\section{Scheme 179}

The tetrahydro- $6 H$-azepino[1,2- $a$ ] benzimidazole 555 was alternatively synthesized in a good yield by lithiation of either the $N$-alkylated $1 H$-benzimidazole 556 or 2-methylbenzimidazole 557 using lithium diisopropylamide (LDA) in THF at $-78{ }^{\circ} \mathrm{C}$ (Scheme 180). ${ }^{297}$

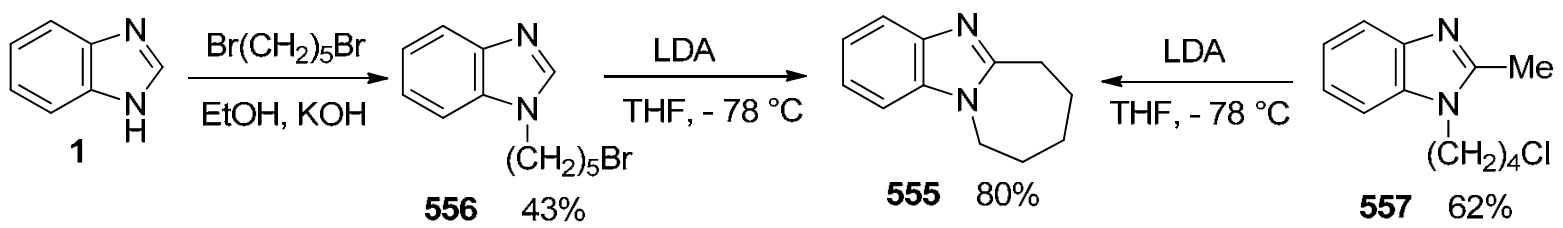

\section{Scheme 180}

Rhodium-catalysed reactions of $N$-(4-methylpent-4-enyl)-1,2-diaminobenzene 558 with hydrogen and carbon monoxide gave the 7,8,9,10-tetrahydro-7-methyl-6H-azepino[1,2a]benzimidazole 561 in good yield. This product arised from initial highly regioselective aldehyde formation at the terminal carbon atom followed by cyclisation with subsequent oxidation to the benzimidazole 561 (Scheme 181). ${ }^{298,299}$

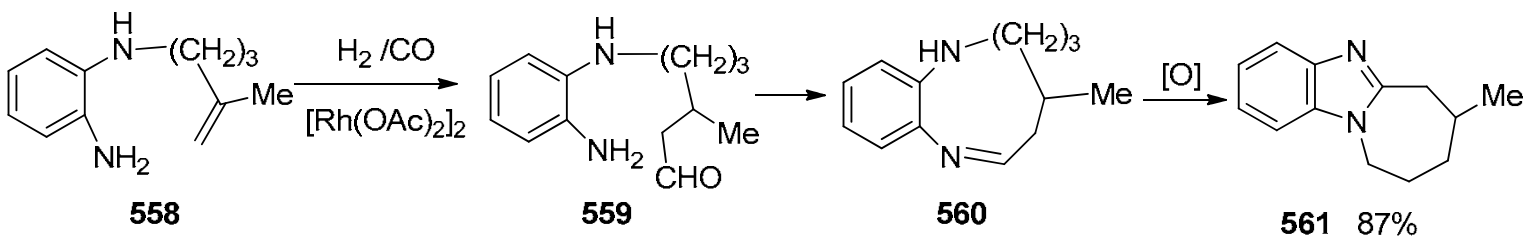

\section{Scheme 181}

\subsection{Diazepinobenzimidazoles}

Reaction of 2-( $\omega$-aminopropyl)benzimidazole 562 with carbon disulfide in alkaline ethanol gave the 1,3-diazepino[3,4-a]benzimidazole-2-thione 563 which on treatment with methyl iodide gave the 2-methylthio derivative 564 (Scheme 182). ${ }^{300}$ 


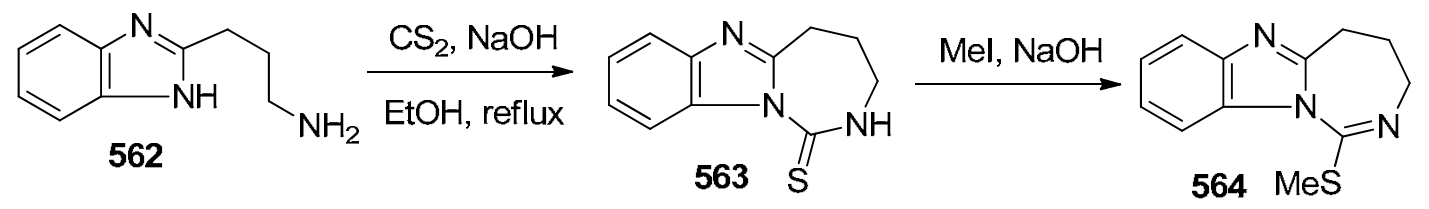

\section{Scheme 182}

\subsection{Triazepinobenzimidazoles}

Heating a mixture 1,2-diaminobenzimidazole 462 and 1,3-diketones 565 in polyphosphoric acid (PPA) at $110-115{ }^{\circ} \mathrm{C}$ or in the presence of $\mathrm{ZnCl}_{2}$ at $240-250{ }^{\circ} \mathrm{C}$ gave the corresponding 1,2,4triazepino[2,3-a] benzimidazole derivatives $\mathbf{5 6 6}$ in good yields (Scheme 183). ${ }^{301}$

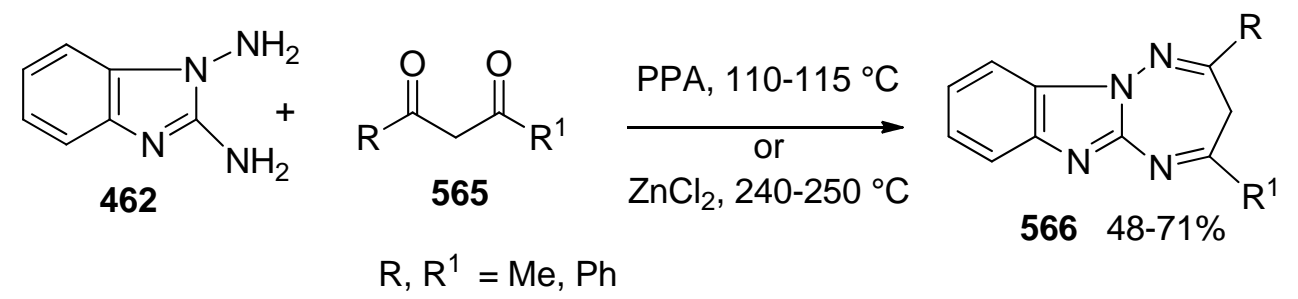

\section{Scheme 183}

When 1,2-diaminobenzimidazole 462 was treated with $\beta$-ketoesters 567 under reflux condition either in acetic acid or without solvent it gave the corresponding 1,2,4-triazepino[2,3a] benzimidazol-4-ones 568 (Scheme 184). ${ }^{53,301-303}$

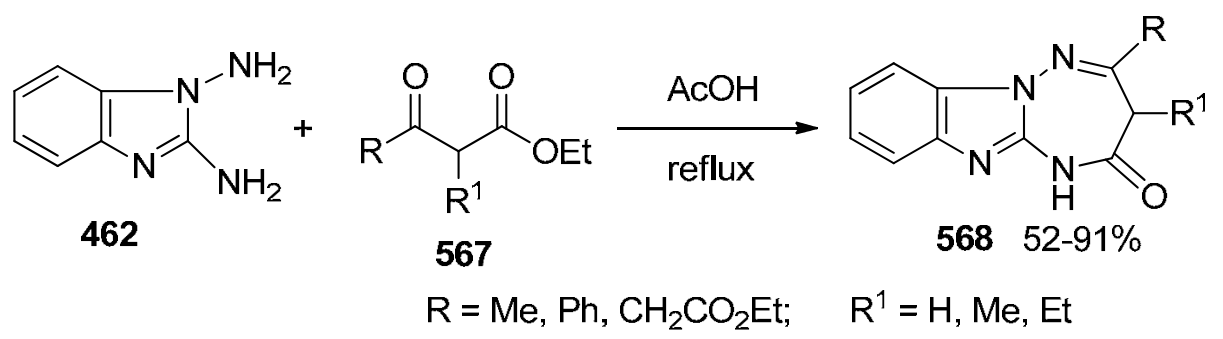

\section{Scheme 184}

2-Chlorobenzimidazole 47 was condensed with $\beta$-bromoketones 569 to give 1-(2benzoylethyl)-2-chlorobenzimidazoles $\mathbf{5 7 0}$ which cyclized with hydrazines to give the corresponding 1,2,4-triazepino[4,3-a] benzimidazoles 571 (Scheme 185). ${ }^{304}$ 


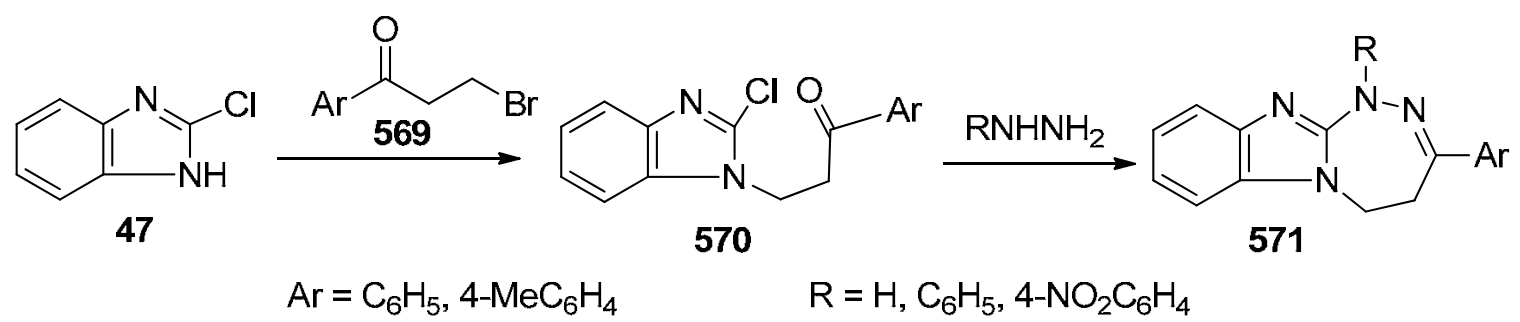

\section{Scheme 185}

Reaction of 2-(benzylhydrazino)benzimidazole 572 with 4-phenyl-3-butyn-2-one 573 in DMF in the presence of $\mathrm{Et}_{3} \mathrm{~N}$ gave $73 \%$ of 1-benzyl-3-methyl-5-phenyl-1,2,4-triazepino[4,3a]benzimidazole 574 (Scheme 186). ${ }^{305}$

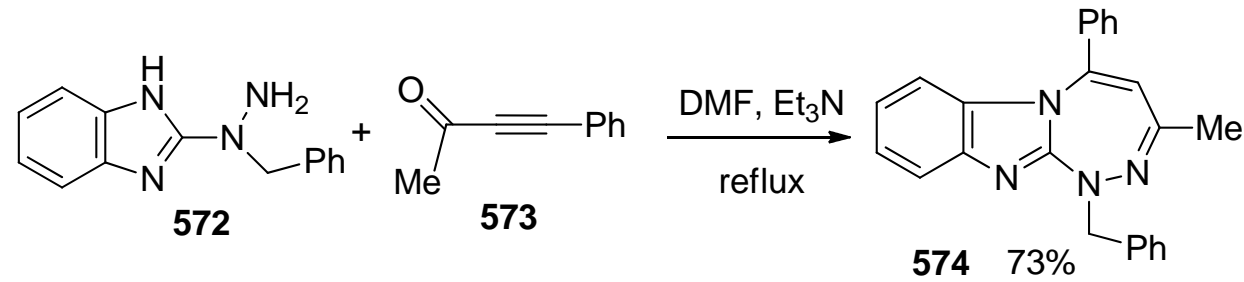

\section{Scheme 186}

Reaction of 2-hydrazonobenzimidazole 575 with tetracyanoethylene (TCNE) $\mathbf{3 8 0}$ gave the 1,2,4-triazepino[4,3-a] benzimidazole derivatives 576 (Scheme 187). ${ }^{306}$

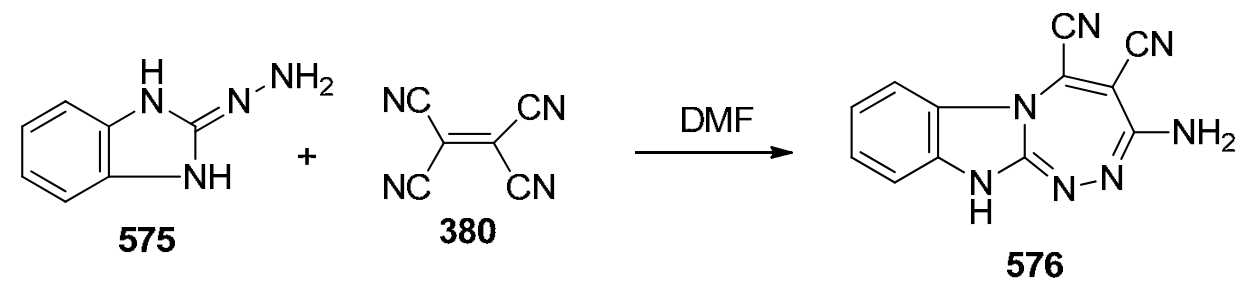

\section{Scheme 187}

\subsection{Thiazepinobenzimidazoles}

Reaction of 2-mercaptobenzimidazole 165 with two equivalents of tetracyanoethylene $\mathbf{3 8 0}$ in ethyl acetate at room temperature gave the 1,3-thiazepino[3,2-a]benzimidazole derivative 577 in low yield (Scheme 188). ${ }^{307}$ 


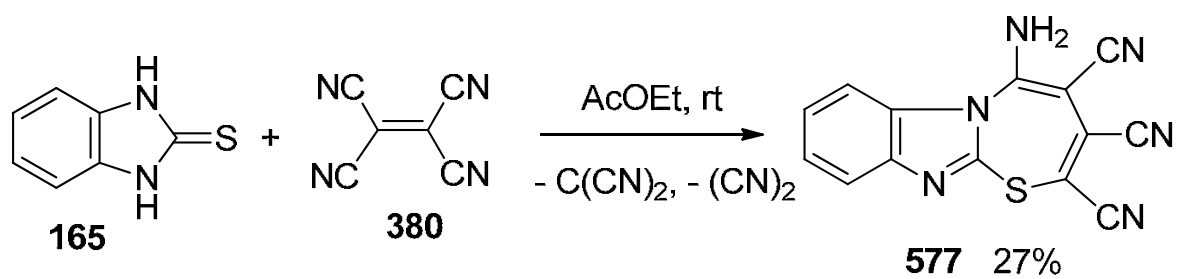

\section{Scheme 188}

\section{References}

1. Islam, I.; Skibo, E. B. J. Med. Chem. 1991, 34, 2954.

2. Zhou, R.; Skibo, E. B. J. Med. Chem. 1996, 39, 4321.

3. Skibo, E. B.; Gordon, S.; Bess, L.; Boruah, R.; Heileman, M. J. J. Med. Chem. 1997, 40, 1327.

4. Craigo, W. A.; LeSueur, B.W.; Skibo, E. B. J. Med. Chem. 1999, 42, 3324.

5. Huang, X.; Suleman, A.; Skibo, E. B. Bioorg. Chem. 2000, $28,324$.

6. (a) Grimaudo, S.; Raimondi, M. V.; Capone, F.; Chimirri, A.; Poretto, F.; Monforte, A. M.; Simoni, D.; Tolomeo, M. Eur. J. Cancer 2001, 37, 122. (b) Grimaudo, S.; Tolomeo, M.; Chimirri, A.; Zappala, M.; Gancitano, R. A.; Alessandro, N. D. Eur. J. Cancer 1998, 34, 1756. (c) Maryanoff, B. E.; McComsey, D. F.; Ho, W.; Shank, R. P. Bioorg. Med. Chem. Lett. 1996, 6, 333.

7. (a) Demirayak, S.; Kayagil, I.; Yurttas, Y. Eur. J. Med. Chem. 2011, 46, 411. (b) Fu, R.; You, Q.; Yang, L.; Wu, W.; Jiang, C.; Xu, X. Bioorg. Med. Chem. 2010, 18, 8035. (c) Ishida, J.; Wang, H-K.; Bastow, K.F.; Huand, C. Q.; Lee, K. H. Bioorg. Med. Chem. Lett. 1999, 9, 3319.

8. (a) Hranjec, M.; Pavlović, G.; Marjanović, M.; Kralj, M.; Zamola, G. K. Eur. J. Med. Chem. 2010, 45, 2405. (b) Dupuy, M.; Pinguet, F.; Chavignon, O.; Chezal, J-M.; Teulade, J-C.; Chapat, J-P.; Blache, Y.Chem. Pharm. Bull. 2001, 49, 1061. (c) Chiba, T.; Shigeta, S.; Numazaki, Y. Biol. Pharm. Bull. 1995, 18, 1081. (d) El-Hawash, S. A. M.; Badawey, E- S. A. M.; Kappe, T. Pharmazie 1999, 54, 341.

9. Ho, W.; Maryanoff, B. E.; McComsey, D. F.; Nortey, S. O. US 5521200, 1996; Chem. Abstr. 1996, 125, 114628r.

10. Reitz, A. B.; Fitzpatrick, L. J.; Jordan, A. D.; Sanfilippo, P. J. US PCT Int. Appl. WO 9900389, 1999; Chem. Abstr. 1999, 130, 95551v.

11. Reitz, A. B.; Jordan, A. D.; Sanfilippo, P. J.; Pauline, J.; Scott, M. K.; Smith, A. V. US 5817668, 1998; Chem. Abstr. 1998, 129, 290133s.

12. Maryanoff, B. E.; Nortey, S. O.; McNally, J. J.; Sanfilippo, P. J.; McComsey, D. F.; Dubinky, B.; Shank, R. P.; Reitz, A. B. Bioorg. Med. Chem. Lett. 1999, 9, 1547. 
13. Jordan, A. D.; Vaidya, A. H.; Rosenthal, D. I.; Dubinsky, B.; Kordik, C. P.; Sanfilippo, P. J.; Wu, W-N.; Reitz, A. B. Bioorg. Med. Chem. Lett. 2002, 12, 2381.

14. Goto, K. Jpn. Kokai Tokkyo Koho, JP 03215488, 1992; Chem. Abstr. 1992, 116, 128962w.

15. Settimo, F. D.; Primofiore, G.; Settimo, A. D.; Mottta, C. L.; Taliani, S.; Simorini, F.; Novellino, E.; Greco, G.; Lavecchia, A.; Boldrini, E. J. Med. Chem. 2001, 44, 4359.

16. Gulyas, G.; Emri, T.; Simon, A.; Gyorgydeak, Z. Folia Microbiol. 2002, 47, 29; Chem. Abstr. 2002, 136, 337623p.

17. Dawood, K.M.; Abdel-Wahab, B. F. Arkivoc 2010, (i), 333.

18. Plenkiewicz, J.; Mazurek, A. Pol. Pat 194479, 2007; Chem. Abstr. 2008, 148, 495939.

19. Wang, B.; Hu, J.; Zhang, X.; Hu, Y.; Hu, H. J. Heterocycl. Chem. 2000, 37, 1533.

20. Georgescu, E. I.; Georgescu, F.; Roibu, C.; Iuhas, P. C.; Draghici, C. C.; Caproiu, M. T. Rev. Roum. Chim. 2002, 47, 885.

21. Tkachenko, P. V.; Popov, I. I.; Simonov, A. M.; Medvedev, Yu. V. Chem. Heterocycl. Compd. 1976, 12, 805.

22. Tomilov, Y. V.; Platonov, D. N.; Frumkin, A. E.; Lipilin, D. L.; Salikov, R. F. Tetrahedron Lett. 2010, 51, 5120.

23. Anisimova, V. A.; Spasov, A. A.; Bocharova, I. A.; Ostrovskii, V.; Panchenko, T. I.; Dudchenko, G. P. Pharm. Chem. J. 1996, 30, 22.

24. Tan, K. L.; Vasudevan, A.; Bergman, R. G.; Ellman, J. A.; Souers, A. J. Org. Lett. 2003, $5,2131$.

25. Nazarenko, K. G.; Shyrokaya, T. I.; Tolmachev, K. V. S. Synth. Commun. 2003, 33, 4303.

26. Normand, A. T.; Yen, S. K.; Huynh, H. V.; Hor, T. S. A.; Cavell, K. J. Organometallics 2008, 27, 3153 .

27. Lee, C.-H.; Baik, H.-J.; Kim, K.-J.; Cho, K.-U.; Oh, K. T. J. Korean Chem. Soc. 1995, 39, 408.

28. Edowaado, Bii Sukibo; Imadaru, Isuramu. Jpn. Kokai Tokkyo Koho JP 05112570, 1993; Chem. Abstr. 1993, 119, 180786.

29. Islam, I.; Skibo, E. B. J. Org. Chem. 1990, 55, 3195.

30. Volovenko, Y. M.; Resnyanska, E. V.; Tverdokhlebov, A. V. Collect. Czech. Chem. Commun. 2002, 67, 365.

31. Ohta, S.; Narita, Y.; Yuasa, T.; Hatakeyama, S.; Kobayashi, M.; Kaibe, K.; Kawasaki, N; Yamashita, M. Chem. Pharm. Bull. 1991, 39, 2787.

32. Balasubramaniyan, V.; Balasubramaniyan, P.; Patil, S. V. Indian J. Chem. 1990, 29B, 124.

33. Tatevosyan, G. T.; Esayan, Z. V. USSR SU 449054, 1974; Chem. Abstr. 1975, 82, 57699.

34. Kuz'menko, T. A.; Kuz'menko, V. V.; Anisimova, V. A. Zh. Org. Khim. 1996, 32, 114; Chem. Abstr. 1996, 125, 300891. 
35. Tanaka, M.; Ubukata, M.; Matsuo, T.; Yasue, K.; Matsumoto, K.; Kajimoto, Y.; Ogo, T.; Inaba, T. Org. Lett. 2007, 9, 3331.

36. Gagosz, F.; Zard, S. Z. Org. Lett. 2002, 4, 4345.

37. Fang, X.; Wu, Y. M.; Dengand, J.; Wang, S. W. Tetrahedron 2004, 60, 5487.

38. Wu, K.; Chen, Q-Y. Synthesis 2003, 35.

39. Ibrahim, H. K.; El-Tamany, S. H.; El-Shaarawy, R. F.; El-Deen, I. M. Macedonian J. Chem. Chem. Eng. 2008, 27, 65.

40. Elwan, N. M. Tetrahedron 2004, 60, 1161.

41. Awadallah, Ad. M.; Seppelt, K.; Shorafa, H. Tetrahedron 2006, 62, 7744.

42. Langer, P.; Wuckelt, J.; Doering, M.; Goerls, H. J. Org. Chem. 2000, 65, 3603.

43. Peter, L.; Manfred, D. Synlett 1998, 399.

44. Shen, Z.; Wang, B.; Shen, Y.; Zhou, Y.; Shen, J.; Hu, H. Nanjing Shida Xuebao, Ziran Kexueban 2005, 28, 55; Chem. Abstr. 2005, 145, 377257.

45. Popov, I. I. Chem. Heterocycl. Compd. 1996, 32, 672.

46. O'Shaughnessy, J.; Cunningham, D.; Kavanagh, P.; Leech, D.; McArdle, P.; Aldabbagh, F. Synlett 2004, 2382.

47. Kuz'menko, T. A.; Kuz'menko, V. V.; Pozharskii, A. F.; Kryshtalyuk, O. V.; Aleksandrov, G. G. Chem. Heterocycl. Compd. 1992, $28,167$.

48. Kuz'menko, V. V.; Komissarov, V. N.; Simonov, A. M. Chem. Heterocycl. Compd. 1980, 634.

49. Kuz'menko, T. A.; Kuz'menko, V. V.; Simonov, A. M. Chem. Heterocycl. Compd. 1988, 36.

50. Kuzmenko, T. A.; Kuzmenko, V.V.; Anisimova, V. A. Russ. J. Org. Chem. 2004, 40, 221.

51. Crawley, M. W., PCT Int. Appl. WO 9101984, 1991; Chem. Abstr. 1992, 116, 95570.

52. Kuz'menko, T. A.; Kuz'menko, V. V.; Kryshtalyuk, O. V.; Pozharskii, A. F. Chem. Heterocycl. Compd. 1992, 28, 1461.

53. Romano, C.; De la Cuesta, E.; Avendano, C. J. Org. Chem. 1991, 56, 74.

54. Kluge, R.; Schulz, M.; Pobisova, M.; Nuechter, M. Chem. Ber. 1994, 127, 1729.

55. Wilde, H.; Hauptmann, S.; Ostermann, G.; Mann, G. J. Prakt.Chem. 1984, 326, 829.

56. Khan, M. I. A.; Ribeiro, V. L. T. Monatsh. Chem. 1983, 114, 425.

57. Clark, B. A. J.; McNab, H.; Sommerville, C. C. Chem. Commun., 1996, 1211.

58. Carra, C.; Bally, T.; Albini, A. J. Am. Chem. Soc., 2005, 127, 5552.

59. Crawley, M. W.; Gibson, A. W.; Williamson, H. M. PCT Int. Appl. WO 9200299, 1992; Chem. Abstr. 1992, 116, 237378.

60. El-Din, N. S. Zagazig J. Pharm. Sci. 1995, 4, 198.

61. Insuasty, B.; Fernadez, F.; Quiroga, J.; Martinez, R.; Gavino, R.; Angeles, E. Heterocycl. Commun. 2002, 8, 151.

62. Trapani, G.; Franco, M.; Latrofa, A.; Genchi, G.; Lacobazzi, V.; Ghiani, C. A.; Maciocco, E.; Liso, G. Eur. J. Med. Chem. 1997, 32, 83. 
63. Anisimova, V. A.; Lukova, O. A. Chem. Heterocycl. Compd. 1994, 3, 369.

64. Mas, T.; laramunt, R.; Santa Maria, M. D.; Sanz, D.; Alarcon, S. H.; Perez-Torralba, M.; Elguero, J. Arkivoc 2002, (v), 48.

65. Hamdy, N. A.; Gamal-Eldeen, A. M.; Abdel-Aziz, H. A.; Fakhr, I. M. I. Eur. J. Med. Chem. 2010, 45, 463.

66. Dawood, K. M.; Ragab, E. A.; Farag, A. M. J. Chem. Res. 2009, 630.

67. Döpp, D.; Orlewska, C.; Saczewski, F. J. Heterocycl. Chem. 1993, 30, 833.

68. Langer, P.; Wuckelt, J.; Döring, M.; Schreiner, P. R.; Görls, H. Eur. J. Org. Chem. 2001, 2245.

69. Han, X.; Pin, S. S.; Burris, K.; Fung, L. K.; Huang, S.; Taber, M. T.; Zhang, J.; Dubowchik, G. M. Bioorg. Med. Chem. Lett. 2005, 15, 4029.

70. Farag, A. M.; Dawood, K. M. Heteroatom Chem. 1997, 8, 129.

71. Molina, P.; Alajarin, M.; Lopez-Leonardo, C.; Madrid, I.; Foces-Foces, C.; Cano, F. H. Tetrahedron, 1989, 45, 1823.

72. Kumar, A.; Kumar, S.; Kumar, D.; Gupta, R. K., J. Chem. Res., (S) 2007, 519.

73. Soni, R. P. J. Prakt. Chem., 1981, 323, 516.

74. Martineau, A.; Dejongh, D. C. J. Anal. Appl. Pyrolysis 1983, 5, 39.

75. Abramova, N. D.; Andriyankova, L. V.; Skvortsov, Yu. M.; Mal'kina, A. G.; Skvortsova, G. G. Izv. Akad. Nauk SSSR, Ser. Khim. 1987, 197; Chem. Abstr. 1987, 107, 236597.

76. Wahe, H.; Asobe, P. F.; Cherkasova, R. A.; Fomun, Z. T.; Doepp, D. Arkivoc 2004, (i), 130.

77. Trofimov, B. A.; Andriyankova, L. V.; Mal'kina, A. G.; Belyaeva, K. V.; Nikitina, L. P.; Dyachenko, O. A.; Kazheva, O. N.; Chekhlov, A. N.; Shilov, G. V.; Afonin, A. V.; Ushakov, I. A.; Baikalova, L. V. Eur. J. Org. Chem. 2007, 1018.

78. Povstyanoi, M. V.; Kruglenko, V. P.; Povstyanoi, V. M. Chem. Heterocycl. Compd. 2001, 37, 1179 .

79. Katritzky, A. R.; Aslan, D. C.; Leeming P.; Steel, P. J. Tetrahedron: Asymmetry 1997, 8, 1491.

80. Katritzky, A. R.; Aslan, D. C.; Oniciu, D. C. Tetrahedron: Asymmetry 1998, 9, 2245.

81. Chimirri, A.; Monforte, P.; Rao, A.; Zappala, M.; Monforte, A. M.; De Sarro, G.; Pannecouque, C.; Witvrouw, M.; Balzarini, J.; De Clercq, E. Antivir. Chem. Chemother. 2001, 12, 169.

82. Abdel-Mohdy, F; A.; Abdelhamid, A. O. Arch. Pharm. Res. 1992, 15, 9.

83. Abdelhamid, A. O; Attaby, F. A. J. Heterocycl. Chem. 1991, $28,41$.

84. Abdelhamid, A. O.; Metwally, N. H.; Bishai, N. S. J. Chem. Res. (S) 2000, 462.

85. Dawood, K. M.; Raslan, A. M.; Farag, A. M. Synth. Commun. 2003, 33, 4079.

86. Shawali, A. S.; Abdallah, M. A.; Zayed, M. E. M. J. Chin. Chem. Soc. 2002, 49, 1035.

87. Bentarzi, Y.; Nedjar-Kolli, B.; Plas, A.; Chalard, P.; Troin, Y. Arkivoc 2010, (x), 328.

88. Chimirri, A.; Grasso, S.; Monforte, A. M.; Monforte, P.; Zappala, M. Farmaco 1991, 46, 817. 
89. Porretta, G. C.; Biava, M.; Fioravanti, R.; Fischetti, M.; Melino, C.; Venza, F. Farmaco $1991,46,913$.

90. Chimirri, A.; Grasso, S.; Monforte, A. M.; Monforte, P.; Rao, A.; Zappalà, M.; Bruno, G.; Nicolò, F.; Pannecouque, C.; Witvrouw, M.; De Clercq, E. Antivir. Chem. Chemother. 1998, 9, 431.

91. Rao, A.; Chimirri, A.; Ferro, S.; Monforte, A. M.; Monforte, P.; Zappalà, M. Arkivoc 2004, (v), 147.

92. Pozarentzi, M.; Stephanatou, J. S.; Tsoleridis, C. A.; Zika, C.; Demopoulos, V. Tetrahedron 2009, 65, 7741.

93. El-Shorbagi, A. A.; Hayallah, A. A.; Omar, N. M.; Ahmed, A. N. Bull. Pharm. Sci., Assiut Uni. 2001, 24, 7; Chem. Abstr. 2001, 136, 151102.

94. Mohan, J.; Anjaneyulu, G. S. R. Indian J. Chem. 1989, 28B, 631.

95. Bercin, E.; Eroglu, Y.; Noyanalpan, N. J. Fac. Pharm. Gazi Univ. 1993, 10, 93; Chem. Abstr. 1994, 121, 179548.

96. Bercin, E.; Eroglu, Y.; Cakir, B. J. Fac. Pharm. Gazi Univ. 1993, 10, 25; Chem. Abstr. 1994, 121, 9244.

97. Narayan, S.; Kumar, V.; Pujary, H.K. Indian J. Chem. 1986, 25B, 267.

98. Daboun, H. A.; Abdel Fattah, A. S. M.; Abdel Aziz, M. A. Egypt. J. Chem. 1984, 27, 435.

99. Mavrova, A. Ts.; Anichina, K. K.; Vuchev, D. I.; Tsenov, J. A.; Denkova, P. S.; Kondeva, M. S.; Micheva, M. K. Eur. J. Med. Chem. 2006, 41, 1412.

100. Mavrova, A.; Anichina, K.; Vuchev, D. J. Uni. Chem. Tech. Metall. 2003, 38, 251; Chem. Abstr. 2004, 141, 307028.

101. Sahu, M.; Sahu, J. K.; Nayak, A. Indian J. Chem. 1986, 25B, 126.

102. Hirpara, K.; Patel, S.; Joshi, A.; Parekh, H. Indian J. Heterocycl. Chem. 2004, 13, 221.

103. Dahiya, R.; Pujari, H. K. J. Fluorine Chem. 1989, 42, 245.

104. Crossley, R. US 4873237, 1989; Chem. Abstr. 1990, 112, 198401.

105. Crossley, R.; Meade, P J. US 4725605, 1988; Chem. Abstr. 1988, 109, 211051.

106. Crossley, R.; Meade, P. J. Eur. Pat. Appl. EP 129409, 1984; Chem. Abstr.,1985, 103, 6337.

107. Park, Y. J.; Suh, K. H.; Kang, E. C.; Yoon, H. S.; Kim, Y. H.; Kang, D. P.; Chang, M. S. Korean J. Med. Chem., 1993, 3, 124.

108. Oh, Ch.-H.; Ham, Y.-W.; Hong, S.-Y.; Cho, J.-H. Arch. Pharm. 1995, 328, 289.

109. Dianov, V. M.; Sibiryak, S. V.; Sadykov, R. F.; Strokin, Y. V.; Khaibullina, S. F. Khim. Farm. Zhur. 1991, 25, 40; Chem. Abstr. 1991, 115, 29202.

110. Hayashibe, S.; Kamikubo, T.; Tsukamoto, S.; Sakamoto, S. Heterocycles 2004, 62, 815.

111. Korotkikh, N. I.; Aslanov, A. F.; Raenko, G. F.; Shvaika, O. P. Russ. J. Org. Chem. 1999, 35,730 .

112. Lee, K. J.; Jeong, J. U.; Choi, D. O.; Kim, S. H.; Kim, S.; Park, H. Bull. Korean Chem. Soc. 1991, 12, 360. 
113. Chimirri, A.; Grasso, S.; Ottana, R.; Romeo, G.; Valle, G.; Zappala, M. Heterocycles 1987, 26, 2469.

114. Sarhan, A. E.; El-Sherief, H. A. A.; Mahmoud, A. M. J. Chem. Res. 1996 (S) 4, (M) 116.

115. Sarhan, A. E.; El-Sherief, H. A. A.; Mahmoud, A. M. Tetrahedron 1996, 52, 10485.

116. Roussel, C.; Andreoli, F.; Roman, M.; Hristova, M.; Vanthuyne, N. Molecules 2005, 10, 327.

117. Bellec, N.; Lorcy, D.; Robert, A. Synthesis 1998, 1442.

118. Abe, N.; Nishiwaki, T. Heterocycles 1981, 16, 537.

119. Popov, I. I. Chem. Heterocycl. Compd. 1995, 31, 500.

120. Ochiai, M.; Tada, N. Chem. Commun. 2005, 5083.

121. Oehler, E.; Kang, H. S.; Zbiral, E. Chem. Ber. 1988, 121, 977.

122. Elwan, N. M.; Fahmy, A. A.; Abdallah, T. A.; Hassaneen, H. M. Sulfur Lett. 1994, $18,9$.

123. Hassan, N. M.; Abdelhamid, A. O. J. Chem. Res. 1997 (S) 350, (M) 2244.

124. Abdelhamid, A. O.; Zohdi, H. F.; Sallam, M. M.; Ahmed, N. A. Phosphorus, Sulfur, Silicon, Relat. Elem. 2000, 164, 181.

125. Shawali, A. S.; Sayed, A. R. J. Chem. Res. (S) 2005, 285.

126. Elfahham, H. A.; Sadek, K. U.; Elgemeie, G. E. H. and Elnagdi, M. H. J. Chem. Soc. Perkin Trans. 1 1982, 2663.

127. Sayanna, E.; Venkatachaliah V. R.; Thyagarajan, G. Heterocycles 1985, 23, 2183.

128. Badr, M. Z.; Mahmoud, A. M.; Mahgoub, S. A.; Hozein, Z. A. Bull. Chem. Soc. Jpn., 1988, 61, 1339.

129. Achour, R.; Essassi, M.; Zniber, R. Tetrahedron Lett. 1988, 29, 195.

130. Liu, K. C.; Chang, J. L. Taiwan Yaoxue Zazhi 1984, 36, 57; Chem. Abstr. 1985, 102, 6320.

131. Liu, K. C.; Chang, J. L.; Chen, C. F. Taiwan Yaoxue Zazhi 1984, 36, 33; Chem. Abstr. 1985, 102, 6319.

132. Kuźmenko, T. A.; Kuźmenko, V. V.; Anisimova, V. A. Zh. Org. Khim. 1995, 31, 106; Chem. Abstr. 1996, 124, 8695e.

133. Tumkevicius, S.; Labanauskas, L.; Bucinskaite, V.; Brukstus, A.; Urbelis, G. Tetrahedron Lett. 2003, 44, 6635.

134. Matulis, D.; Dudutiene, V.; Matuliene, J.; Mistinaite, L. PCT Int. Appl. WO 2008016288, 2008; Chem. Abstr. 2008, 148, 215062.

135. Dudutiene, V.; Baranauskiene; L.; Matulis, D. Bioorg. Med. Chem. Lett. 2007, 17, 3335.

136. Sahu, M.; Sahu, J. K.; Nayak, A. Indian J. Chem., Sect. B 1986, 25B, 1266.

137. Pilgram, K. H. Phosphorus, Sulfur and Silicon Relat. Elem. 1988, 36, 139.

138. Martin, D.; Wenzel, A. J. Prakt. Chem. 1978, 320, 677.

139. Karimian, K.; Tam, T. F.; Desilets, D.; Lee, S.; Cappelletto, T.; Li, W. US 97-803651, 1997; Chem. Abstr. 2000, 133, 207900.

140. Leung-Toung, R. L.; Tam, T. F.; Zhao, Y.; Simpson, C. D.; Li, W.; Desilets, D.; Karimian, K. J. Org. Chem. 2005, 70, 6230. 
141. Katritzky, A. R.; Nikonov, G. N.; Tymoshenko, D. O.; Steel, P. J. Heterocycles 2002, 58, 311.

142. L'abbe, G.; Buelens, J; Dehaen, W. J. Chem. Soc. Perkin Trans. 1 1993, 1825.

143. Dawood, K. M. Heteroatom Chem. 2004, 15, 432.

144. Alajarin, M.; Vidal, A.; Tovar, F. Tetrahedron Lett. 2000, 41, 7029.

145. Zimmermann, T. J. Prakt. Chem. 1993, 335, 717.

146. Anderson, D. J.; Taylor, A. J. J. Heterocycl. Chem. 1986, 23, 1091.

147. Abe, N.; Nishiwaki, T.; Komoto, N. Bull. Chem. Soc. Jpn. 1980, 53, 3308.

148. Hammad, M.; Abdel Meguid, S.; El-Anani, M. M.; Shafik, N. Egypt. J. Chem. 1986, 29, 549.

149. Raslan, M. A. J. Chin. Chem. Soc. 2000, 47, 961.

150. Hammad, M. A.; Kamel, M. M.; Abbasi, M. M.; El-Wassimi, M. T.; Hassan, H. N. A. Pharmazie 1986, 41, 141.

151. El-Sayed, A. S. Egypt. J. Pharm. Sci. 1999, 40, 129.

152. Hishmat, O. H.; El-Diwani, H. I.; Melek, F. R.; El-Sahrawi, H. M.; El-Shabrawi, O. Indian J. Chem. 1996, 35B, 30.

153. Abd El Latif, F. M.; El Rady, E. A.; Dopp, D. J. Heterocycl. Chem. 2003, 40, 57.

154. Bogdanowicz-Szwed, K.; Czarny, A. J. Prakt. Chem. 1993, 335, 279.

155. Abdelhamid, A. O.; Afifi, M. A. M. J. Adv. Res. 2010, 1, 137.

156. Volovenko, Y. M.; Ivanov, V. V. Chem. Heterocycl. Comp. 1997, 33, 1124.

157. Otero, I.; Feist, H.; Michalik, D.; Michalik, M.; Quincoces, J.; Peseke, K. Z. Naturforsch., B 2005, 60, 1175.

158. Dawood, K. M.; Kandeel, Z. E.; Farag, A. M. Heteroat. Chem. 1999, 10, 417.

159. Dawood, K. M.; Farag, A. M.; Kandeel, Z. E. J. Chem. Res. (S) 1999, 88.

160. Dawood, K. M.; Kandeel Z. E.; Farag A. M. J. Chem. Res. (S) 1998, 208.

161. Al-Afaleq, E. I. J. Saudi Chem. Soc. 2002, 6, 59.

162. Shaaban, M. R.; Eldebss, T. M. A.; Darweesh, A. F.; Farag, A. M. J. Heterocycl. Chem. 2008, 45, 1739.

163. Elmaati, T. M. A. Acta Chim. Slov. 2002, 49, 721.

164. Elmaati, T. A.; Said, S.; Elenein, N. A.; Sofan, M.; Khodeir, N. Polish J. Chem. 2002, 76, 945.

165. Hyssein, M. M. Mansoura Sci. Bull., A: Chem. 2002, 29, 1; Chem. Abstr. 2003, 141, 243471.

166. Al-Afaleq, E. I. Synth. Commun. 2000, 30, 1985.

167. Hassanien, A. A.; Mohamed, M. H.; Gohzlan, S. A. S. J. Chem. Res., $(S)$ 2005, 440.

168. Shaaban, M. R. Heterocycles 2008, 75, 3005.

169. Kreutzberger, A.; Kreutzberger, E.; Wiedemann, D. Chem.-Zeitung 1985, 109, 153.

170. Nath, M.; Srivastava, P.; Goel, A.; Ram, V. J. Eur. J. Org. Chem. 1998, 2083.

171. Reddy, K. V.; Rao, A. V. S. Org. Prep. Proced. Int. 1997, 29, 355. 
172. Bari, A.; Milicevic, S.; Feist, H.; Michalik, D.; Michalik, M.; Peseke, K. Synthesis 2005, $16,2758$.

173. Montero, A.; Feist, H.; Michalik, M.; Quincoces, J.; Peseke, K. Synthesis 2002, 664.

174. Rangnekar, D. W.; Rajadhyaksha, D. D. Indian J. Technology 1990, 28, 75; Chem. Abstr. 1990, 113, 134153.

175. Kotovskaya, S. K.; Baskakova, Z. M.; Charushin, V. N.; Chupakhin, O. N.; Belanov, E. F.; Bormotov, N. I.; Balakhnin, S. M.; Serova, O. A. Pharm. Chem. J. 2005, 39, 574.

176. Rida, S. M.; Soliman, F. S. G.; Badawey, E. A. M.; Kappe, T. J. Heterocycl. Chem. 1988, $25,1725$.

177. Le, H. P.; Kelbig, A.; Lindauer, A.; Neidlein, R.; Suschitzky, H. J. Chem. Res., (S) 2004, 453.

178. Babu, V. N. S. R.; Babu, A. N.; Anand, V.; Hanumanthu, P. Synth. Commun. 1998, 28, 4439.

179. Soliman, F. S. G.; Rida, S. M.; Badawey, E. A. M.; Kappe, T. Arch. Pharm. 1984, 317 , 951.

180. Rida, S. M.; Soliman, F. S. G.; Badawey, E. A. M.; El-Ghazzawi, E.; Kader, O.; Kappe, T. J. Heterocycl. Chem. 1988, 25, 1087.

181. Kuz'menko, V. V.; Komissarov, V. N.; Simonov, A. M. Chem. Heterocycl. Compd. 1981, 1090.

182. Chiba, T.; Takahashi, T.; Kaneko, C. Chem. Pharm. Bull. 1985, 33, 4002.

183. Elgemeie, G. H.; Metwally, N. H. Monatsh. Chem. 2000, 131, 779.

184. Badawey, E. A. M.; Kappe, T. Eur. J. Med. Chem. 1995, 30, 327.

185. Tereshchenko, A. D.; Tolmachev, A. A.; Tverdokhlebov, A. V. Synthesis 2004, 373.

186. Panda, K.; Suresh, J. R.; Ila, H.; Junjappa, H. J. Org. Chem. 2003, 68, 3498.

187. Schiifer, H.; Gruner, M; GrofImann, G.; Gewald, K. Monatsh. Chem. 1991, 122, 959.

188. Kandeel, Z. E. J. Chem. Res., (S) 1995, 290.

189. Dhamnaskar, S. V.; Rangnekar, D. W. Dyes Pigm. 1988, 9, 467.

190. Elgemeie, G. H.; Elghandour, A. H.; Hussein, A. M. Synth. Commun. 2004, 34, 3293.

191. Yan, C. G.; Wang, Q F.; Song, X. K.; Sun, J. J. Org. Chem. 2009, 74, 710.

192. Lynch, M.; Hehir, S.; Kavanagh, P.; Leech, D.; O'Shaughnessy, J.; Carty, M. P.; Aldabbagh, F. Chem.-Eur. J. 2007, 13, 3218.

193. Babaev, E. V.; Tikhomirov, G. A. Chem. Heterocycl. Compd. 2005, 41, 119.

194. Reitz, A. B.; Nortey, S. O.; Sanfilippo, P.; Scott, M. K. PCT Int. Appl. WO 2001009132 2001; Chem. Abstr. 2001, 134, 163038.

195. Reitz, A. B.; Fitzpatrick, L. J.; Jordan, A. D.; Sanfilippo, P. J. PCT Int. Appl. WO 9900389, 1999; Chem. Abstr. 1999, 130, 95551.

196. Cohen, J. H.; Maryanoff, C. A.; Stefanick, S. M.; Sorgi, K. L.; Villani, F. J. Org. Process Res. Dev. 1999, 3, 260.

197. Maryanoff, B. E.; Ho, W.; McComsey, D. F.; Reitz, A. B.; Grow, P. P.; Nortey, S. O.; Shank, R. P.; Dubinsky, B.; Taylor, Jr., R. J.; Gardocki, J. F. J. Med. Chem. 1995, 38, 16. 
198. Kondo, T.; Kotachi, S.; Ogino, S.; Watanabe, Y. Chem. Lett. 1993, 1317.

199. Frolov, A. N.; Rtishchev, N. I. Zh. Org. Khim. 1992, 28, 2175; Chem. Abstr. 1994, 120, 54482.

200. Frolov, A. N. Russ. J. Org. Chem. 1998, 34, 1047.

201. Frolov, A. N.; Rtishchev, N. I. Zh. Obshch. Khim. 1993, 63, 422; Chem. Abstr. 1993, 119, 13863.

202. Tan, K. L.; Bergman, R. G.; Ellman, J. A. J. Am. Chem. Soc. 2001, 123, 2685.

203. Tan, K. L.; Bergman, R. G.; Ellman, J. A. J. Am. Chem. Soc. 2002, 124, 3202.

204. Uetake, T.; Nishikawa, M.; Tada, M. J. Chem. Soc., Perkin Trans. 1 1997, 3591.

205. Iwaki, T.; Yasuhara, A.; Sakamoto, T. J. Chem. Soc., Perkin Transs 1 1999, 1505.

206. Prostakov, N. S.; Varlamov, A. V.; Shendrik, I. V.; Anisimov, B. N.; Krapivko, A. P.; Lavani-Edogiaverie, S.; Fomichev, A. A. Chem. Heterocycl. Compd. 1983, 1102.

207. Dikshit, D. V.; Samant, S. D.; Kanekar, D. S.; Deodhart, K. D. Dyes Pigm. 1983, 4, 35.

208. Pednekar, S. R.; Samant, S. D.; Deval, S. D.; Deodhar, K. D. Indian J. Chem. 1981, 20B, 709.

209. Shaaban, M. R.; Saleh, T. S.; Mayhoub, A. S.; Mansour, A.; Farag, A. M. Bioorg. Med. Chem. 2008, 16, 6344.

210. Al-Enezi, A.; Al-Salah, B.; Elnagdi, M. H. J. Chem. Res. (S) 1997, 4 (M), 116.

211. Shaaban, M. R.; Saleh, T. S.; Farag, A. M. Heterocycles 2007, 71, 1765.

212. Dawood, K. M.; Farag, A. M.; Ragab, E. A. J. Chin. Chem. Soc. 2004, 51, 853.

213. Dawood, K. M.; Farag, A. M.; Kandeel, Z. E. J. Chem. Res. (S) 1999, 88 (M), 537.

214. Meziane, M. A. A.; Rahmouni, M.; Bazureau, J. P.; Hamelin, J. Synthesis 1998, 967.

215. Liu, G.; Shao, Q.; Tu, S.; Cao, L.; Li, C.i; Zhou, D.; Han, B. J. Heterocycl. Chem. 2008, 45, 1127.

216. Dandia, A.; Singh, R.; Jain, A. K.; Singh, D. Synth. Commun. 2008, 38, 3543.

217. Dandia, A.; Sarawgi, P.; Bingham, A. L.; Drake, J. E.; Hursthouse, M. B.; Light, M. E.; Ratnani, R. J. Chem. Res. (S) 2007, 155.

218. Hassan, A. A. Pharmazie 1994, 49, 239.

219. Ghozlan, S. A. S.; Abdelhamid, I. A.; Gaber, H.; Elnagdi, M. H. J. Chem. Res. 2004, (S), 789.

220. Abdel-Hafez, A. A. Arch. Pharm. Res. 2007, 30, 678.

221. Wahe, H.; Asobo, P. F.; Cherkasov, R. A.; Nkengfack, A. E.; Folefoc, G. N.; Fomum, Z. T.; Doepp, D. Arkivoc 2003, (xiv), 170.

222. Yogo, M.; Hirota, K.; Senda, S. Chem. Pharm. Bull. 1984, 32, 3695.

223. Frolov, A. N. Zh. Org. Khim. 1994, 30, 1059; Chem. Abstr. 1995, 123, 9411.

224. Frolov, A. N.; Rtishchev, N. I. Zh. Org. Khim. 1993, 29, 2035; Chem. Abstr. 1994, 121, 255747.

225. Frolov, A. N. Russ. J. Org. Chem. 2004, 74, 1949.

226. Terashima, K.; Muraoka, O.; Ono, M. Chem. Pharm. Bull. 1995, 43, 1985. 
227. Bakavoli, M.; Nikpour, M.; Ebrahimi, A. R.; Taghizadeh, A.; Rahimizadeh, M.; Davoodnia, A. J. Heterocycl. Chem. 2008, 45, 1465.

228. Badawey, El S. A. M.; Rida, S. M.; Soliman, F. S. G.; Kappe, T. J. Heterocycl. Chem. 1989, 26, 1401.

229. Abdelhamid, A. O.; Zohdi, H. F.; Ziada, M. M. Indian J. Chem. 2001, 40B, 284.

230. Abdelhamid, A. O.; Elghandour, A. H.; Rateb, N. A.; Awad, A. M. Phosphorus, Sulfur Silicon Relat. Elem. 2006, 181, 1637.

231. Vovk, M. V.; Lebed, P. S.; Pirozhenko, V. V.; Tsymbal, I. F. Russ. J. Org. Chem. 2004, 40, 1669.

232. Nawwar, G. A. M.; Zaki, M. M. ; Chabaka, L. M. Phosphorus, Sulfur, Silicon Relat. Elem. 1993, 79, 195.

233. Rahmouni, M.; Derdour, A.; Bazureau, J. P.; Hamelin, J. Tetrahedron Lett. 1994, 35, 4563.

234. Badawey, E. A. M.; Rida, S. M.; Soliman, F. S. G.; Kappe, T. J. Heterocycl. Chem. 1989, $26,405$.

235. Krasovsky, A. L.; Hartulyari, A. S.; Nenajdenko,V. G.; Balenkova, E. S. Synthesis 2002, 133.

236. Bayomi, S.M.; Amin, Kamelia M.; Al-Obaid, A. M.; Hares, Nadia G. Egypt. J. Pharm. Sci. 1993, 34, 117.

237. Hammad, M. A.; Nawwar, G. A.; Elgemeie, G. H.; Elnagdi, M. H. Heterocycles 1985, 23, 2177.

238. Elgemeie, G. H.; Sood, S. A. J. Chem. Res. (S) 2001, 438.

239. El-Gazzar, A. B. A. Egypt. J. Chem. 2003, 45, 995.

240. Ibrahim, M. K. A. Indian J. Chem. 1988, 27B, 478.

241. Nawroka, W. Pol. J. Chem. 1996, 70, 193.

242. Abdelhamid, A. O.; Riad, B. Y.; Aziz, S. I. Arch. Pharm. 1987, 320, 642.

243. Al-Zaydi, K. M.; Al-Shiekh, M. A.; Hafez, E. A. Z. J. Chem. Res., (S) 2000,13.

244. El-Ella, D. A.; GöBnitzer, E.; Wendelin, W. J. Heterocycl. Chem. 1997, 33, 373.

245. Insuasty, B.; Salcecdo, A.; Abonia, R.; Quiroga, J.; Noguersas, M. Heterocycl. Commun. 2000, 8, 287.

246. Lipson, V. V.; Desenko, S. M.; Orlov, V. D.; Ryndina, E. N.; Chuvurin, A. V.; Gorbenko, N. I.; Kirichenko, A. A. Pharm. Chem. J. 1994, 28, 92.

247. Metwally, M. A.; Yousif, M. Y.; Ismail, A.-K. M.; Etman, H. A. Heterocycles 1985, 23, 2251.

248. Asobo, P. F.; Wahe, H.; Mbafor, J. T.; Fomum, Z. T.; Sopbue, E. F.; Doepp, D. J. Chem. Soc., Perkin Trans. 1 2001, 457.

249. Kreutzberger, A.; Leger, M. Arch. Pharm. 1982, 315, 651.

250. Sondhi, S. M.; Rajvanshi, S.; Johar, M.; Bahrati, N.; Azam, A.; K.Singh, A. Eur. J. Med. Chem. 2002, 37, 835.

251. Sondhi, S. M.; Azam, A. Aust. J. Chem. 2001, 54, 461. 
252. Smolii, O. B.; Muzychka, L. V.; Chernega, A. N.; Drach, B. S. Russ. J. Gen. Chem. 2002, $72,1703$.

253. Somlii, O. B.; Shakhnin, D. B.; Drach, B. S. Zh. Obshch. Khim. 1995, 65, 1225; Chem. Abstr. 1996, 124, 146053v.

254. Zama, Y.; Okamoto, Y.; Takage, K. J. Heterocycl. Chem. 1995, 32, 851.

255. Anwar, H. F.; Metwally, N. H.; Gaber, H.; Elnagdi, M. H. J. Chem. Res., (S) 2005, 29.

256. Romano, C.; De la Cuesta, E.; Avendano, C. Heterocycles 1990, 31, 267.

257. Nawrocka, W. P.; Sztuba, B.; Drys, A.; Wietrzyk, J.; Kosendiak, J.; Opolski, A. Polish J. Chem. 2006, 80, 279.

258. Nawrocka, W.; Sztuba,B.; Kowalska, M. W.; Liszkiewicz, H.; Wietrzyk, J.; Nasulewicz, A.; Pełczyn'ska, M.; Opolski, A. Farmaco 2004, 59, 83.

259. Nawrocka, W. Polish J. Chem. 1994, 68, 2659.

260. Bassyouni, F. A.; Ismail, I. I. Afinidad 2001, 58, 375.

261. Niwa, T.; Katagiri, S.; Kato, T. Jpn. Kokai Tokkyo Koho JP 61063680, 1986; Chem. Abstr. 1986, 105, 172498.

262. Demirayak, S.; Mohsen, U. A.; Cagrikaraburun, A. Eur. J. Med. Chem. 2002, 37, 255.

263. Bergman; J.; Vallberg, H. Acta Chem. Scand. 1997, 51, 742.

264. Ghandi, M.; Zarezadeh, N.; Taheri, A. Tetrahedron 2010, 66, 8231.

265. Alen, J.; Robeyns, K.; De Borggraeve, W. M.; Meervelt, L. V.; Compernolle, F. Tetrahedron 2008, 64, 8128.

266. Abdelhamid, A. O.; Zohdi, H. F.; Ziada, M. M. Indian J. Chem. 2000, 39B, 202.

267. Yamada, Y.; Yasuda, H.; Yoshihara, Y.; Yoshizeiwa, K. J. Heterocycl. Chem. 1999. 36, 1317.

268. Farag, A. M.; Dawood, K. M.; Kandeel, Z. E. Tetrahedron 1996, 52, 7893.

269. Dawood, K. M.; Farag, A. M.; Abdel-Aziz, H. A. J. Chem. Res. (S) 2005, 378.

270. Farag, A. M. J. Chem. Res., (S) 1995, 96.

271. Bilek, P.; Slouka, J. Heterocycl. Commun. 2004, 10, 67.

272. Bilek, P.; Slouka, J. Heterocycl. Commun. 2002, 8, 123.

273. Bilek, P.; Slouka, J. Heterocycl. Commun. 1998, 4, 325.

274. Bilek, P.; Slouka, J. Heterocycl. Commun. 1999, 5, 231.

275. Kruglenko, V. P.; Povstyanov, M. V.; Gnidets, V. P. Ukr. Khim. Zh. 2001, 67, 54; Chem. Abstr. 2002, 136, 247555.

276. G. Primofiore, F. Da Settimo, S. Taliani, A. M. Marini, F. Simorini, E. Novellino, G. Greco, L. Trincavelli, C. Martini, Arch. Pharm. Pharm. Med. Chem. 2003, 336, 413.

277. Settimo, F. D.; Primofiore, G.; Tahani, S.; Marin, A. M.; Motta, C. L.; Novellino, E.; Greco, G.; Lavecchia, A.; Trincavelli, L.; Martini, C. J. Med. Chem. 2001, 44, 316.

278. N'Diaye, I.; Mayrargue, J.; Farnoux, C. C.; Miocque, M.; Gayral, P. Eur. J. Med. Chem. 1987, 22, 403.

279. Venkataratnam, R. V.; Sujatha, K. Synth. Commun. 1988, 18, 805.

280. Venkataratnam, R. V.; Sayanna, E.; Sujatha, K. Synth. Commun. 1987, 17, 1533. 
281. Balogh, M.; Gonczi, C.; Hermecz, I. Stud. Surf. Sci. Cat. 1997, 108, 603; Chem. Abstr. 1998, 129, 161527.

282. Ghoneim, K. M.; El-Basil, S.; Osman, A. N.; Said, M. Egypt. J. Pharm. Sci. 1990, 31, 169.

283. Britsum, V. M.; Esipenko, A. M.; Bodnar, V. M.; Lozinskii, M. O. Ukr. Khim. Zh. 2002, 68, 52; Chem. Abstr. 2003, 139, 101084z.

284. Jain, K.; Jain, K. K.; Chadha, V. K.; Handa, R. N. J. Indian Chem. Soc. 1984, 61, 1053.

285. Kumar, S.; Dahiya, R.; Pujari, H. K. Indian J. Chem. 1990, 29B, 989,

286. Korotkikh, N. I.; Raenko, G. F.; Aslanov, A. F. Zh. Org. Khim. 1996, 32, 632; Chem. Abstr. 1997, 126, 18833.

287. Korotkikh, N. I.; Raenko, G. F.; Shvaika, O. P. Chem. Heterocycl. Compd. 1995, $31,359$.

288. Hassan, A. A.; Aly, A. A.; Mohamed, N. K.; Mourad, A. F. E. Heterocycl. Commun. 1996, $2,441$.

289. Heravi, M.; Nami, N.; Oskooie, H.; Hekmatshoar, R. Phosphorus, Sulfur, Silicon Relat. Elem. 2005, 180, 1605.

290. Acheson, R. M.; Wallis, J. D. J. Chem. Soc., Perkin 1 1981, 415.

291. Abe, N.; Fujii, H.; Kakehi, A.; Shiro, M. J. Chem. Res., (S) 1999, 322.

292. Ohta, S.; Narita, Y.; Okamoto, M.; Hatakeyama, S.; Kan, K.; Yuasa, T.; Hayakawa, H. Chem. Pharm. Bull. 1990, 38, 301.

293. Nazarenko, K. G.; Shirokaya, T. I.; Shvidenko, K. V.; Tolmachev, A. A.; Tolmachev, K. V. S. Il'chenko, A. Y. Chem. Heterocycl. Compd. 2004, 40, 120.

294. Fahey, K.; Aldabbagh, F. Tetrahedron Lett. 2008, 49, 5235.

295. Kovtunenko, V. A.; Potikha, L. M.; Turelyk, A. R.; Turov, A. V. Chem. Heterocycl. Compd. 2008, 44, 632.

296. Aldabbagh, F.; Bowman, W. R. Tetrahedron 1999, 55, 4109.

297. McClure, J. R.; Cluster, J. H.; Schwarz, D. H.; Lill, D. A. Synlett 2000, 710.

298. Anastasiou, D.; Chaouk, H.; Jackson, W. R. Tetrahedron Lett. 1991, 32, 2499.

299. Anastasiou, D.; Campi, E. M.; Chaouk, H.; Jackson, W. R. Tetrahedron 1992, 48, 7467.

300. Cherkaoui, O.; Essassi, E.; Zniber, R. Tetrahedron Lett. 1990, 31, 5467.

301. Kruglenko, V. P.; Gnidets, V. P.; Klyuev, N. A.; Povstyanoi, M. V. Chem. Heterocycl. Compd. 2002, 38, 598.

302. Romano, C.; De la Cuesta, E.; Avendano, C.; Florencio, F.; Sainz-Aparicio, J. Tetrahedron 1988, 44, 7185.

303. Povstyanoi, M. V.; Kruglenko, V. P.; Gnidets, V. P. Chem. Heterocycl. Compd. 1984, 568.

304. Priimenko, B. A. Farm. Zh. 1982, 68; Chem. Abstr. 1983, 97, 127614.

305. Povstyanoi, M. V.; Kruglenko, V. P.; Povstyanoi, V. M. Chem. Heterocycl. Compd. 2003, 39, 398.

306. Hassan, A. A. Phosphorus, Sulfur, Silicon, Relat. Elem. 1996, 113, 231. 
307. Hassan, A. A.; Mohamed, N. K.; El-Tamay, E. H.; Ali, B. A.; Mourad, A.-F. E. Monatsh. Chem. 1995, 126, 653.

\section{Authors' Biographies}

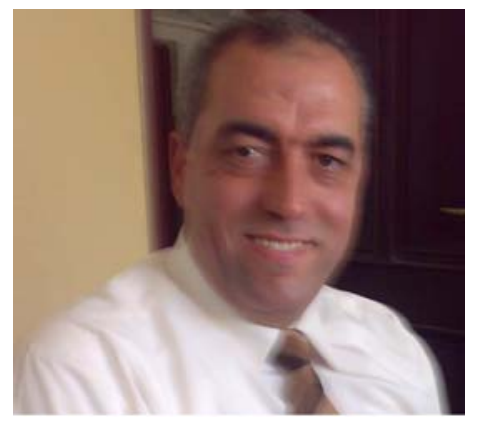

Kamal M. Dawood was born in 1965 in Kafr-Elsheikh, Egypt. He graduated from Cairo University, Egypt in 1987 then he carried out his MSc and PhD studies under the supervision of Professor Ahmad M. Farag, Cairo University. He received his PhD in 1995 in the applications of hydrazonoyl halides in heterocyclic chemistry. In 1997 he was awarded the UNESCO Fellowship for one year at Tokyo Institute of Technology (TIT) and collaborated with Prof. Toshio Fuchigami in the field of 'Electrochemical Partial Fluorination of Heterocyclic Compounds'. In 1999, he was awarded the JSPS (Japan Society for Promotion of Science) Fellowship for two years and worked again with Professor Fuchigami at TIT in the same field. He was awarded the Alexander von Humboldt Fellowship at Hanover University in 2004-2005 with Prof. Andreas Kirschning in the field of polymer supported palladium catalyzed cross coupling reactions and in 2007 and 2008 with Prof. Peter Metz at TU-Dresden, Germany, in the field of total synthesis of natural products. In 2002 he promoted to Associate Professor and in May 2007 he was appointed as Professor of Organic chemistry, Faculty of Science, Cairo University. In 2002 he received the Cairo University Award in Chemistry and in 2007 he received the State-Award in Chemistry. He is a member of the international Editorial Board of ISRN Organic Chemistry, part of the International Scholarly Research Network (ISRN), open access journals. He published more than 75 scientific papers and reviews in distinguished international journals. There are about 690 citations of his work from 1993 until 2010 ( $h$-index 16). 


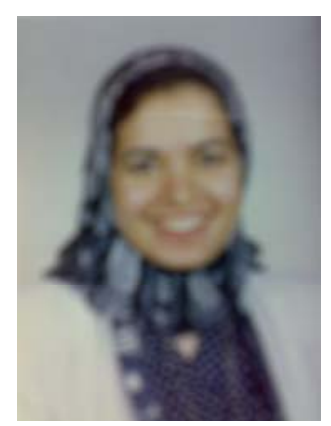

Nehal M. Elwan was born in 1959 in Giza, Egypt. She graduated from Cairo University, Egypt in 1980 then she carried out her MSc and $\mathrm{PhD}$ studies under the supervision of Professors Hamdi M. Hassaneen and Ahmad S. Shawali (DSc.), Chemistry Department, Faculty of Science, Cairo University. She received her $\mathrm{PhD}$ in 1990 on the applications of hydrazonoyl halides in heterocyclic chemistry. In 1990 she was appointed as a lecturer of organic chemistry at Faculty of Science, Cairo University. In 1995 she was promoted to Associate Professor and in 2004 she was appointed as Professor of Organic chemistry, Faculty of Science, Cairo University. In 2005 she received the Cairo University Award in chemistry. Currently, she is the director of the Microanalysis Centre, Cairo University.

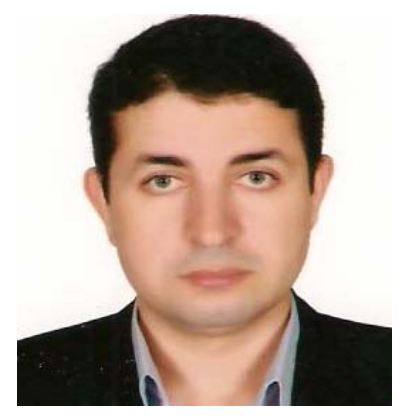

Bakr F. Abdel-Wahab was born in 1978 in Mansoura, Egypt. He is a researcher of organic chemistry at National Research Centre, Giza, Egypt. He has got his B.Sc. in 1999 from Chemistry Department, Faculty of Science, Mansoura University, Egypt. He received his M.Sc. in 2003 from Mansoura University under the supervision of Professor Fathy A. Amer. He has awarded his Ph.D. degree in 2007 from Ain-Shams University, Cairo under the supervision of Professor Maher A. El-Hashash (D.Sc). His current research interests cover the development and mechanistic aspects of organic reactions and their applications in medicinal chemistry. Currently, he is an assistant professor of organic chemistry at the Department of Chemistry, Faculty of Science and Arts, King Abdulaziz University, Khulais Branch, Saudi Arabia. 